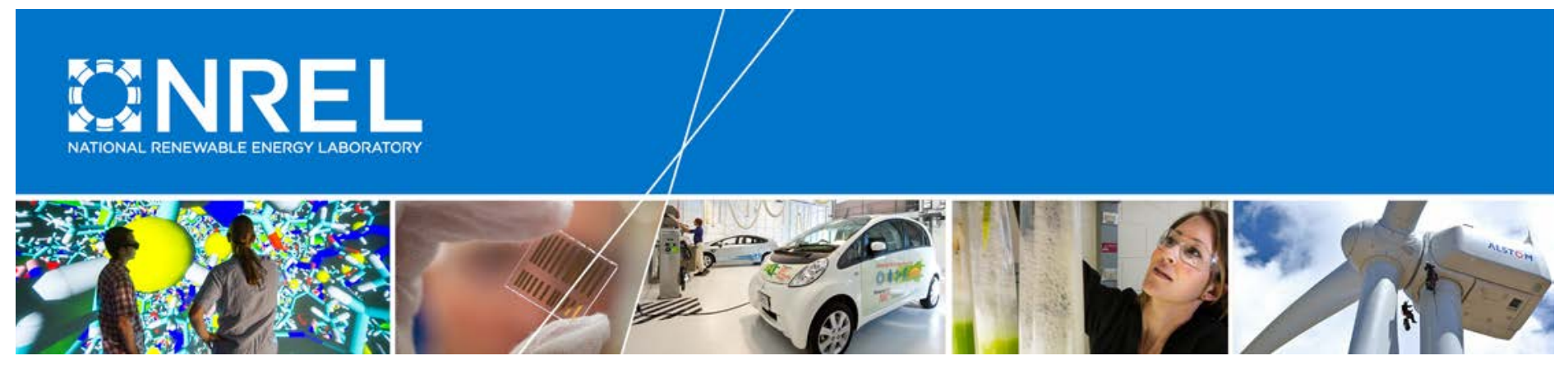

\title{
Innovation Incubator: Whisker Labs Technical Evaluation
}

Bethany Sparn, Stephen Frank, Lieko Earle, and Jennifer Scheib

National Renewable Energy Laboratory

NREL is a national laboratory of the U.S. Department of Energy Office of Energy Efficiency \& Renewable Energy Operated by the Alliance for Sustainable Energy, LLC

This report is available at no cost from the National Renewable Energy Laboratory (NREL) at www.nrel.gov/publications.

\section{Technical Report}

NREL/TP-5500-68476

July 2017 


\section{Innovation Incubator: Whisker Labs Technical Evaluation}

Bethany Sparn, Stephen Frank, Lieko Earle, and Jennifer Scheib

National Renewable Energy Laboratory

Prepared under Task No. ACTC.11A3

NREL is a national laboratory of the U.S. Department of Energy Office of Energy Efficiency \& Renewable Energy Operated by the Alliance for Sustainable Energy, LLC

This report is available at no cost from the National Renewable Energy Laboratory (NREL) at www.nrel.gov/publications.

\section{Technical Report}

NREL/TP-5500-68476

July 2017

Contract No. DE-AC36-08GO28308 


\section{NOTICE}

This report was prepared as an account of work sponsored by an agency of the United States government. Neither the United States government nor any agency thereof, nor any of their employees, makes any warranty, express or implied, or assumes any legal liability or responsibility for the accuracy, completeness, or usefulness of any information, apparatus, product, or process disclosed, or represents that its use would not infringe privately owned rights. Reference herein to any specific commercial product, process, or service by trade name, trademark, manufacturer, or otherwise does not necessarily constitute or imply its endorsement, recommendation, or favoring by the United States government or any agency thereof. The views and opinions of authors expressed herein do not necessarily state or reflect those of the United States government or any agency thereof.

This report is available at no cost from the National Renewable Energy Laboratory (NREL) at www.nrel.gov/publications.

Available electronically at SciTech Connect http:/www.osti.gov/scitech

Available for a processing fee to U.S. Department of Energy and its contractors, in paper, from:

U.S. Department of Energy

Office of Scientific and Technical Information

P.O. Box 62

Oak Ridge, TN 37831-0062

OSTI http://www.osti.gov

Phone: 865.576.8401

Fax: 865.576.5728

Email: reports@osti.gov

Available for sale to the public, in paper, from:

U.S. Department of Commerce

National Technical Information Service

5301 Shawnee Road

Alexandria, VA 22312

NTIS http://www.ntis.gov

Phone: 800.553 .6847 or 703.605 .6000

Fax: 703.605.6900

Email: orders@ntis.gov 


\section{Preface}

This work was supported by the Wells Fargo Innovation Incubator $\left(\mathrm{IN}^{2}\right)$, which is designed to facilitate early-stage technologies that provide scalable solutions to reduce the energy impact of commercial buildings. $\mathrm{IN}^{2}$ is funded by the Wells Fargo Foundation and co-administered by the U.S. Department of Energy's National Renewable Energy Laboratory (NREL). For more information, visit http://in2.wf.com. 


\section{Acknowledgments}

The authors would like to recognize the following efforts and people for their assistance in this project:

- The Wells Fargo Innovation Incubator $\left(\mathrm{IN}^{2}\right)$ program for funding the project through a competitive selection process

- Whisker Labs for partnering with NREL to ensure successful execution of the laboratory and field portions of the project

- The Wells Fargo Corporate Properties Group and CBRE Group, Inc. for identifying an appropriate field demonstration site and supporting the installation and decommissioning of the field demonstration equipment

- Mountain Energy Partnership for installing the field demonstration equipment

- Willy Bernal Heredia for gathering lab and field data and performing data analysis

- Mike Heaney for providing statistical analysis support

- Dane Christensen and Xin Jin for providing peer reviews of the report. 


\section{List of Acronyms}

$\begin{array}{ll}\text { A/C } & \text { air conditioner } \\ \text { API } & \text { application programming interface } \\ \text { CBRE } & \text { CBRE Group, Inc. } \\ \text { CI } & \text { confidence interval } \\ \text { CPG } & \text { Corporate Properties Group } \\ \text { CT } & \text { current transducer } \\ \text { ESIF } & \text { Energy Systems Integration Facility } \\ \text { FDD } & \text { fault detection and diagnostics } \\ \text { GUI } & \text { graphical user interface } \\ \text { HVAC } & \text { heating, ventilating, and air conditioning } \\ \text { IN }{ }^{2} & \text { Innovation Incubator } \\ \text { LEED } & \text { Leadership in Energy and Environmental Design } \\ \text { M\&V } & \text { measurement and verification } \\ \text { NILM } & \text { non-intrusive load monitoring } \\ \text { MEL } & \text { miscellaneous electric load } \\ \text { NREL } & \text { National Renewable Energy Laboratory } \\ \text { PV } & \text { photovoltaic } \\ \text { RMSE } & \text { root-mean-squared error } \\ \text { SPL } & \text { Systems Performance Laboratory }\end{array}$




\section{Executive Summary}

The Wells Fargo Innovation Incubator $\left(\mathrm{IN}^{2}\right)$ is a program to foster and accelerate startup companies with building energy-efficiency and demand management technologies. The program is funded by the Wells Fargo Foundation and co-administered by the National Renewable Energy Laboratory (NREL). Whisker Labs, an Oakland, California-based company, was one of four awardees in the first $\mathrm{IN}^{2}$ cohort and was invited to participate in the program because of its novel electrical power sensing technology for circuit breakers. The stick-on Whisker meters install directly on the front face of the circuit breakers in an electrical panel using adhesive, eliminating the need to access the interior of the panel and install current transducers (CTs) on the circuit wiring. See Figure ES1 and Figure ES2 below comparing conventional submetering installed in a residential electrical panel and the Whisker Labs meters installed on a similar panel. Because all interactions with the electrical panel during installation are touch-safe (see Figure ES2), no electrical shutdown is required and the installer needs no special expertise (such as an electrician's license).

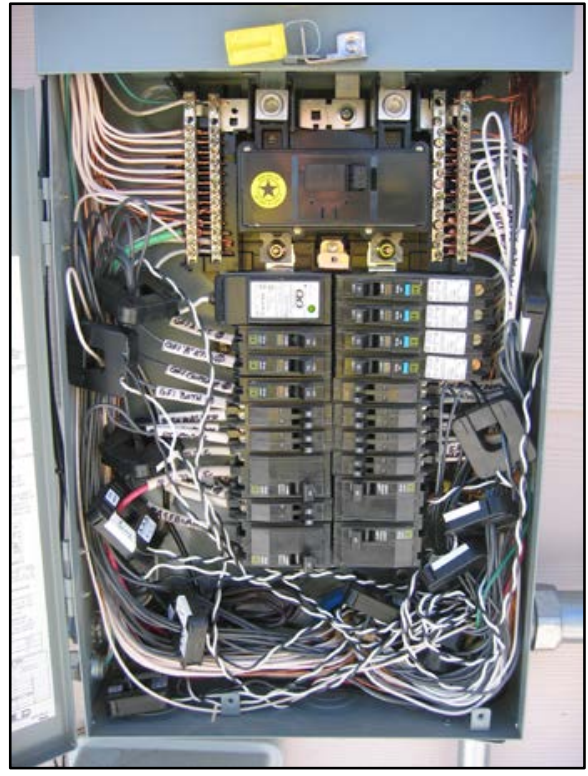

Figure ES1. Conventional submetering installed inside a residential electrical panel.

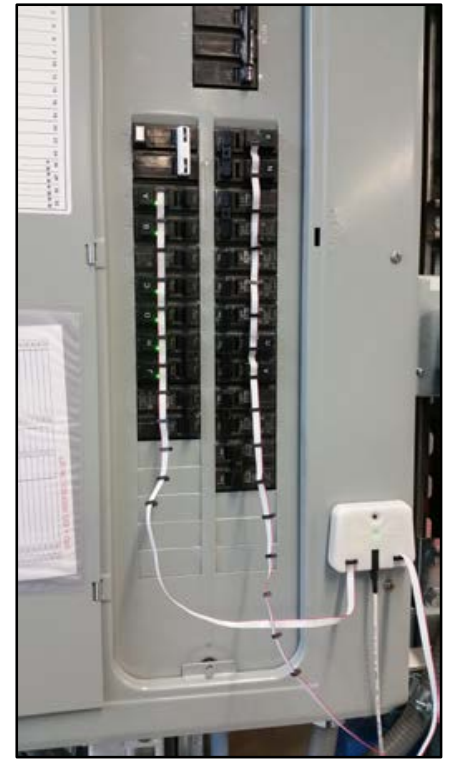

Figure ES2. The Whisker Labs meters installed on the front of breakers in an electrical panel.

Cost and installation inconvenience are the primary barriers to widespread adoption of conventional metering systems. As a result of the meter design and installation simplification, the stick-on meters show potential for a $90 \%$ hardware cost reduction and a $75 \%$ installation cost reduction. The Whisker Labs technology is specifically designed to allow more building owners to install submetering, better understand their energy consumption, and find ways to save energy.

Whisker meters measure the electric and magnetic fields near a circuit breaker to infer the voltage, current, and power at the breaker, and as a result they are susceptible to interference from the magnetic fields generated by nearby circuits. The second generation of Whisker Labs meters tested was described as having a typical single-circuit accuracy of $\pm 10 \%$ and a typical interference rejection ratio of 10:1 for power on nearby circuits. (An interference rejection ratio of 10:1 means that $10 \mathrm{~W}$ of power on an adjacent circuit will produce only $1 \mathrm{~W}$ of measurement 
noise for the circuit being measured.) Figure ES3 illustrates the single-circuit accuracy and observed cross-circuit interference of a Whisker meter monitoring a residential refrigerator during the laboratory testing.

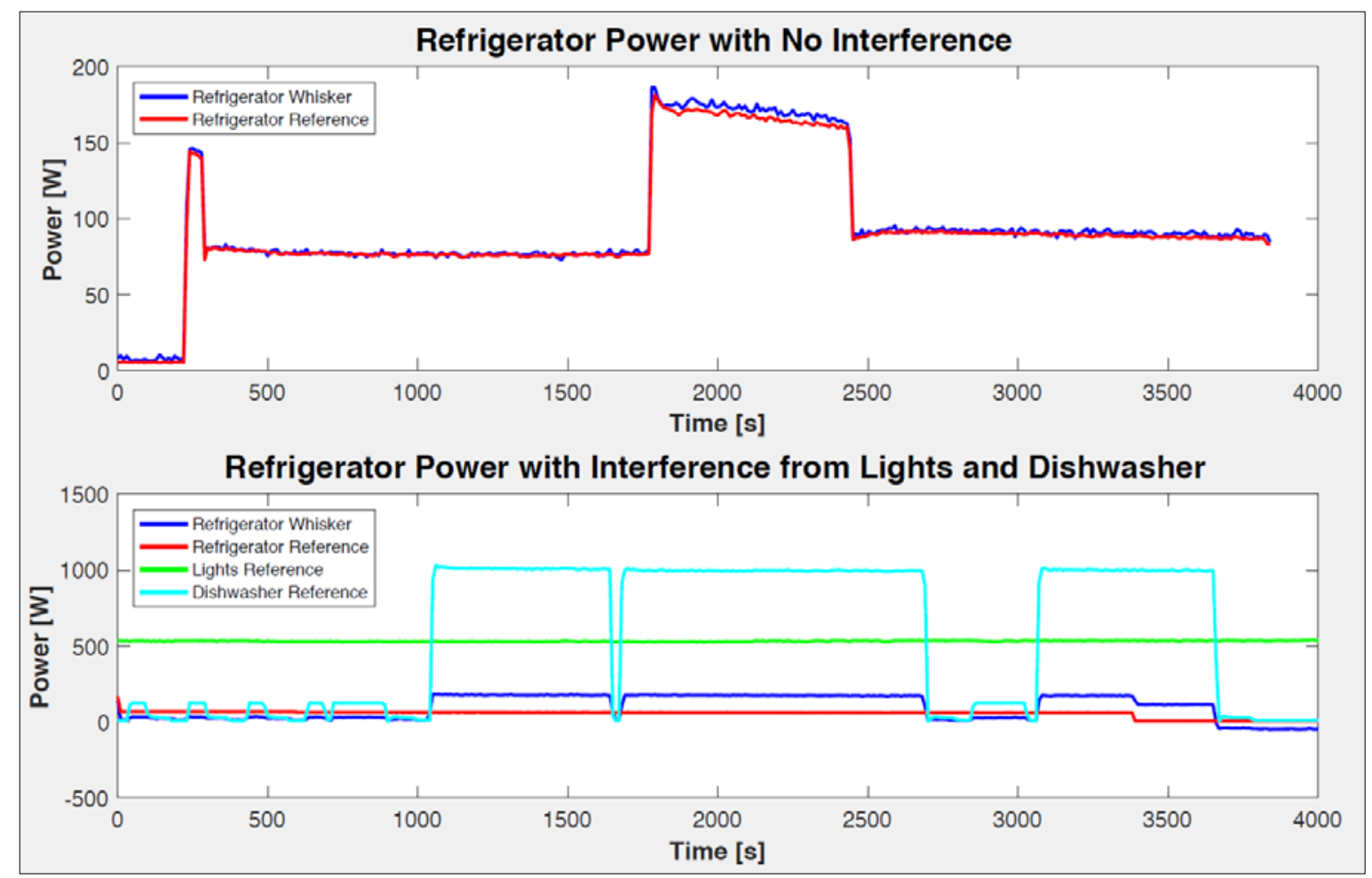

Figure ES3. Data from the Whisker and reference meters for the refrigerator are shown, with and without interference. In the lower graph, lights and the dishwasher were also running, which impacted the Whisker meter reading for the refrigerator.

Whisker Labs has continued to develop its product and technology since this project began in 2015, as shown in Figure ES4. The laboratory testing described in this report evaluated both the Alpha - Generation 1 and Alpha - Generation 2 systems. The field demonstration described in this report used the Alpha - Generation 2 version. Late in 2016, Whisker Labs was acquired by Earth Networks and now exists as a wholly owned subsidiary of Earth Networks. It continues to improve its technology and has shifted focus from submetering specific circuits in an electric panel to measuring the power consumption at the main breakers in a panel, which is reflected in its first generation production model. 


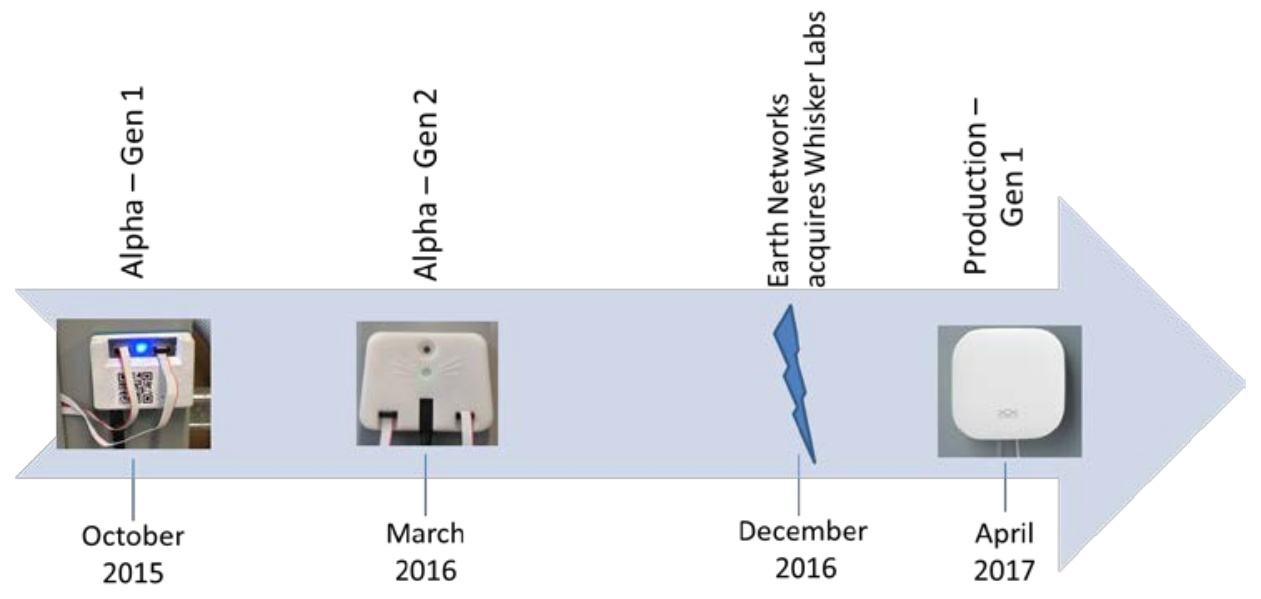

Figure ES4. Product development timeline for Whisker Labs

\section{Objectives}

The $\mathrm{IN}^{2}$ program provides awardees technical support in achieving technology development milestones. Whisker Labs was primarily looking for technical support in the form of an independent technology evaluation, so the NREL technical team defined a project to first evaluate the technology's performance in an NREL laboratory and then, based on the outcome of this phase, move the technology to a Wells Fargo corporate real estate property for a field demonstration. The primary goals of the technology evaluations were to:

1. Validate the stated power measurement accuracy and interference rejection performance specifications of the second-generation Whisker Labs technology (lab and field).

2. Understand and quantify (when possible) the installation and ease-of-use benefits of the Whisker Labs technology versus conventional metering technology (lab and field).

3. Evaluate potential commercial buildings applications for the Whisker Labs technology (field).

\section{Laboratory Testing Phase}

In the project's laboratory phase, NREL installed the submetering technology on a residential research electrical panel in the Systems Performance Laboratory (SPL) in the Energy Systems Integration Facility (ESIF) on the NREL campus. The research panel included laboratory-grade reference power meters on each circuit that were used for comparison to Whisker Labs' power meters. To perform an accuracy test, the team installed the Whisker meters on 10 breakers (a combination of single-pole and double-pole breakers) that supplied power to a total of seven common household appliances.

The sensors were installed on the front of the breakers using a plastic stencil to locate the correct mounting location unique to that make and model of breaker. An adhesive pad on the back of sensors kept the sensors firmly stuck to the breakers. Once all the sensors were in place, a ribbon cable was used to daisy-chain the sensors together and connect them to the hub. The hub itself is magnetic, which allows it to be mounted to the electrical panel. The hub was connected to a WiFi network to upload data to the Whisker Labs' server for analysis. An online tool, called the Whisker Labs Plotter, was used to view and download data, which can either be viewed in terms 
of power or current. Data were pulled programmatically via an API, although they also can be downloaded manually in comma-separated values (CSV) format.

The team then observed the response of the Whisker and reference measurements to operational tests of single and multiple appliances. In the single appliance trials, the team observed a reliable linear relationship between the Whisker and reference meter power measurements. Overall, the Whisker meters exhibited a typical relative accuracy (fractional scaling error) on the order of $\pm 10 \%$, which is consistent with the expected accuracy. The exact scaling error varied by appliance, with some appliances (or meters) showing significantly better than $\pm 10 \%$ accuracy and a few showing errors of up to $\pm 26 \%$. Figure ES5 displays the absolute value of the interference coefficients (inverse of the interference rejection ratio) for each appliance estimated from the multiple-appliance trials. Nearly all coefficient magnitudes are less than 0.1 , which corresponds to the specified 10:1 interference rejection ratio. Thus, in the multiple appliance tests, the observed interference rejection ratios for each Whisker meter with respect to nearby interfering circuits were typically 10:1 or better. These results support the specified accuracy and interference rejection ratios of the second-generation Whisker Labs technology.

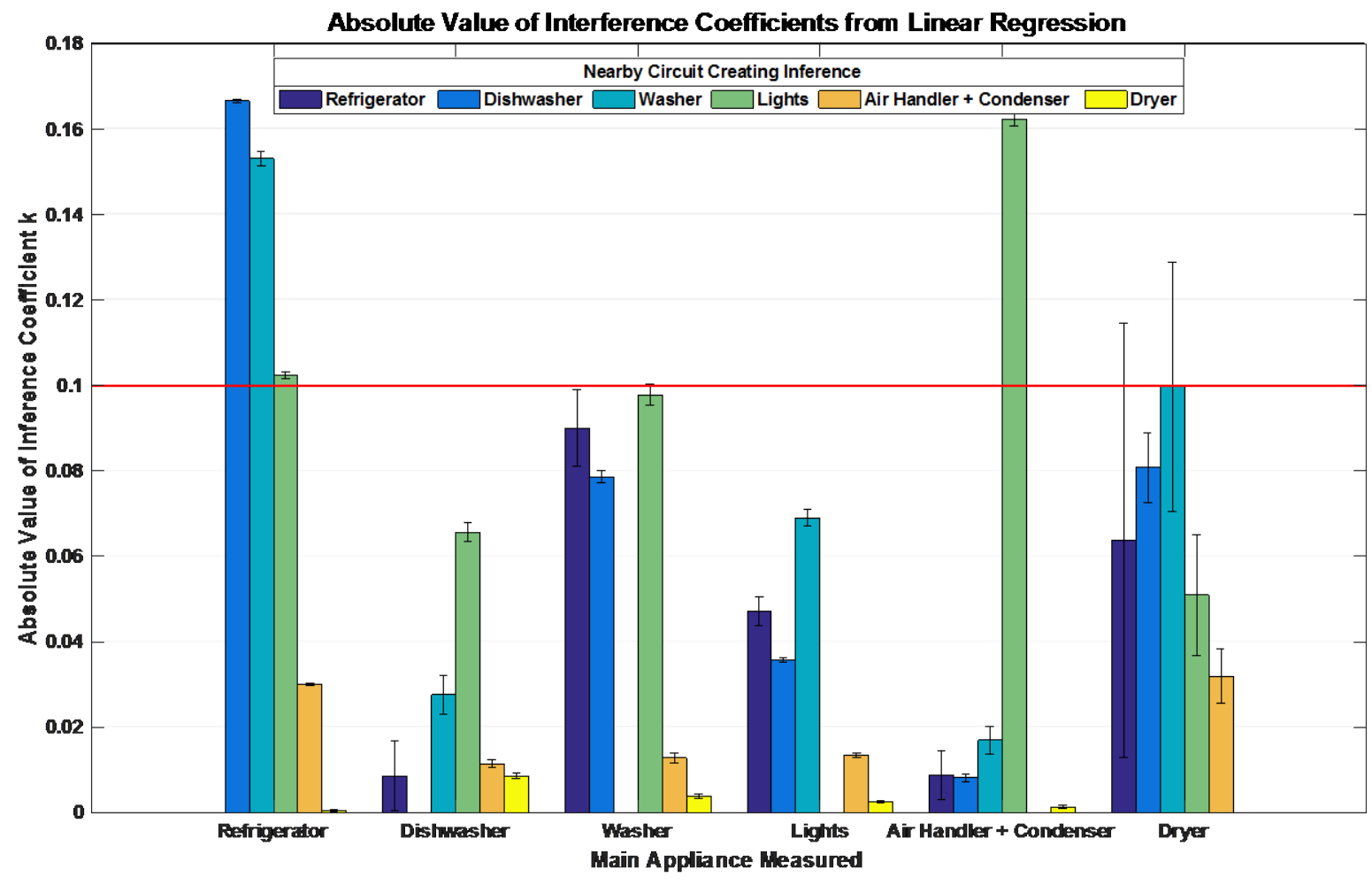

Figure ES5. Estimated absolute value of interference coefficients (inverse of interference rejection ratio) for each appliance: smaller is better.

The results from the laboratory tests provided an understanding of the accuracy that can be expected from Whisker Labs' power meters, the factors that affect that accuracy, and under what conditions these meters will be most effective. The results suggest that the tested version of Whisker Labs meters will provide greatest accuracy and utility when used to meter the main disconnect of a panel; when used in a subpanel where there are few circuits, such as a dedicated panel for an electric vehicle charger or photovoltaic system; when used to provide submetering 
for the largest loads in a panel; or when applied to an electrical panel that contains only loads of similar magnitude. The results also indicate potential for additional data modeling and crosschannel interference correction to further improve the accuracy of power measurements.

\section{Field Demonstration Phase}

After the laboratory phase of the project was completed, the team installed a set of Whisker Labs' meters and a smaller set of reference meters on a three-phase electrical panel at the Havana Gardens Wells Fargo branch bank in Aurora, Colorado. This field installation examined the Whisker meters' applicability to commercial buildings with three-phase power systems and was the first test of the Whisker Labs technology on a three-phase electrical panel. The team estimated the installation labor cost for the Whisker Labs system at one-fourth the cost of installing conventional measurement and verification (M\&V) equipment. The monitoring equipment collected field demonstration data for eight months.

Because reference data for all adjacent circuits was not independently measured in the field test, it was not possible to disaggregate and independently verify the $\pm 10 \%$ single-circuit accuracy and 10:1 interference rejection ratio specifications. However, the collected field data again generally support the specified 10:1 interference rejection ratio of the second-generation Whisker Labs technology. In some cases, the observed single-circuit accuracy in the field tests was outside of the specified $\pm 10 \%$ range. Several sources of error contributed to this outcome, including the use of the meters in a three-phase power system (a first for the Whisker Labs technology), errors in the time alignment process for comparisons with reference meter data, and interference from adjacent breakers. Nevertheless, the Whisker meters correctly captured trends and step changes in the metered circuits and performed better with larger loads. These results imply that the Whisker meters should also provide reasonable accuracy in three-phase commercial applications with additional tuning.

\section{Applications and Performance Summary}

In addition to evaluating ease of installation and accuracy, the field demonstration examined applications related to energy efficiency or cost savings in buildings. During the course of the field demonstration, the team identified three categories of analytics applications that are relevant for the Havana Gardens site: miscellaneous electric loads (MELs) control for portfoliolevel energy cost savings; heating, ventilating, and air conditioning (HVAC) equipment sequence of operations tuning for site-specific energy cost savings; and fault or outage detection for exterior lighting and signage.

As an extension of the specific applications identified at the Havana Gardens site, the team recommends a broader range of analytics applications for the Whisker meters, based on the installation evaluation and accuracy results of the laboratory and field tests. Although the accuracy of the Whisker Labs meters is not (and is not expected to be) as good as conventional, in-panel power meters, the Whisker meters are easier to install, have a lower cost, and are capable of providing valuable, actionable information for a variety of applications, including:

- Schedule verification

- Fault detection and diagnostics (FDD)

- Demand response verification 
- Tracking energy use/generation in subpanels

- General energy efficiency recommendations.

The $\mathrm{IN}^{2}$ program provided Whisker Labs with a third-party evaluation of functionality, accuracy, and applications of its power meters. Based on laboratory and field installations, the Whisker meters reduced the complexity and installation time significantly, relative to conventional metering equipment. Unlike conventional submeters, the Whisker meters require no special expertise to install, do not require access to the interior of an electrical panel, do not expose the installer to potentially dangerous electrical hazards, and may be installed without an electrical site shutdown or other major disruption to the building. Additionally, the meters are currently meeting the company's accuracy goals. The accuracy of the Whisker system is sufficient for a large number of applications that require status checks or general trends of expected system performance for relatively large loads. NREL performed interference correction tests to show that there is room for further improvement in interference rejection without changing anything about the physical hardware. Whisker Labs continues to develop its technology in this vein, as well as expanding applicability to a broader set of electrical infrastructure architectures and geometries. 


\section{Table of Contents}

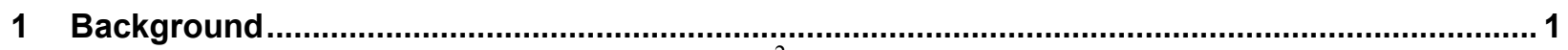

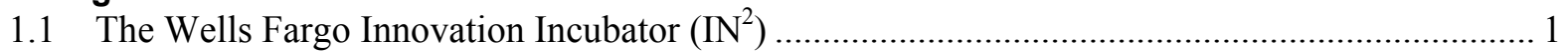

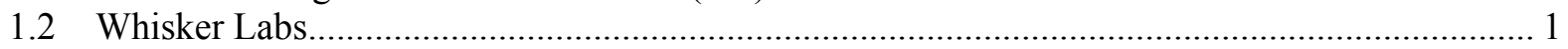

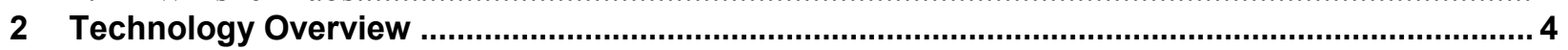

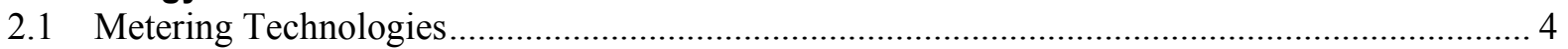

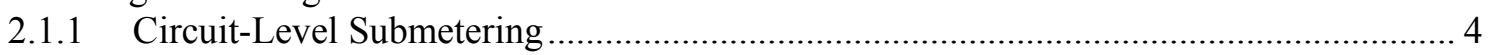

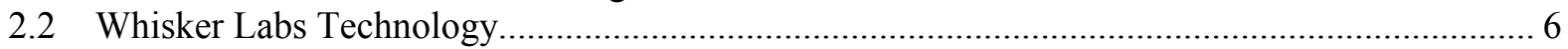

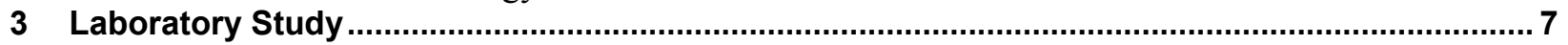

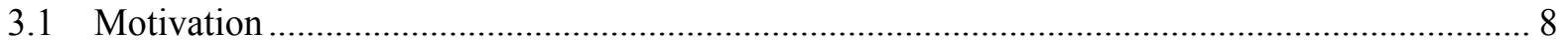

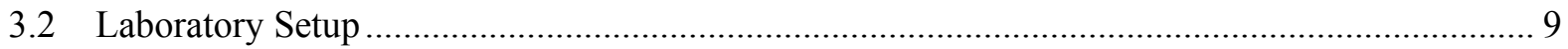

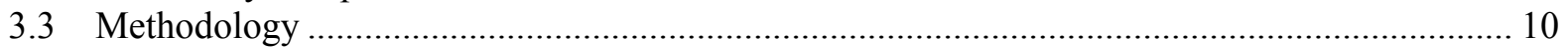

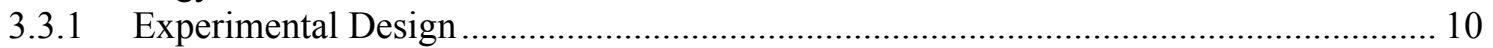

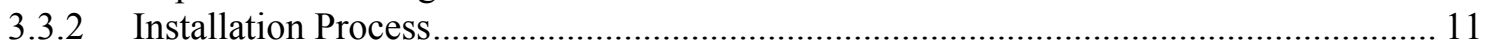

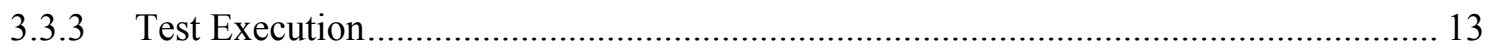

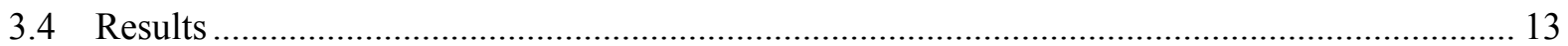

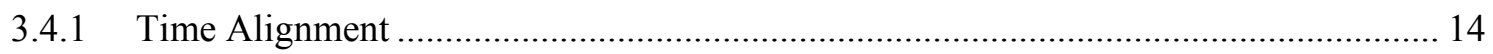

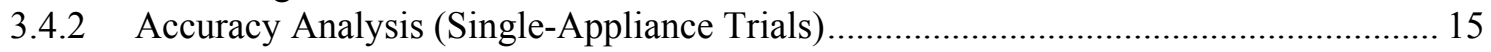

3.4.3 Interference Analysis (Multiple-Appliance Trials) .............................................. 23

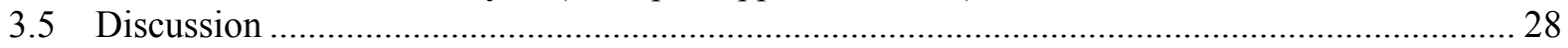

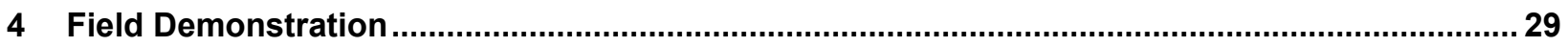

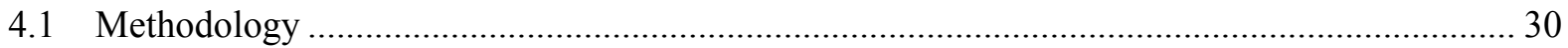

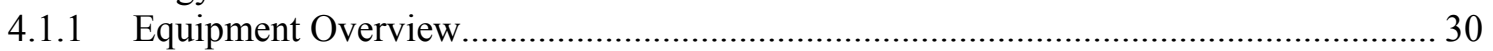

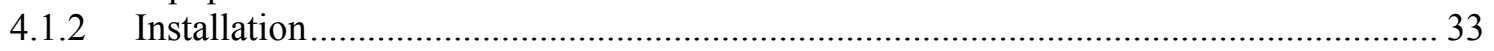

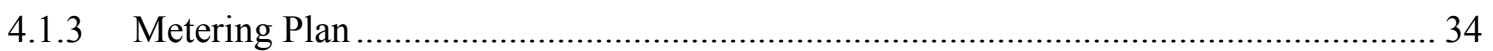

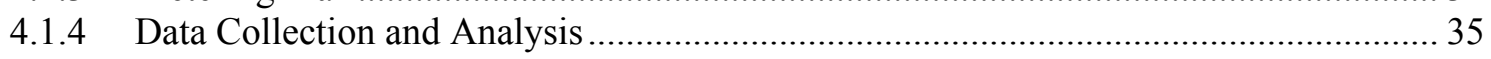

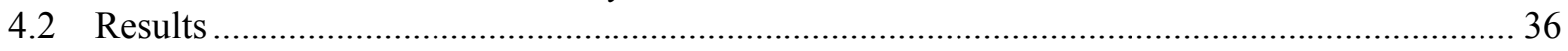

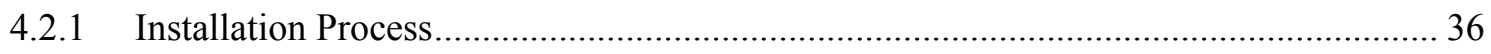

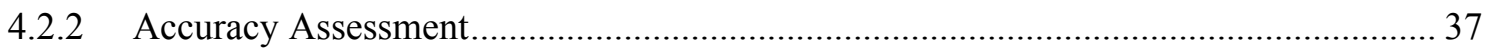

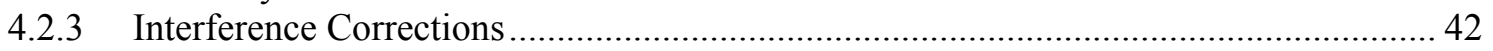

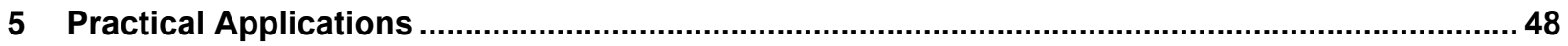

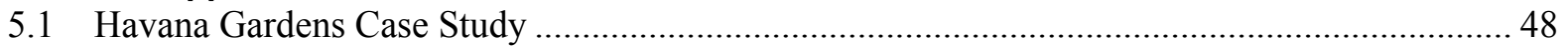

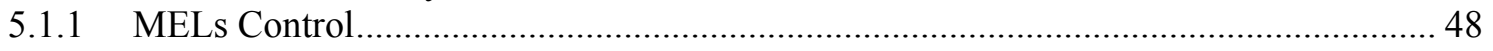

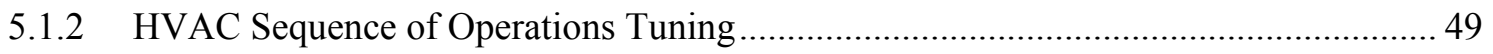

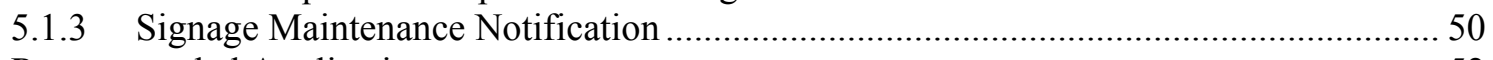

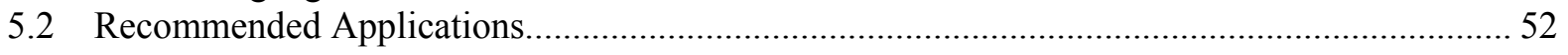

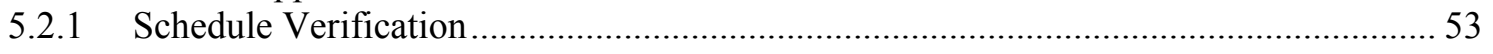

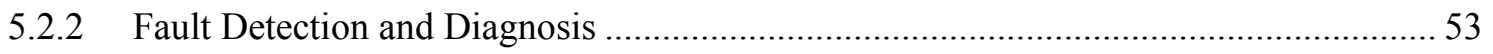

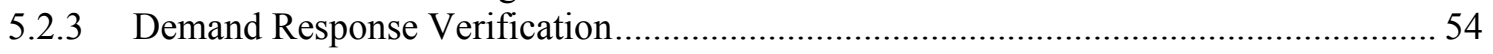

5.2.4 Energy Consumption/Generation Tracking in Subpanels ...........................................54

5.2.5 Energy Auditing and Retro-commissioning ......................................................... 54

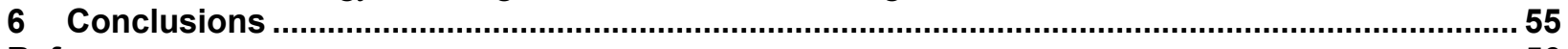

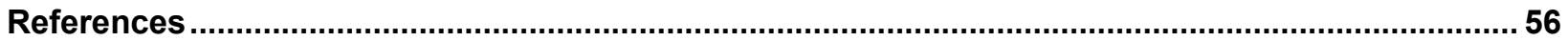




\section{List of Figures}

Figure ES1. Conventional submetering installed inside a residential electrical panel.............................. vi

Figure ES2. The Whisker Labs meters installed on the front of breakers in an electrical panel. ...............vi

Figure ES3. Data from the Whisker and reference meters for the refrigerator are shown, with and without interference. In the lower graph, lights and the dishwasher were also running, which impacted the Whisker meter reading for the refrigerator..................................................... vii

Figure ES4. Product development timeline for Whisker Labs ........................................................ viii

Figure ES5. Estimated absolute value of interference coefficients (inverse of interference rejection ratio) for each appliance: smaller is better................................................................................. ix

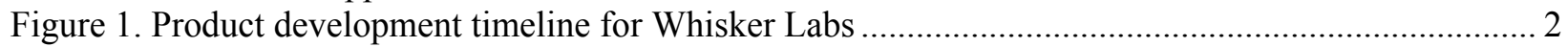

Figure 2. Residential electrical panel with CTs installed on all breakers ................................................ 5

Figure 3. First-generation Whisker Labs equipment: Hub, sensors, and full system................................ 7

Figure 4. Second-generation Whisker Labs equipment: Hub, sensors, and full system. ........................... 7

Figure 5. Layout of electrical panel used for testing of the second-generation system. Loads shaded in blue were monitored by Whisker Labs sensors.................................................................. 8

Figure 6. Data from the Whisker sensors and the reference meters for the refrigerator are shown, with and without interference. In the lower graph, lights and the dishwasher were also running, which

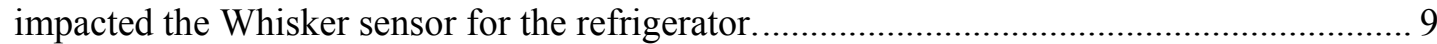

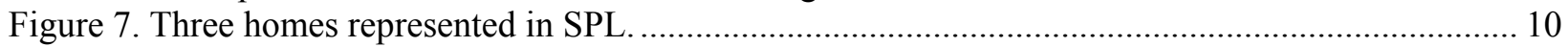

Figure 8. Stencil used to ensure proper placement of the sensor on the breaker. .................................... 12

Figure 9. Step 1 - Use stencil as a guide to position the sensor on the breaker....................................... 12

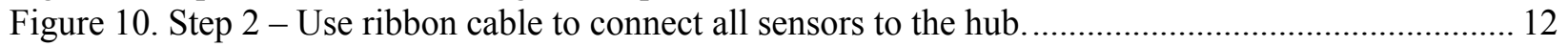

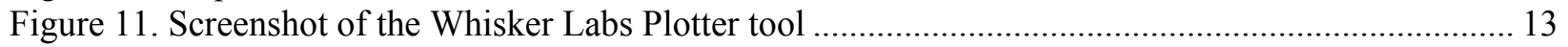

Figure 12. Comparison of data from the lights circuit from the reference power meters and the Whisker

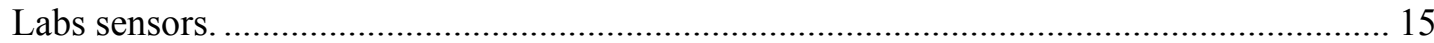

Figure 13. Reference data from the lights circuit was shifted in 1-second increments to find the point

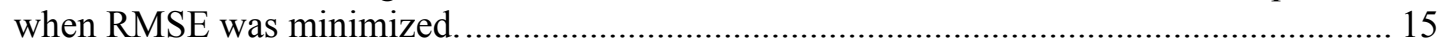

Figure 14. Data from the reference power meters and Whisker Labs meter after the time alignment and averaging reference data down to 10 -second intervals. ...................................................... 15

Figure 15. Single-appliance Whisker vs. reference power (10-second sampling interval)...................... 16

Figure 16. Comparison of absolute offset only, fractional scaling error only, and combined error models

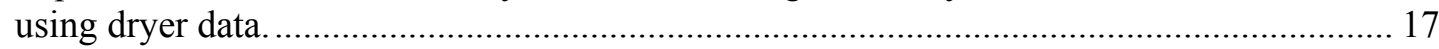

Figure 17. Estimated absolute offset error for each Whisker meter ..................................................... 19

Figure 18. Estimated fractional scaling error for each Whisker meter ................................................... 20

Figure 19. Linear regression $95 \%$ CIs shown for single-appliance results using 10-second interval data. 21

Figure 20. Linear regression 95\% CIs shown for single appliance results using 1-minute interval data ... 22

Figure 21. Residual error in Whisker meter readings vs. modeled interference for six appliances using a

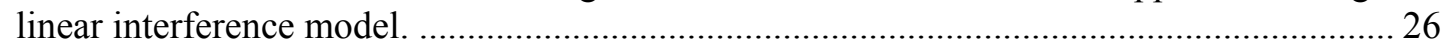

Figure 22. Estimated absolute value of interference coefficients (inverse of interference rejection ratio) for

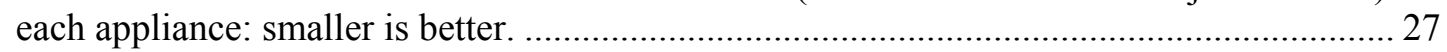

Figure 23. Location of Panel L1-3 within Havana Gardens site electrical room....................................... 31

Figure 24. Havana Gardens metering equipment: (1) Whisker and (2) M\&V meters............................ 32

Figure 25. Network diagram for meter installation at the Havana Gardens site ..................................... 33

Figure 26. L1-3 Panel schedule and metering plan for the Havana Gardens site .................................... 35

Figure 27. Wells Fargo/CBRE technician installing a Whisker meter (left) and NREL technical support

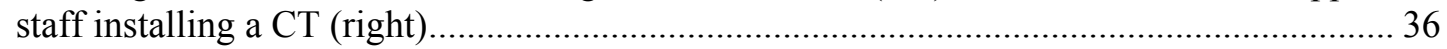

Figure 28. 10-second field test data. Observed scatter is largely an artifact of clock misalignment. ......... 39

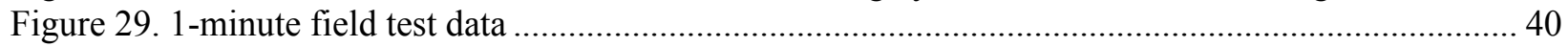

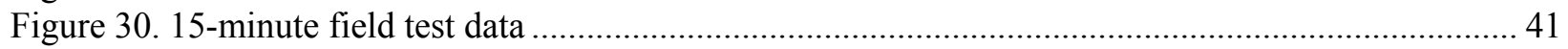

Figure 31. Observed cross-circuit interference rejection in Whisker Labs field demonstration................. 43 
Figure 32. Estimation of cross-circuit interference coefficients from observed step changes................... 45

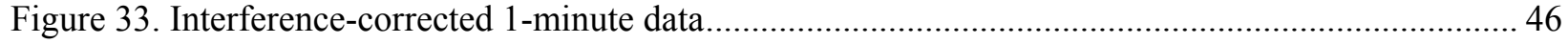

Figure 34. Havana Gardens site MELs control opportunity ................................................................... 49

Figure 35. Havana Gardens site, HVAC sequence of operations potential improvement .........................50

Figure 36. Havana Gardens site, signage maintenance notification ....................................................... 51

\section{List of Tables}

Table 1. Test Matrix Used to Test the Second-generation of Whisker Labs Sensors ............................... 11

Table 2. Single Appliance Offset Error …......................................................................................... 18

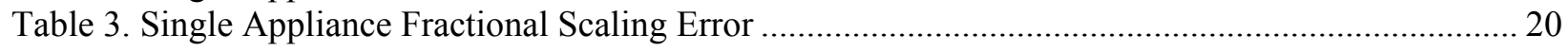

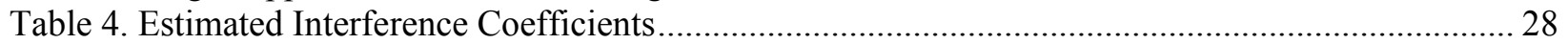

Table 5. Estimated Interference Rejection Ratios........................................................................... 28

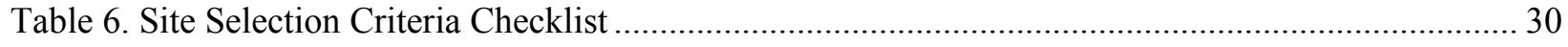

Table 7. Whisker and M\&V Equipment Installation Cost Comparison ................................................. 37

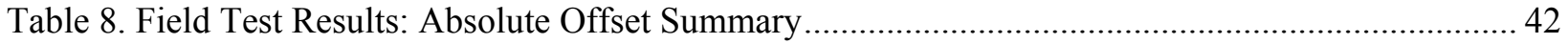

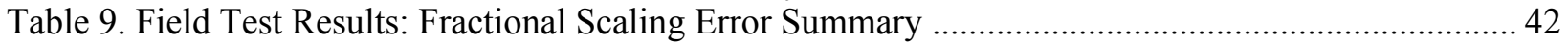

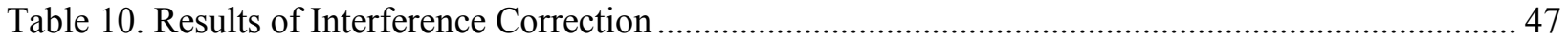




\section{Background}

\subsection{The Wells Fargo Innovation Incubator $\left(\mathrm{IN}^{2}\right)$}

The Innovation Incubator $\left(\mathrm{IN}^{2}\right)$ is an invitation-only technology incubator program funded by the Wells Fargo Foundation and co-administered by the National Renewable Energy Laboratory (NREL). Beginning in 2014, the $\mathrm{IN}^{2}$ program extended three annual rounds of application invitations to startup companies with commercial building energy-efficiency and demand management technologies. Candidate companies were referred for invitation by a group of more than 40 channel partners, which include incubators and universities. Each year, a series of three selection committees evaluated applications based on technical merit of the technologies and feasibility of the business plans, leading to the selection of four, six, and 10 companies for each cohort in 2014, 2015, and 2016, respectively, resulting in 20 total companies in the $\mathrm{IN}^{2}$ portfolio by 2017 . The 20 companies are in a range of product development stages, defined in $\mathrm{IN}^{2}$ as tier 1 , tier 2 , and tier 3 , a scale that captures bench scale to commercially ready products.

Whisker Labs, an Oakland, California-based company, was referred to the program by Prospect Silicon Valley and was one of four awardees in the first $\mathrm{IN}^{2}$ cohort. The program selected Whisker Labs based on the potential for its stick-on power metering technology to increase adoption of submetering practices across the buildings sector. Submetering can lead to greater awareness of building and device energy consumption patterns among building owners and operators.

Whisker Labs joined the $\mathrm{IN}^{2}$ program as a tier 2 company, which indicates that it has prototypes ready for evaluation in an operational environment. Whisker Labs and NREL defined a twostage project scope: first, a laboratory demonstration and validation of the Whisker meters' performance, and second, a field demonstration at a Wells Fargo property. The laboratory demonstration served as a stage gate for progression to a field demonstration.

The laboratory demonstration made use of NREL's Systems Performance Laboratory (SPL) in the Energy Systems Integration Facility (ESIF) and lasted approximately one year from the project start date in the spring of 2015. The team controlled residential building equipment (appliances) in the SPL to impose a variety of power use scenarios on an electrical panel equipped with both the Whisker meters and a set of high accuracy reference meters. The team then analyzed the results, which generally aligned with Whisker Labs' stated accuracy specification. The positive outcome of the laboratory validation led to follow-on funding for a collaborative field demonstration at a Wells Fargo bank branch. This staged approach to the NREL-company partnership is a cornerstone of the $\mathrm{IN}^{2}$ program.

\subsection{Whisker Labs}

Whisker Labs was founded in 2014 by two engineers from Lawrence Berkeley National Laboratory, Oren Schetrit and Steven Lanzisera. They developed a stick-on electrical power sensor that is applied to the front of circuit breakers in an electrical panel and measures electric and magnetic fields to determine circuit-level power consumption. The sensors can be used in both residential and commercial buildings with a variety of standard model circuit breakers, although Whisker Labs began with a focus on single-phase (residential-type) 120/240 V electrical panels. This project touched on both applications, as the laboratory testing was 
performed with a residential electrical panel and the field demonstration was carried out in a small commercial building.

The technology created by Whisker Labs overcomes many of the issues with conventional energy monitoring equipment, such as high costs and inconvenient installation. Conventional electrical metering equipment requires installation of voltage measurements and current transducers (CTs) inside the electrical panel. In the case of residential power meter systems, many metering products are advertised as "do-it-yourself" installations, which could pose a significant safety risk as most homeowners are not qualified to perform electrical work, particularly within a live panel. Hiring an electrician is the preferred method for installation of conventional power meters in both commercial and residential buildings but represents an added cost. Industry safety guidelines state that electrical power to the panel should be disconnected prior to performing any work inside the panel in order to eliminate shock and arc flash hazards. This imposes additional cost and inconvenience to building occupants since disconnecting a panel typically requires a site-wide electrical shutdown. Another significant shortcoming of conventional power meters is cost. Commercially available power meters typically cost between $\$ 1,000$ and $\$ 5,000$ per circuit, including all associated data acquisition and installation costs, which makes it cost-prohibitive to fully instrument an entire building (Parker, et al. 2015) (Federal Energy Management Program 2006) (ENERGY STAR 2002). The difficulty and high cost for submetering were recognized by DOE when they issued a challenge to industry in 2013 to create a low-cost wireless electric energy submetering system for commercial buildings, called the Wireless Energy Meter Challenge. The challenge specifications included performance metrics and pricing goals to bring the cost down to $\$ 100$ per meter (not including installation costs). To date, only one meter submitted to the challenge has met all of the specified requirements (Building Technologies Office May 2017).

Whisker Labs' sensors simplify the installation process dramatically and eliminate the need for an electrician and building shutdown. The cost target is also well below typical, with the final, full production costs estimated at roughly $\$ 100$ per circuit, which is $90 \%$ less than the lowest cost of conventional power meters and is consistent with the cost goals laid out by the DOE Wireless Energy Meter Challenge.

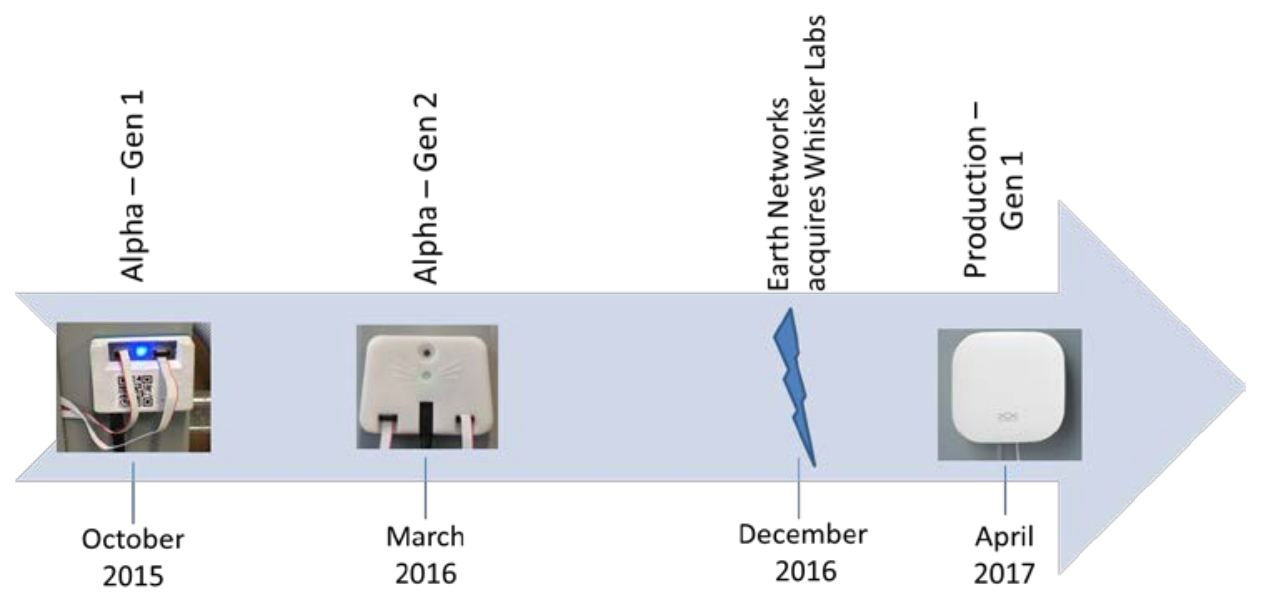

Figure 1. Product development timeline for Whisker Labs 
Whisker Labs has continued to develop its product and technology since the versions used during the laboratory and field demonstrations. The original set of hardware tested in the lab, labeled Alpha-Generation 1 in Figure 1, was an early prototype of the system. The next version, Alpha - Generation 2, was still a prototype system, but improvements were made to the look of the hub, the installation process, and the online data visualization tool. Alpha - Gen 2 was used in the second round of lab testing and in the field demonstration. Late in 2016, Whisker Labs was acquired by Earth Networks and now exists as a wholly owned subsidiary of Earth Networks. It has continued to improve its technology and has also shifted focus from submetering specific circuits in an electric panel to measuring the power consumption at the main breakers in a panel. Production - Generation 1 reflects these changes. 


\section{Technology Overview}

\subsection{Metering Technologies}

Energy monitoring is a key first step to saving energy. A building owner first needs to understand when and where energy is used before they can take action to reduce consumption. There are a variety of strategies that can be employed to save energy, including replacement of inefficient equipment, improvement of control algorithms, identification of required maintenance that may be affecting performance, and detection and correction of faults in building systems and equipment. All of those strategies require some form of metering of the building's performance, including overall energy consumption and, in some cases, metering of specific loads (Parker, et al. 2015) (National Science and Technology Council Committee on Technology: Subcommittee on Building Technology Research and Development 2011).

The most common type of metering technology is a utility meter. Nearly every building in the country has a utility meter to measure total electricity consumption for billing purposes. Some utility meters (typically called "smart" meters) are configured to upload time-series consumption data to a utility database, which may provide a customer-facing website. Less commonly, some utility meters have a secondary radio to send data directly to the building owner. However, most utility meters are used purely for billing purposes and do not provide data in real-time or at a sufficiently high resolution to be useful to a building owner or operator.

Therefore, if a building owner or operator wants to better understand the energy consumption in their building, they must install a separate electrical power meter. There are a variety of available systems that measure whole building power, but nearly all require two or three CTs to be installed around the main power lines that enter a home or commercial building. The power meter will likely also include voltage sensing wires, which must be installed at a new or existing breaker. The installation of a whole house meter requires work inside the electrical panel and should always be performed by a licensed electrician.

Whole building data is a good starting point for understanding what uses the most energy in a building. This can be done by looking at the power consumption profile throughout the day or by turning different appliances on and off while looking at the whole building data. Whole building data is also useful for investigating the base load of a building - the energy consumed when the building is empty or when people are sleeping - which may help identify devices that are left on unnecessarily. A whole building energy meter is the simplest and cheapest option for energy monitoring, but drawing insight via this approach requires a lot of curiosity and initiative on the part of the user. Looking at the energy consumption on a circuit level, termed circuit-level submetering, provides additional detail about how much energy is used by specific devices.

\subsubsection{Circuit-Level Submetering}

A more comprehensive way to learn about energy consumption in a building is to install circuitlevel power meters. Monitoring the energy consumption from individual breakers gives the user a clearer picture of what loads use the most energy. However, installing individual CTs on each breaker is expensive, time-consuming, and may be difficult to fit in the limited space of the electrical panel, as shown in Figure 2. As with whole home/building meters, submeters also are installed inside the electrical panel, require voltage sense wires, and the installation should be done only by a licensed electrician. Rather than just having CTs installed on the main supply 
power wires only, CTs are installed on every circuit of interest in the panel, which may require a large number of CTs, depending on the size of the panel. Not only does this increase cost and installation time compared to a whole-building meter, but the panel itself may not have the room to accommodate all the additional equipment.

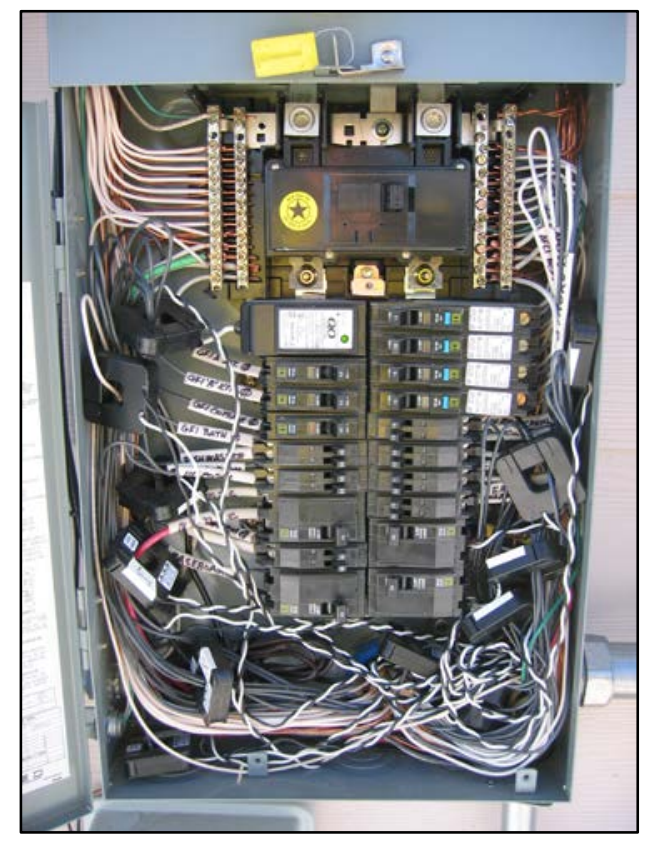

Figure 2. Residential electrical panel with CTs installed on all breakers

There are other technologies available for circuit-level metering that improve upon conventional systems in various ways, such as using wireless CTs or CTs that are integrated with the electric panel, but additional barriers remain. Integrated panel CTs are only practical to install when the building is being built, which limits their application and require forward-looking buildingowners. Wireless CTs draw their power from the circuit they are connected to and so have lower resolution at low power conditions. They also still require installation inside the breaker panel by an electrician. These types of products are often sold to building owners along with energy monitoring services, which makes it difficult to obtain cost information for the hardware, independent from the monitoring service.

In addition to the conventional methods for submetering that require many CTs, there are other means of gathering circuit-level information using disaggregation techniques. Rather than measuring the consumption of every circuit individually, a whole-building power sensor is installed and data from that sensor is used to tease out information about all the circuits in the home in a process typically termed "non-intrusive load monitoring" (NILM) (Mayhorn, et al. 2015). Load disaggregation is a technique that is still under development and its application has largely been limited to research and laboratory demonstrations, though there are some companies starting to sell products with NILM capabilities. There are a variety of different strategies that can be employed for load disaggregation, but the goal is usually to achieve the same level of detail as circuit-level submetering with only a single, central power meter on the supply to the panel. The power meter is still usually a CT-based sensor that measures power consumption of the whole building, and thus requires that the panel be opened by an electrician. Although NILM 
methods are improving rapidly, they still involve significant uncertainty and usually require a training period or some level of interaction with the building owner to identify some of the loads.

Some appliances and equipment are able to self-report their operating state, faults, and importantly, energy consumption. Termed "Internet of Things," these connected devices are emerging rapidly, especially in the residential sector. In the future, it may be sufficient to rely on building equipment to participate in advanced energy-saving strategies. But today's technologies, communications interoperability, and related software applications are insufficiently mature to accurately meet near-term data and analytics needs.

\subsection{Whisker Labs Technology}

The power meters designed by Whisker Labs stick to the front of circuit breakers and measure electric and magnetic fields in order to determine power consumption (Lorek, et al. 2014). This method for measuring power relies heavily on the details of the circuit breaker construction, particularly its geometry. The brand of breaker (which defines the construction of the breaker) informs the details of the power sensing algorithms and also dictates the mounting location on the face of the breaker to ensure maximum accuracy. Whisker Labs has built a library of brandspecific algorithms and mounting requirements for commonly specified electrical panel brands, estimated by Whisker Labs to be compatible with over $75 \%$ of legacy equipment in homes.

Mounting the Whisker meters on the face of the breakers means that the panel cover does not need to be removed for installation, which avoids the cost of hiring an electrician and the inconvenience of turning off power to the entire panel or building. The installation process is much faster - each sensor is placed using a small plastic guide and fastened to the front of each breaker with an adhesive pad. Once all the sensors are attached to the desired breakers, a ribbon cable connects to all the sensors and then connects to a communication hub. The hub plugs into a standard $120 \mathrm{~V}$ outlet and mounts to the panel magnetically. The hub sends all the data collected by the sensors to the Whisker Labs' cloud via Wi-Fi and an Internet connection, which are required for this system. Data is available to authorized users for viewing and downloading from a webpage provided by Whisker Labs or via an application programming interface (API). The design of these sensors eliminates the safety concerns and inconveniences of more conventional submetering technology. Additionally, the installation process is significantly simplified, which may reduce barriers to adoption. 


\section{Laboratory Study}

The laboratory study included two prototype generations of equipment installed on the same GEbrand residential electrical panel in the SPL within the ESIF at NREL. The first generation system was installed on October 16, 2015, and included six sensors. Laboratory testing of the first generation equipment was completed in early November 2015. The second-generation system included simplifications to the installation process, a more polished-looking hub, and improved algorithms and was installed in March 2016. Testing of the second-generation equipment was completed in May 2016. Figure 3 and Figure 4 below show the two generations installed in the SPL.

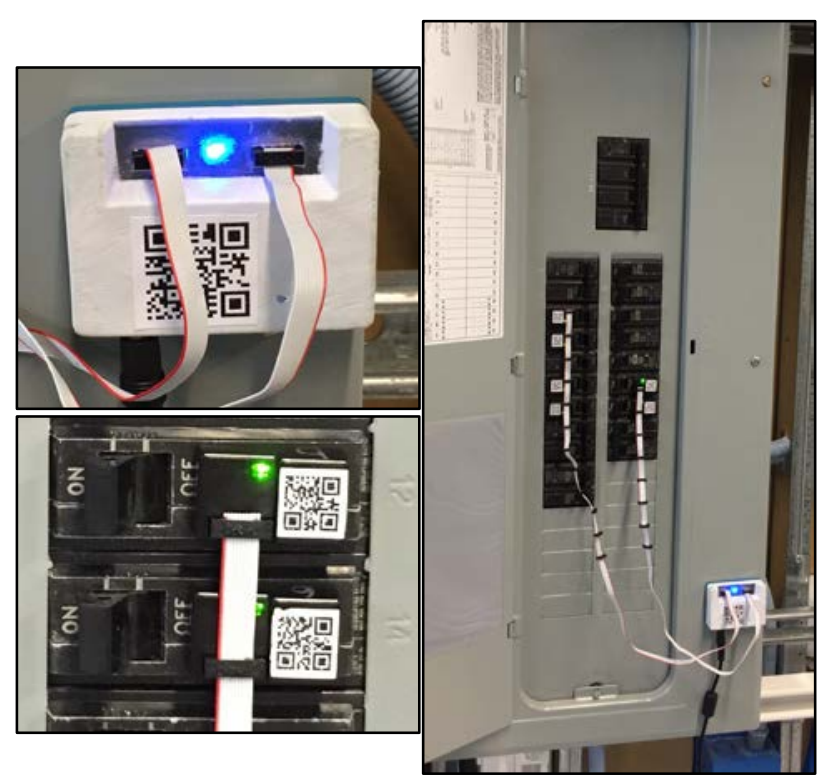

Figure 3. First-generation Whisker Labs equipment: Hub, sensors, and full system.

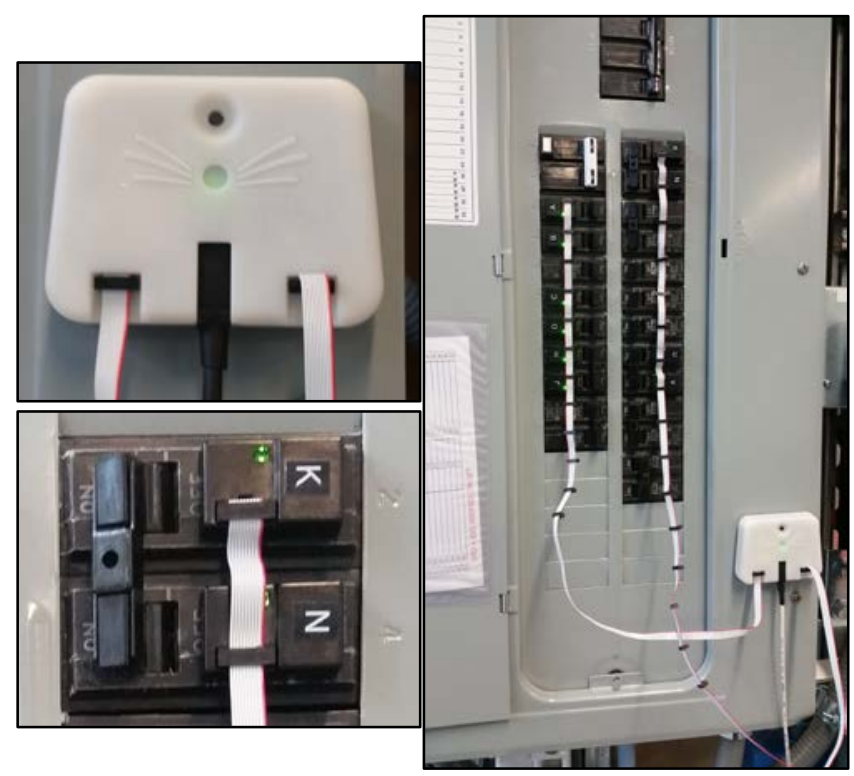

Figure 4. Second-generation Whisker Labs equipment: Hub, sensors, and full system.

While the two versions of equipment were installed on the same electrical panel, the metered breakers differed between the two systems. This was partially due to the fact that the first generation could not be configured to measure two-pole loads (such as a dryer) and partially because NREL had more sensors to work with for the second-generation system. The second generation was able to accommodate two-pole breakers and, because many of the more interesting loads are powered by two-pole breakers, the team included a number of them in the second-generation test set up. The layout of the electrical panel used for this project is shown in Figure 5. The loads highlighted in blue were monitored with the Whisker Labs sensors in the second-generation testing phase. The range was not metered with Whisker Lab sensors but was used during testing to evaluate the impact of interference from an unmetered breaker. 


\begin{tabular}{|l|c|c|l|}
\hline \multicolumn{1}{|c|}{ Load } & Circuit & Circuit & \multicolumn{1}{|c|}{ Load } \\
\hline \multirow{2}{*}{ Range } & 1 & 2 & \multirow{2}{*}{ Dryer } \\
\cline { 2 - 4 } & 3 & 4 & \\
\hline Refrigerator & 5 & 6 & \multirow{2}{*}{ Water Heater } \\
\hline Dishwasher & 7 & 8 & \\
\hline Disposal & 9 & 10 & Outlets (1) \\
\hline Washer & 11 & 12 & Outlets (2) \\
\hline Lighting & 13 & 14 & Outlets (3) \\
\hline \multirow{2}{*}{ A/C Air Handler } & 15 & 16 & \multirow{2}{*}{ A/C Condenser } \\
\cline { 2 - 4 } & 17 & 18 & \\
\hline
\end{tabular}

Figure 5. Layout of electrical panel used for testing of the second-generation system. Loads shaded in blue were monitored by Whisker Labs sensors.

\subsection{Motivation}

The objectives for the laboratory tests were:

1. To gain familiarity with the installation and use of the Whisker meters.

2. To evaluate the measurement accuracy of the Whisker meters.

3. To evaluate the effects of cross-circuit interference on the Whisker measurements.

The first objective is qualitative and included an ease-of-use evaluation, comparison with conventional metering technology, and planning for a field demonstration.

The latter two objectives are quantitative. Single appliance measurement accuracy and multiappliance interference are separate phenomena that both impact the overall accuracy of the Whisker meters in a practical deployment. The single appliance measurement accuracy is the more familiar metric; it defines the degree to which the Whisker measurements represent the true power being consumed on each measured circuit in the absence of interference (other appliances operating). However, because the Whisker meters measure power indirectly using electric and magnetic fields at each circuit breaker, they are subject to interference introduced by the electric and magnetic fields produced by nearby breakers. Figure 6 illustrates the single appliance accuracy (top) and multi-appliance interference (bottom) for power measurements of a refrigerator. 


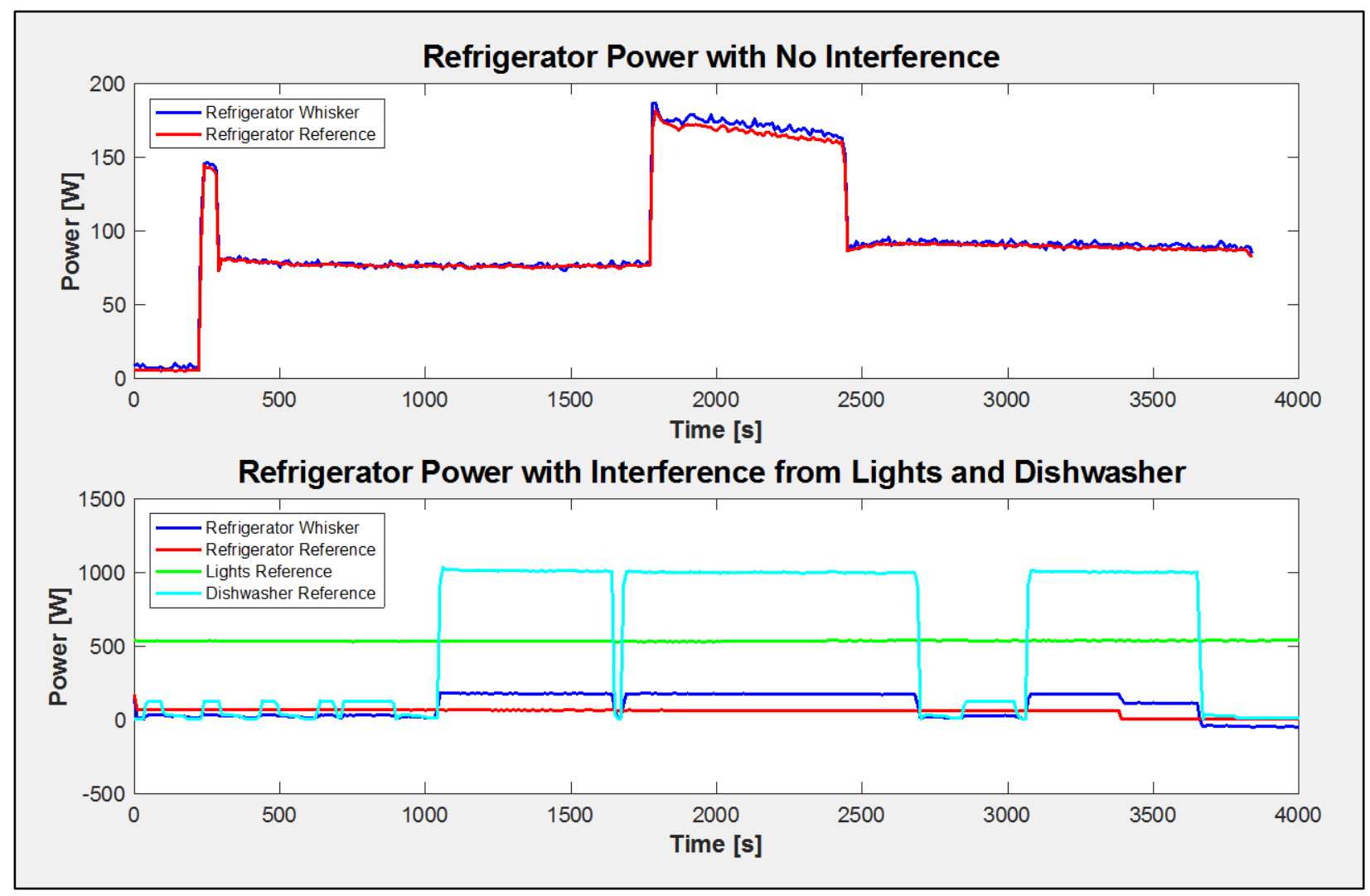

Figure 6. Data from the Whisker sensors and the reference meters for the refrigerator are shown, with and without interference. In the lower graph, lights and the dishwasher were also running, which impacted the Whisker sensor for the refrigerator.

For the second generation of meters tested, Whisker Labs stated a typical single appliance accuracy of $\pm 10 \%$ of the true power reading and a typical interference rejection ratio of at least 10:1. (An interference rejection ratio of 10:1 means that $10 \mathrm{~W}$ of power on an adjacent circuit will produce only $1 \mathrm{~W}$ of measurement noise for the circuit being measured.) The team designed the laboratory experiments to validate these specifications.

\subsection{Laboratory Setup}

The laboratory testing portion of this project was conducted in the SPL, which is a laboratory containing three residential building representations. Each "home" is electrically identical to a residential building with 120/240 VAC split-phase power delivered to a utility meter, then to an electrical panel, and finally out to all of the circuits. Each circuit is individually metered with reference power meters to monitor each load independently. Each home contains a full complement of major appliances and some smaller appliances and plug loads. To facilitate power measurements, each circuit serves one major appliance or end use. There are two HVAC systems located in the SPL, connected to separate homes. The homes also have the ability to integrate less common residential systems such as electric vehicle charging stations, stationary batteries, and photovoltaic (PV) power generation. Figure 7 shows the layout of the laboratory. The Whisker meters were installed on one home's electrical panel. The laboratory power meters monitor every individual circuit and data is collected at $1 \mathrm{~Hz}$ using the lab's permanent data acquisition system. 


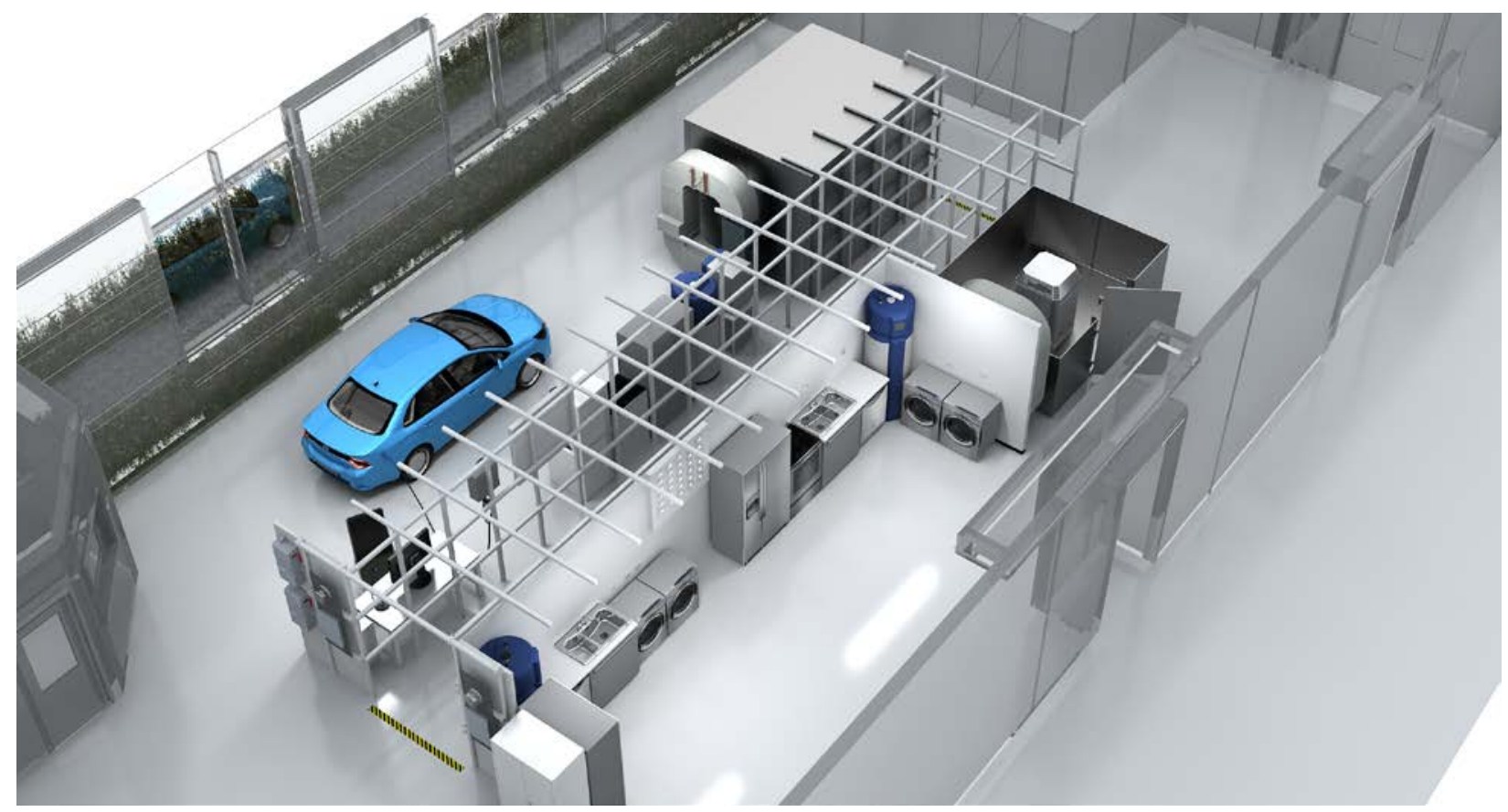

Figure 7. Three homes represented in SPL

\subsection{Methodology}

The team designed and executed the laboratory tests in two phases. In the first phase, the team executed a set of single-appliance trials designed to validate the measurement accuracy of the Whisker meters. In the second phase, the team executed a set of multiple-appliance trials to measure the effects of cross-circuit interference.

\subsubsection{Experimental Design}

Table 1 shows the list of experimental trials carried out and what loads were included in each trial. Trials 1-11 represented the first phase tests and were designed to test the accuracy when appliances operated alone. The remaining trials represent the second phase of testing and were designed to evaluate cross-circuit interference. Trials 12-19 tested combinations of metered appliances, while trials 20-27 tested the same combinations of metered appliances with the addition of one large, unmetered load (the range). 
Table 1. Test Matrix Used to Test the Second Generation of Whisker Labs Sensors

\begin{tabular}{|c|c|c|c|c|c|c|c|c|}
\hline & 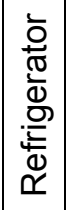 & 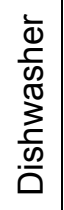 & 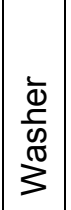 & 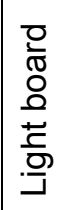 & 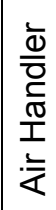 & 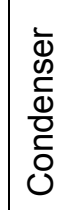 & 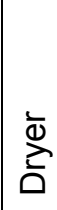 & $\begin{array}{l}0 \\
\mathscr{D} \\
\widetilde{\varpi} \\
\widetilde{\sim}\end{array}$ \\
\hline Trial 1 & $x$ & & & & & & & \\
\hline Trial 2 & & $x$ & & & & & & \\
\hline Trial 3 & & & $x$ & & & & & \\
\hline Trial $4-7^{a}$ & & & & $X$ & & & & \\
\hline Trial 8 & & & & & $X$ & & & \\
\hline Trial $9^{b}$ & & & & & $x$ & $X$ & & \\
\hline Trial 10 & & & & & & & $x$ & \\
\hline Trial 11 & & & & & & & & $x$ \\
\hline Trial 12 & & & & $\mathbf{X}$ & $x$ & $x$ & $x$ & \\
\hline Trial 13 & $x$ & & & & & & $x$ & \\
\hline Trial 14 & & $x$ & & & $x$ & $\mathbf{x}$ & & \\
\hline Trial 15 & $x$ & $x$ & & $x$ & & & & \\
\hline Trial 16 & & & $x$ & $x$ & & & & \\
\hline Trial 17 & $x$ & & $x$ & & $x$ & $x$ & & \\
\hline Trial 18 & & $x$ & $x$ & & & & $x$ & \\
\hline Trial 19 & $x$ & $x$ & $x$ & $x$ & $X$ & $X$ & $x$ & \\
\hline Trial 20 & & & & $x$ & $X$ & $x$ & $x$ & $x$ \\
\hline Trial 21 & $X$ & & & & & & $x$ & $x$ \\
\hline Trial 22 & & $X$ & & & $X$ & X & & $x$ \\
\hline Trial 23 & $X$ & $x$ & & $X$ & & & & $x$ \\
\hline Trial 24 & & & $x$ & $x$ & & & & $x$ \\
\hline Trial 25 & $X$ & & $x$ & & $X$ & 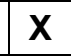 & & $x$ \\
\hline Trial 26 & & $x$ & $x$ & & & & $x$ & $x$ \\
\hline Trial 27 & $\mathbf{X}$ & $x$ & $x$ & $x$ & 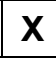 & $x$ & $x$ & $x$ \\
\hline
\end{tabular}

${ }^{a}$ The light board contained three different types of bulbs: LEDs, CFLs, and incandescent bulbs. Each type of bulb was tested individually, and then a trial was done with all lights on. In all subsequent trials, all lights were turned on.

${ }^{b}$ The condenser and air handler are two separate pieces of equipment that make up the air conditioner. The air handler can run alone, but the condenser cannot run without the air handler, so trial 9 is not a true single appliance test, as both the air handler and condenser were run.

\subsubsection{Installation Process}

Since ease of installation is one of the main advantages of this technology, details of the installation process are described here. The installation procedure was simplified between the first and second generation, so we have focused on the details related to the second generation. A total of 10 sensors were installed in a residential electrical panel. Since three of the breakers that were chosen for monitoring fed $240 \mathrm{VAC}$ appliances, the 10 sensors monitored a total of seven circuits (4 single-pole breakers and 3 double-pole breakers). The sensors come with an adhesive 
pad pre-installed on the back that is used to fasten the sensor to a breaker. The exact placement for the sensor is determined using a stencil unique to that make and model of breaker. The stencil, shown in Figure 8, is a piece of plastic that fits snuggly over the front of the breaker with a hole in the middle that dictates where the sensor should be mounted on the breaker.

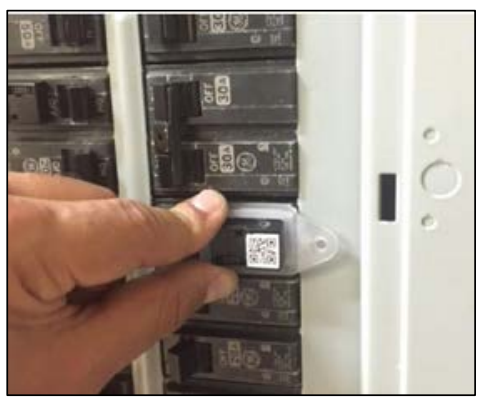

Figure 8. Stencil used to ensure proper placement of the sensor on the breaker

The installer starts by removing the adhesive cover from the back of the sensor. Then they will hold the stencil to the front of the breaker and place the sensor inside the hole in the stencil, with the ribbon cable connector positioned toward the center of the electrical panel (Figure 9). Once all the sensors are in place, a ribbon cable is used to daisy-chain the sensors together and connect them to the hub (Figure 10). Two ribbon cables are needed: one for each side of the electrical panel. (For large panels, such as those found in commercial buildings, multiple hubs may be needed. Each hub can support a maximum of 10 sensors.)

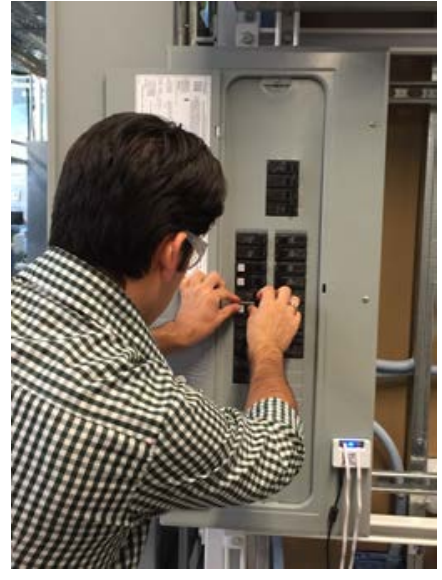

Figure 9. Step 1 - Use stencil as a guide to position the sensor on the breaker

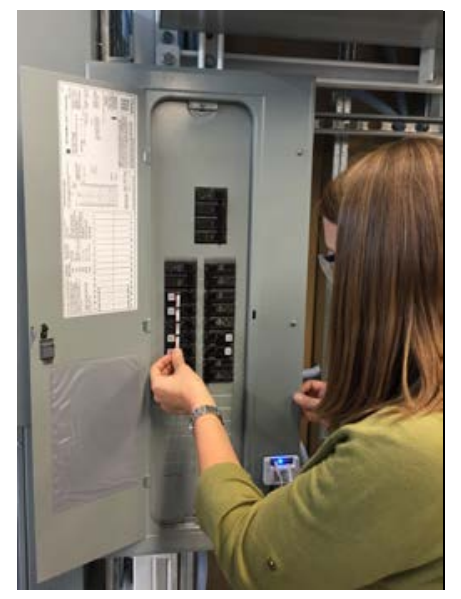

Figure 10. Step 2 - Use ribbon cable to connect all sensors to the hub

The hub must be configured before the ribbon cables are connected. When the hub is connected to power for the first time, it broadcasts its own Wi-Fi signal. The installer uses their computer to find the Whisker Labs' Wi-Fi network and connect to it. They then navigate to a webpage specified in the Whisker Labs instruction manual, which prompts them to point the hub to connect to the local Wi-Fi network and the Internet. Once the hub is connected to the Wi-Fi network of the building owner's choice, the ribbon cables can be connected to the hub. The hub 
itself is magnetic, which allows it to be mounted to the electrical panel. The panel door should be closed once the installation process is completed.

Once connected, raw data is uploaded to the Whisker Labs' server for analysis. Processed information is available to authorized users to view and download using an online tool called the Whisker Labs Plotter, shown in Figure 11. Data from each sensor can either be viewed in terms of power or current. Data can be downloaded manually in comma-separated values (CSV) format or can be pulled programmatically via an API. By default, Whisker Labs data are available at 10second intervals. The early version of the plotter that NREL used during this project did not allow custom names for the sensors or combination of data from two sensors measuring a single 240 VAC breaker. These and other features will be added at a later date.

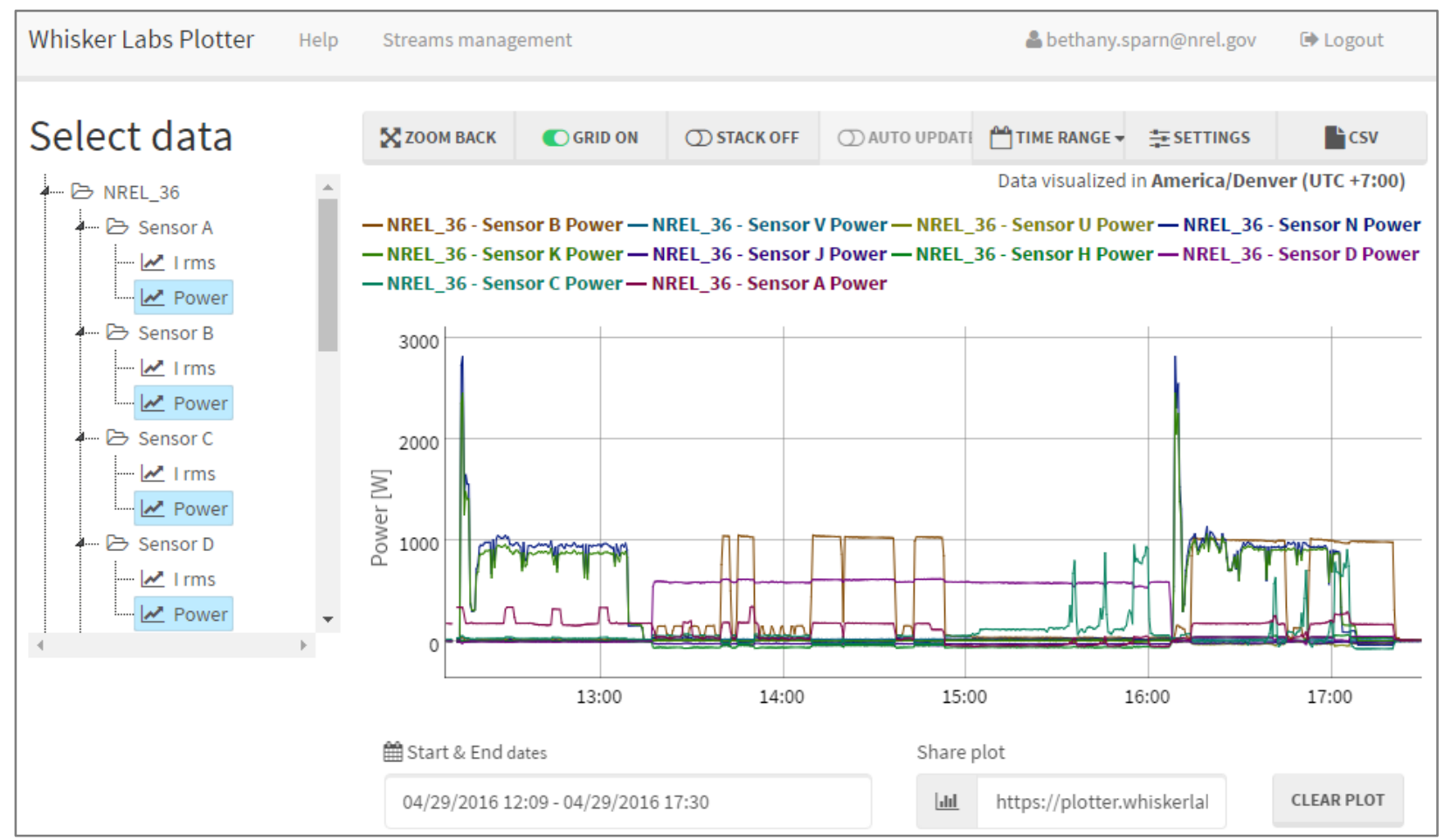

Figure 11. Screenshot of the Whisker Labs Plotter tool

\subsubsection{Test Execution}

Following sensor installation, the team executed the trials identified in Table 1 over several days in March, April, and May 2016. Each trial was run for a minimum of 1 hour. Some appliances, such as the dishwasher and dryer, had finite cycles, so a specific cycle was chosen that would run for close to an hour and that cycle was used for all the trials. Other devices, such as the lights, could be turned on for any amount of time and those were operated for an hour.

\subsection{Results}

The laboratory tests were designed to assess the performance of the Whisker Labs' technology with regard to two metrics: the single appliance accuracy and the interference effects from other circuits. In order to assess these metrics, the team sought to isolate and independently evaluate three sources of measurement error: misalignment of the time series data between the reference 
and Whisker meters; the inherent Whisker meter measurement error, including both offset and scaling error; and multi-appliance interference.

\subsubsection{Time Alignment}

After all the tests were complete, data from the Whisker Labs' server and data from the SPL data acquisition system were collected. Despite the fact that both data collection systems synchronized their clocks to some reference time, there were slight temporal misalignments between the Whisker Labs data and the data collected by the reference meters. In order to ensure that the discrepancies in timestamps did not affect the accuracy and interference analyses, we aligned the two data sets using a large change in power consumption as a reference point. Time alignment of the Whisker data was only needed for comparison to the reference power meters and is not a concern for typical installations.

The temporal resolution of data from the reference power meters and Whisker sensors were not the same: the Whisker Labs data were available at 10-second intervals and the reference data were collected at 1-second intervals. Therefore, for each trial, the two sets were compared for a significant step change in power consumption and the reference data shifted in 1-second increments until the best fit, defined by the root-mean-squared error (RMSE), was obtained. The time shift that resulted in the minimum RMSE value was used to align the two data sets for that particular trial. Once the reference data were shifted, those data were also averaged to produce data at 10 -second intervals with timestamps that matched the Whisker Labs' data. Because the time shift did not necessarily remain constant throughout the testing period, this alignment process was repeated for each trial. This procedure does not completely eliminate time series misalignment as a source of error, but it does minimize it.

The time alignment process is illustrated in the following figures. Figure 12 shows data from the lights circuit from both the reference power meters and the Whisker meters when the lights were turned on, which produced a sharp change in power consumption over a short period of time. In Figure 13, the RMSE for the two data sets is shown for different temporal shifts. The shift producing the minimum RMSE value, around -50 seconds, was used to align the data sets. Figure 14 shows the final result - the data sets are well aligned and the reference data has been averaged at a 10-second interval to match the Whisker Labs' data. 


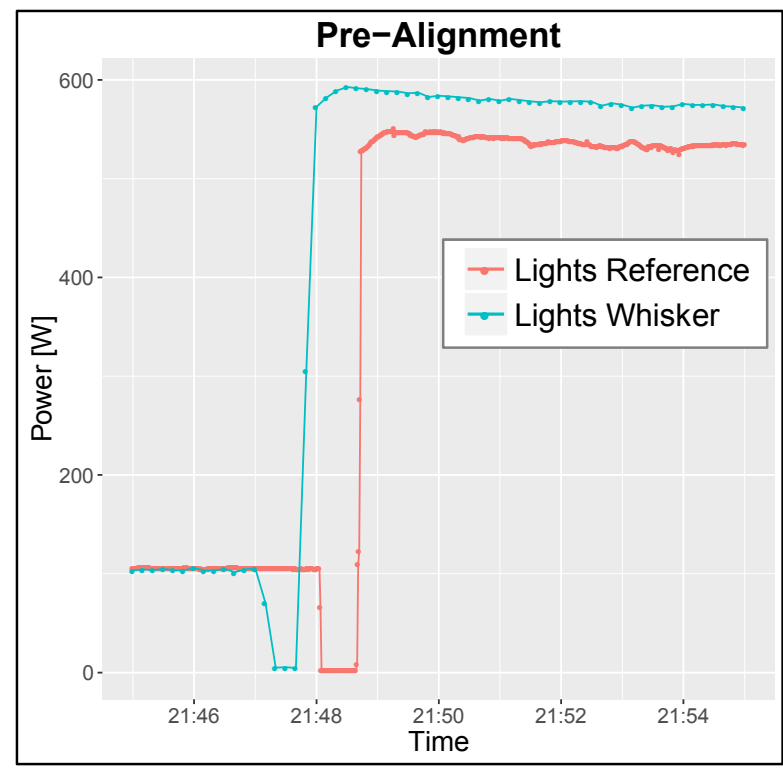

Figure 12. Comparison of data from the lights circuit from the reference power meters and the Whisker Labs sensors

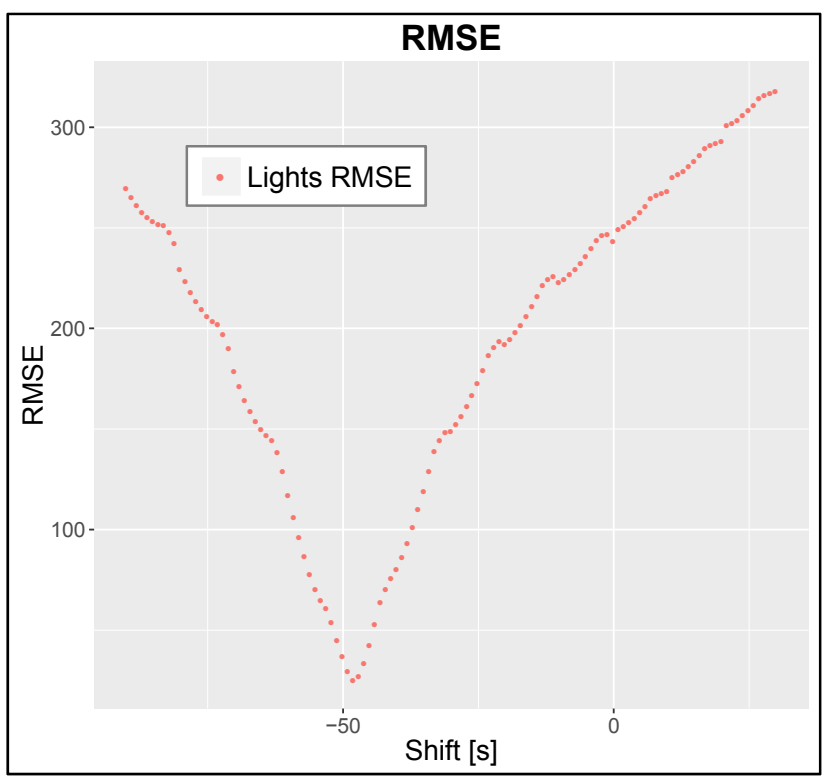

Figure 13. Reference data from the lights circuit was shifted in 1-second increments to find the point when RMSE was minimized

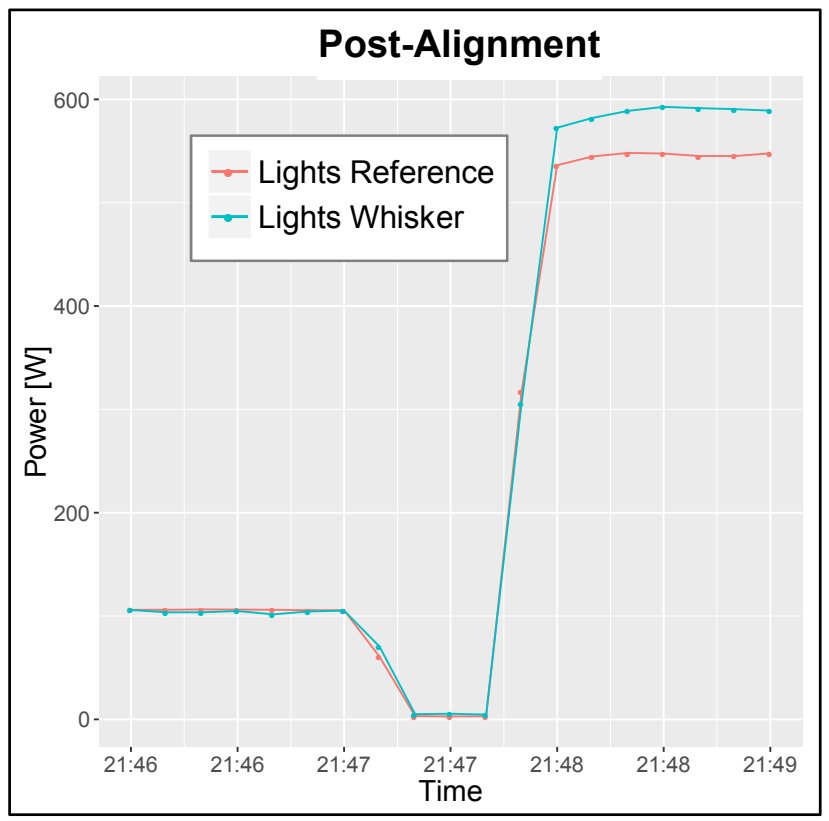

Figure 14. Data from the reference power meters and Whisker Labs meter after the time alignment and averaging reference data down to 10 -second intervals

\subsubsection{Accuracy Analysis (Single-Appliance Trials)}

Trials 1-11 were single-appliance trials designed to test the measurement accuracy of the Whisker meters. Of these, the team analyzed trials 1-8 and 10. Trial 9 was omitted because the air handler and condenser were both operating, and Trial 11 was omitted because the electric range did not have an associated Whisker meter. For $240 \mathrm{~V}$ appliances (appliances with 2-pole 
circuit breakers), the measured power from the two Whisker meters was added together for total measured power.

Two different models of Ohio Semitronics power meters were employed in these tests as reference meters: GWV5 series and PC5 series; their accuracy specifications for power measurements are $0.02 \%$ of reading and $0.05 \%$ of full scale, respectively. Whisker meter measurement errors overwhelmingly dominate the uncertainties in the reference power meters so the latter are not entered into the calculations presented here.

Figure 15 presents a parity plot for all of the raw results: the Whisker meter measurements ( $y$ axis) are plotted against the reference power meter measurements ( $x$ axis). To capture adequate resolution over the entire dynamic range, the results are shown in two separate figures, one for low loads $(0-300 \mathrm{~W})$ and one for high loads $(300-3,000 \mathrm{~W})$. Because each test's duration was approximately 1 hour, with data recording at a 10-second sampling interval, there are approximately 360-390 data points per test. The legend shows the appliance being measured, and the black line, $y=x$, indicates perfect agreement.

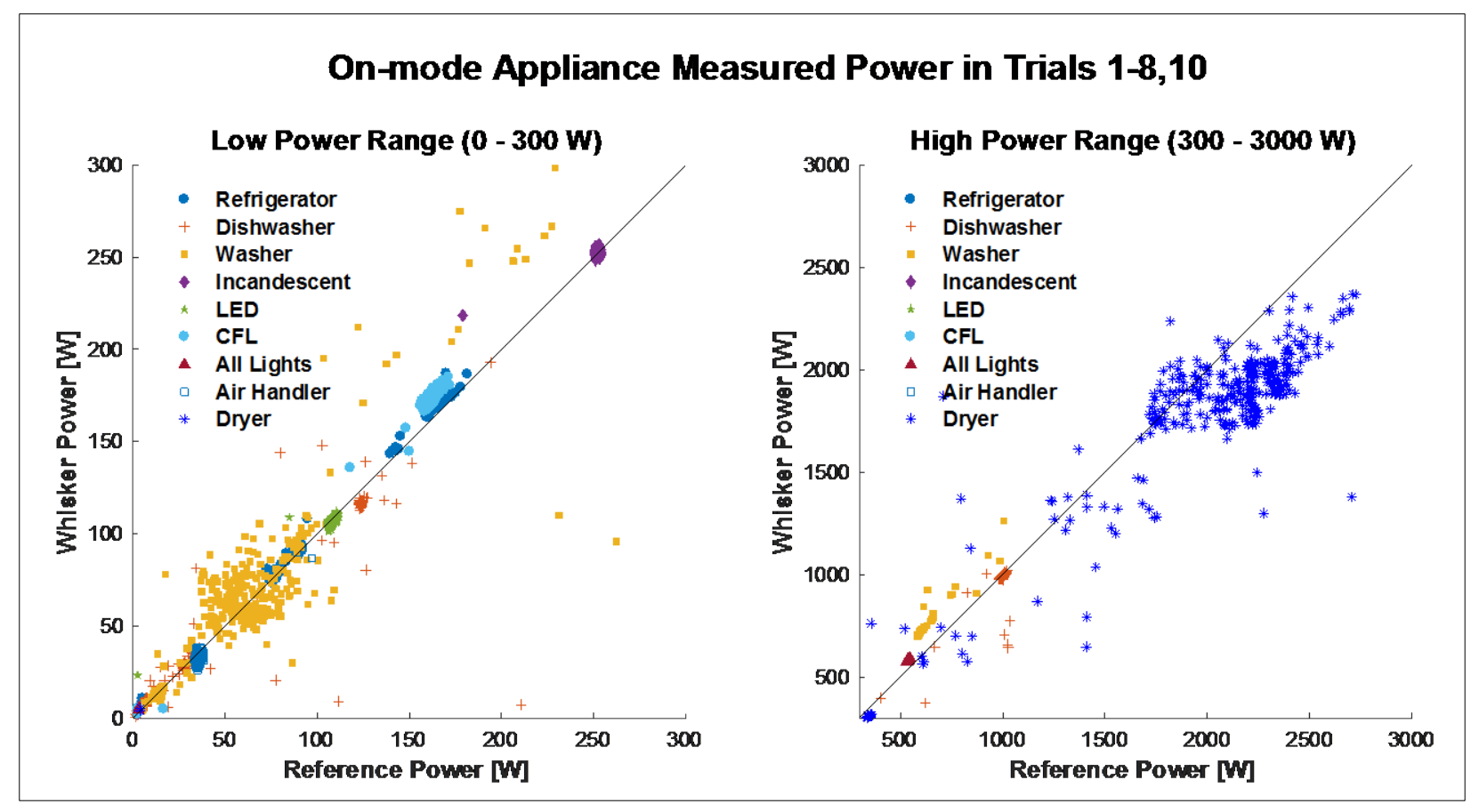

Figure 15. Single-appliance Whisker vs. reference power (10-second sampling interval)

Overall, Figure 15 indicates good agreement between the Whisker and reference measurements. However, some scatter is present in the data, including significant outliers. The scatter may be due to residual time misalignment issues, systematic measurement errors, or random noise. (Multi-appliance interference is not present because only one appliance was operated during each trial.)

The team considered three possible models for the systemic error: absolute offset only, fractional scaling error only, and standard linear regression error (a combination of offset error and fractional scaling error). Consider a set of power measurements taken for an appliance operating at constant power, with $\bar{P}_{W}$ representing the mean of the Whisker measurements and $\bar{P}_{R}$ 
representing the mean of the reference measurements. In the first model, the only source of systemic error is a constant offset, or bias, $b$ :

$$
\bar{P}_{W}=\bar{P}_{R}+b
$$

The second model assumes only a fractional scaling error, $s$ :

$$
\bar{P}_{W}=(1+s) \bar{P}_{R}
$$

The third model assumes that both an offset and a fractional scaling error may be present:

$$
\bar{P}_{W}=(1+s) \bar{P}_{R}+b
$$

When these error models are extended to time-varying power, they create various types of linear fits of the Whisker measurements as functions of the reference. The type of model selected has implications both for the value of the estimated error metrics (offset $b$ and/or fractional scaling error $s$ ) and the level of confidence that the estimated metrics are correct.
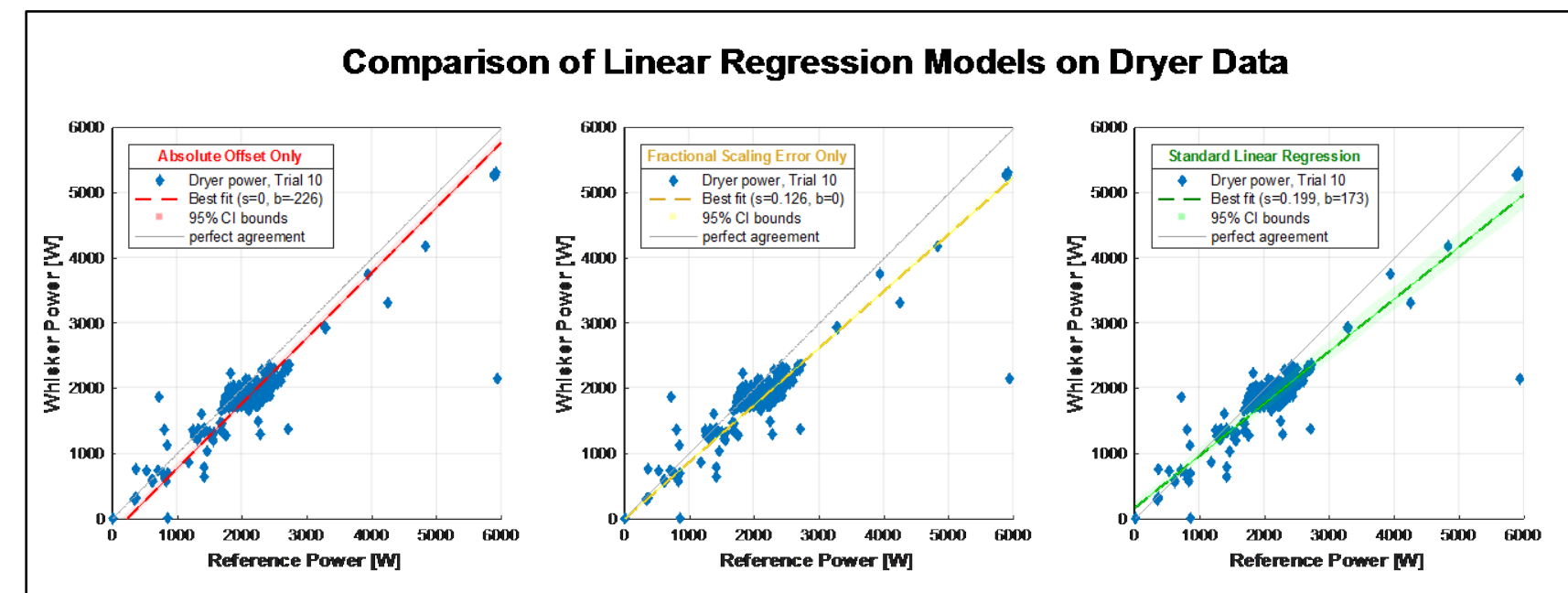

\section{Figure 16. Comparison of absolute offset only, fractional scaling error only, and combined error models using dryer data}

Figure 16 illustrates the difference in analysis results obtained by assuming each of the three error models. For each model, the dashed line represents the estimated best fit relationship between the Whisker and reference measurements and the thin shaded region indicates the boundaries of the $95 \%$ confidence interval (CI) on this best fit line. ${ }^{1}$ A line representing perfect agreement between the Whisker measurements and reference measurements $(y=x)$ is shown for reference.

\footnotetext{
${ }^{1}$ The $95 \%$ CI boundaries indicate that if the team replicated the same study multiple times with different random samples, we would expect the estimated slope and/or intercept (depending on the model used) of the best fit line to fall between these boundaries for $95 \%$ of the tests. The CI does not define the boundaries within which $95 \%$ of individual samples are expected to fall; many samples may fall outside of these bounds due to random noise or other transient sources of measurement error.
} 
Of the three linear models examined, the standard linear regression model resulted in the smallest RMSE for the majority of single appliance trials. The RMSE characterizes the magnitude of the scatter of the data about the fitted line. The analyses presented in this report are therefore based on the combined linear regression model. The estimated relationship between sampled vectors for reference power, $P_{R}$, and Whisker power, $P_{W}$, for each appliance using the linear regression model:

$$
P_{W}=\left(1+s \pm \sigma_{s 95}\right) P_{R}+b \pm \sigma_{b 95}
$$

where $s$ is the fractional scaling error, $\sigma_{s 95}$ is its margin of error at a $95 \% \mathrm{CI}, b$ is the absolute offset, and $\sigma_{b 95}$ is its margin of error at a $95 \%$ CI These parameters were derived for the 10 second and 1-minute sampling interval data. The 15-minute data sets were excluded because these data sets only have 4 or 5 data points per trial given that each trial was approximately 1 hour in duration.

\subsubsection{Offset Error}

Table 2 gives the offset error and associated 95\% CI for each appliance, calculated based on the single-appliance trials. The estimated offset error for almost all appliances was small, and the offset error was statistically significant (at 95\% CI) for only three of the appliances at both the 10 -second and 1-minute sampling intervals. Figure 17 displays the same data, in which the central point is the estimated offset error (blue for 10-second interval data, green for 1-minute interval data) and the error bars represent the $95 \%$ CI for the offset error. The dryer is the only clear outlier.

Table 2. Single Appliance Offset Error

\begin{tabular}{|c|c|c|c|c|c|c|c|}
\hline \multirow[t]{2}{*}{ Appliance } & \multirow[t]{2}{*}{ Trial } & \multicolumn{2}{|c|}{$\begin{array}{c}\text { Mean Reference } \\
\text { Power } \\
\overline{P_{R}} \\
{[\mathbf{W}]}\end{array}$} & \multicolumn{2}{|c|}{$\begin{array}{c}\text { Estimated Offset } \\
\text { Error } \\
b \\
{[\mathbf{W}]}\end{array}$} & \multicolumn{2}{|c|}{$\begin{array}{c}95 \% \mathrm{Cl} \\
\text { Margin of Error } \\
\sigma_{b 95} \\
{[\mathrm{~W}]}\end{array}$} \\
\hline & & 10s & $1 \mathrm{~m}$ & $10 \mathrm{~s}$ & $1 \mathrm{~m}$ & $10 \mathrm{~s}$ & $1 \mathrm{~m}$ \\
\hline Refrigerator & 1 & 93.5 & 93.8 & -0.657 & -0.741 & 0.502 & 0.795 \\
\hline Dishwasher & 2 & 644 & 646 & -1.37 & -3.47 & 6.55 & 8.28 \\
\hline Washer & 3 & 131 & 131 & -5.23 & -4.14 & 5.86 & 5.29 \\
\hline Incandescent & 4 & 248 & 249 & 3.35 & 1.88 & 1.77 & 2.21 \\
\hline LED Lights & 5 & 107 & 107 & 9.70 & 21.3 & 2.23 & 3.81 \\
\hline CFL Lights & 6 & 159 & 159 & -0.837 & -1.42 & 1.39 & 1.87 \\
\hline All Lights & 7 & 533 & 534 & 16.3 & 25.8 & 4.67 & 7.26 \\
\hline Air Handler & 8 & 35.4 & 35.2 & 1.76 & 6.12 & 2.15 & 13.3 \\
\hline Dryer & 10 & $2.00 \times 10^{3}$ & $2.01 \times 10^{3}$ & 173 & 128 & 65.0 & 57.2 \\
\hline
\end{tabular}




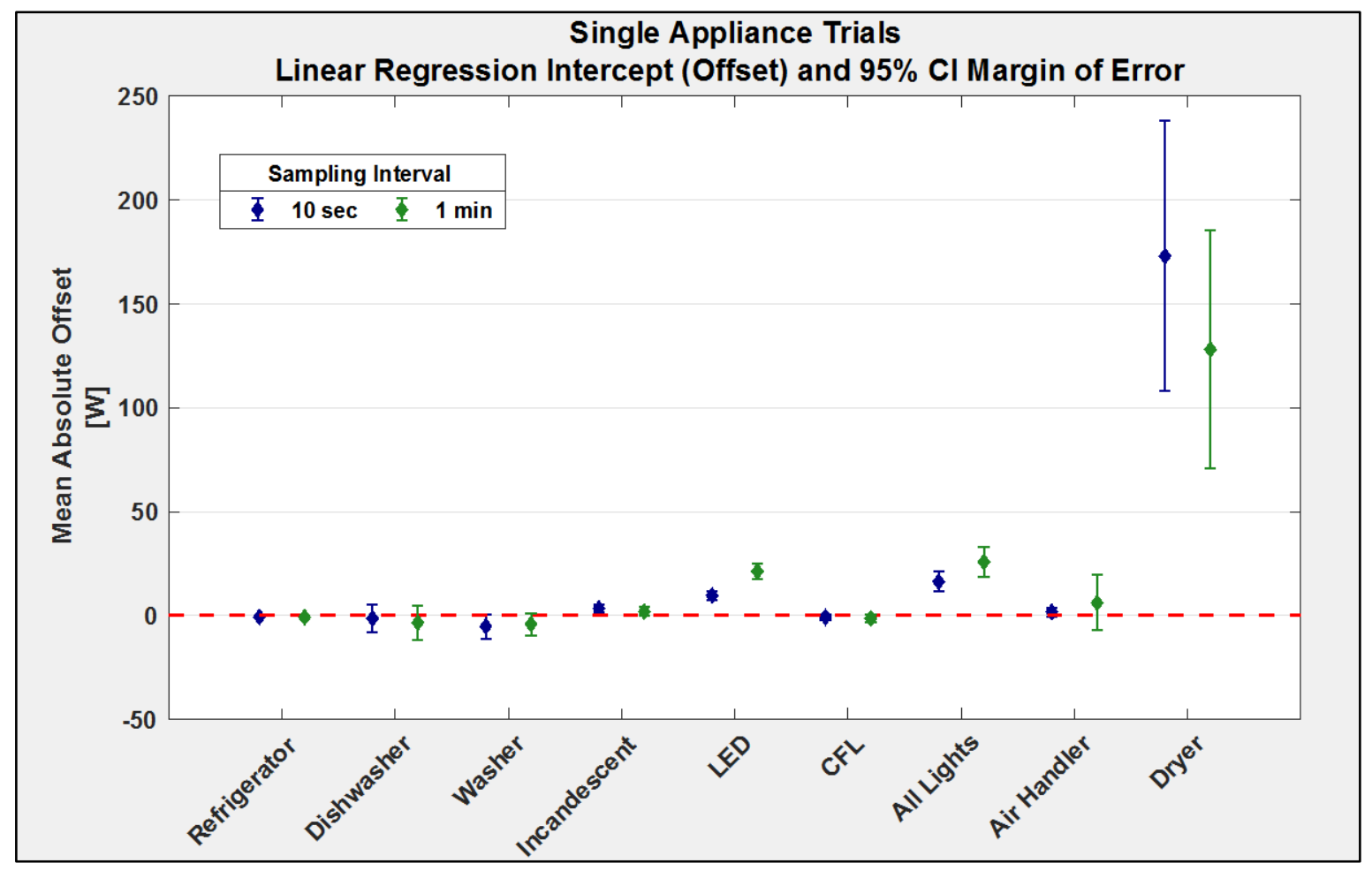

Figure 17. Estimated absolute offset error for each Whisker meter

\subsubsection{Scaling Error}

Table 3 gives the fractional scaling error and associated $95 \%$ CI for each appliance, calculated based on the single-appliance trials, and Figure 18 displays the same data in graphical form. Fractional scaling error or scaling bias is defined as the deviation of the best fit slope from unity. Five of the nine appliances had an estimated fractional scaling error of less than \pm 0.1 , which represents the $10 \%$ relative error that Whisker Labs established as the goal for their secondgeneration meters. The remaining appliances had a fractional scaling error on the order of \pm 0.2 (or $20 \%$ relative error). The margin of error for the air handler at the 1-minute sampling interval was an extreme outlier, but this estimate was highly uncertain because the 1-minute average load for this appliance was near constant in trial 8 (discussed in further detail below). 
Table 3. Single Appliance Fractional Scaling Error

\begin{tabular}{|c|c|c|c|c|c|c|c|}
\hline \multirow[t]{2}{*}{ Appliance } & \multirow[t]{2}{*}{ Trial } & \multicolumn{2}{|c|}{$\begin{array}{c}\text { Mean Reference } \\
\text { Power } \\
\overline{\boldsymbol{P}_{R}} \\
{[\mathrm{~W}]}\end{array}$} & \multicolumn{2}{|c|}{$\begin{array}{c}\text { Estimated Fractional } \\
\text { Scaling Error } \\
s\end{array}$} & \multicolumn{2}{|c|}{$\begin{array}{c}95 \% \mathrm{Cl} \\
\text { Margin of Error } \\
\sigma_{s 95}\end{array}$} \\
\hline & & 10s & $1 \mathrm{~m}$ & 10s & $1 \mathrm{~m}$ & 10s & $1 \mathrm{~m}$ \\
\hline Refrigerator & 1 & 93.5 & 93.8 & 0.0282 & 0.0290 & 0.00494 & 0.00787 \\
\hline Dishwasher & 2 & 644 & 646 & -0.0126 & -0.00930 & 0.00830 & 0.0106 \\
\hline Washer & 3 & 131 & 131 & 0.180 & 0.172 & 0.0254 & 0.0237 \\
\hline Incandescent & 4 & 248 & 249 & -0.0110 & -0.00502 & 0.00708 & 0.00881 \\
\hline LED Lights & 5 & 107 & 107 & -0.103 & -0.212 & 0.0208 & 0.0355 \\
\hline CFL Lights & 6 & 159 & 159 & 0.0733 & 0.0768 & 0.00869 & 0.0117 \\
\hline All Lights & 7 & 533 & 534 & 0.0509 & 0.0331 & 0.00872 & 0.0136 \\
\hline Air Handler & 8 & 35.4 & 35.2 & -0.141 & -0.266 & 0.0605 & 0.378 \\
\hline Dryer & 10 & $2.00 \times 10^{3}$ & $2.01 \times 10^{3}$ & -0.199 & -0.177 & 0.0299 & 0.0268 \\
\hline
\end{tabular}

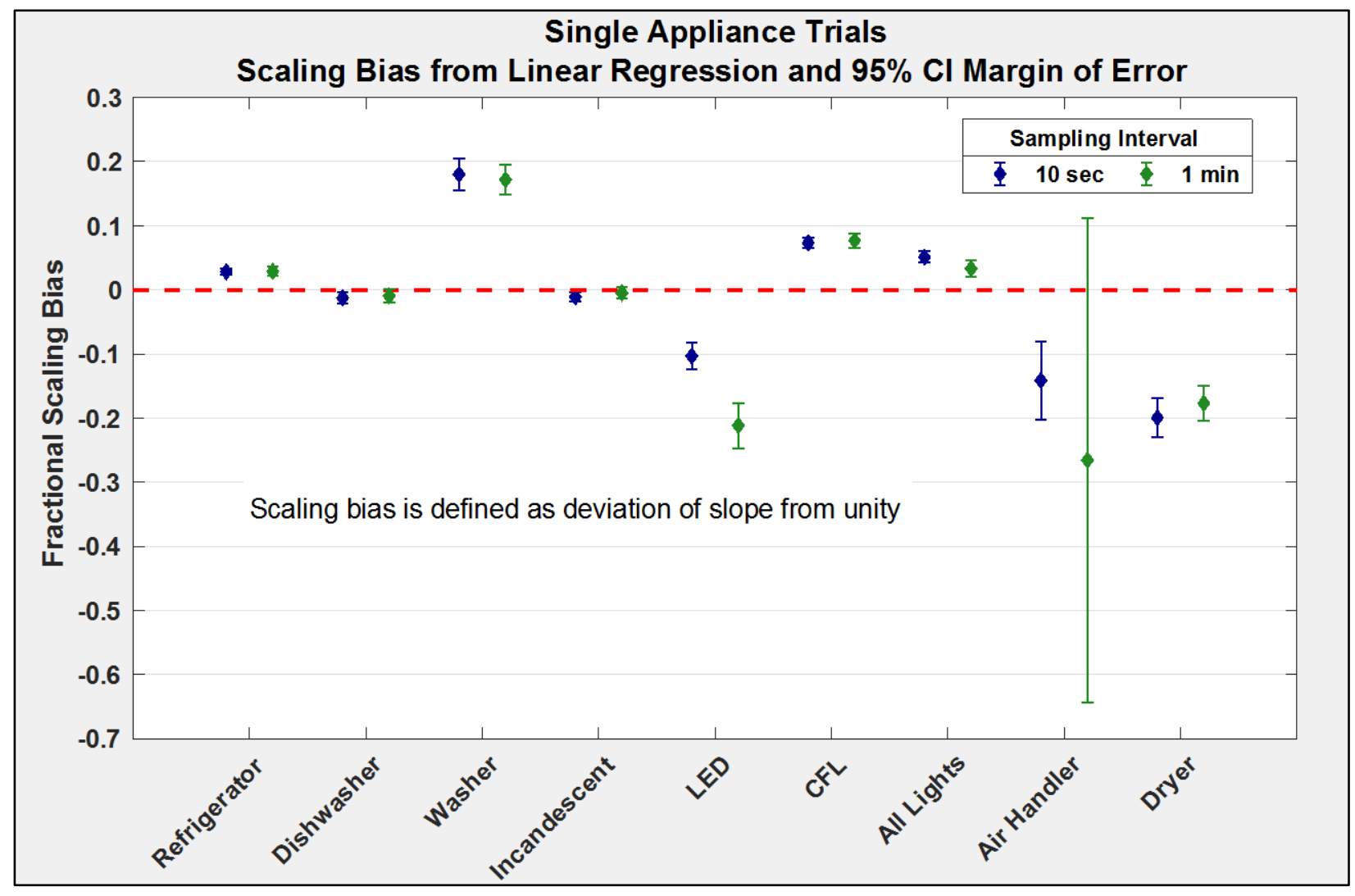

Figure 18. Estimated fractional scaling error for each Whisker meter 


\subsubsection{Discussion}

Figure 19 and Figure 20 are individual parity plots overlaid with the regression CIs for the single appliance tests using the 10-second and 1-minute data sets, respectively. In order to better show the range of values for each appliance, the axis scales differ among the plots. The blue "+" symbols are power measurements and the dashed red lines indicate the upper and lower bounds of the $95 \%$ confidence envelope.

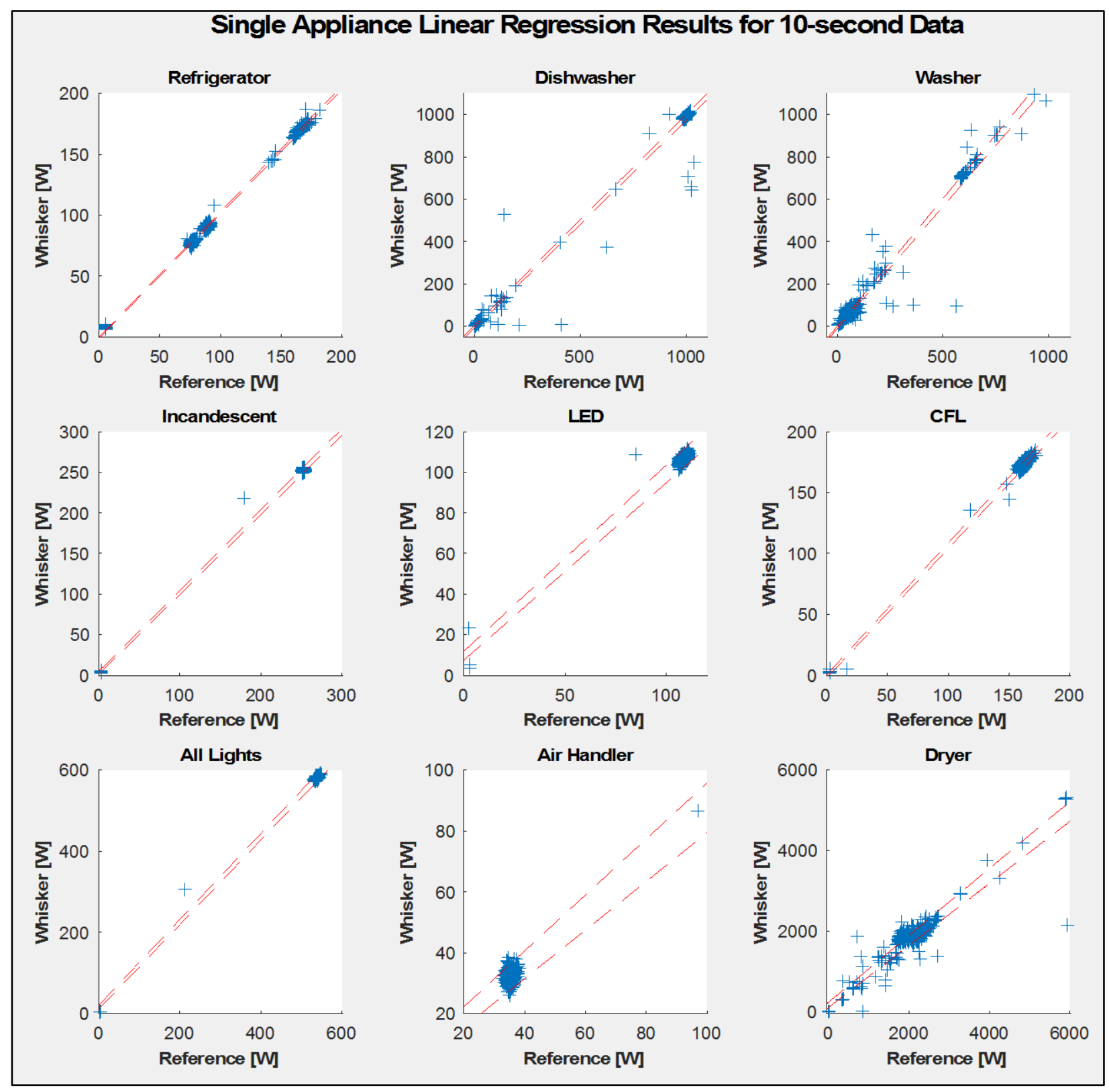

Figure 19. Linear regression $95 \%$ Cls shown for single-appliance results using 10 -second interval data 


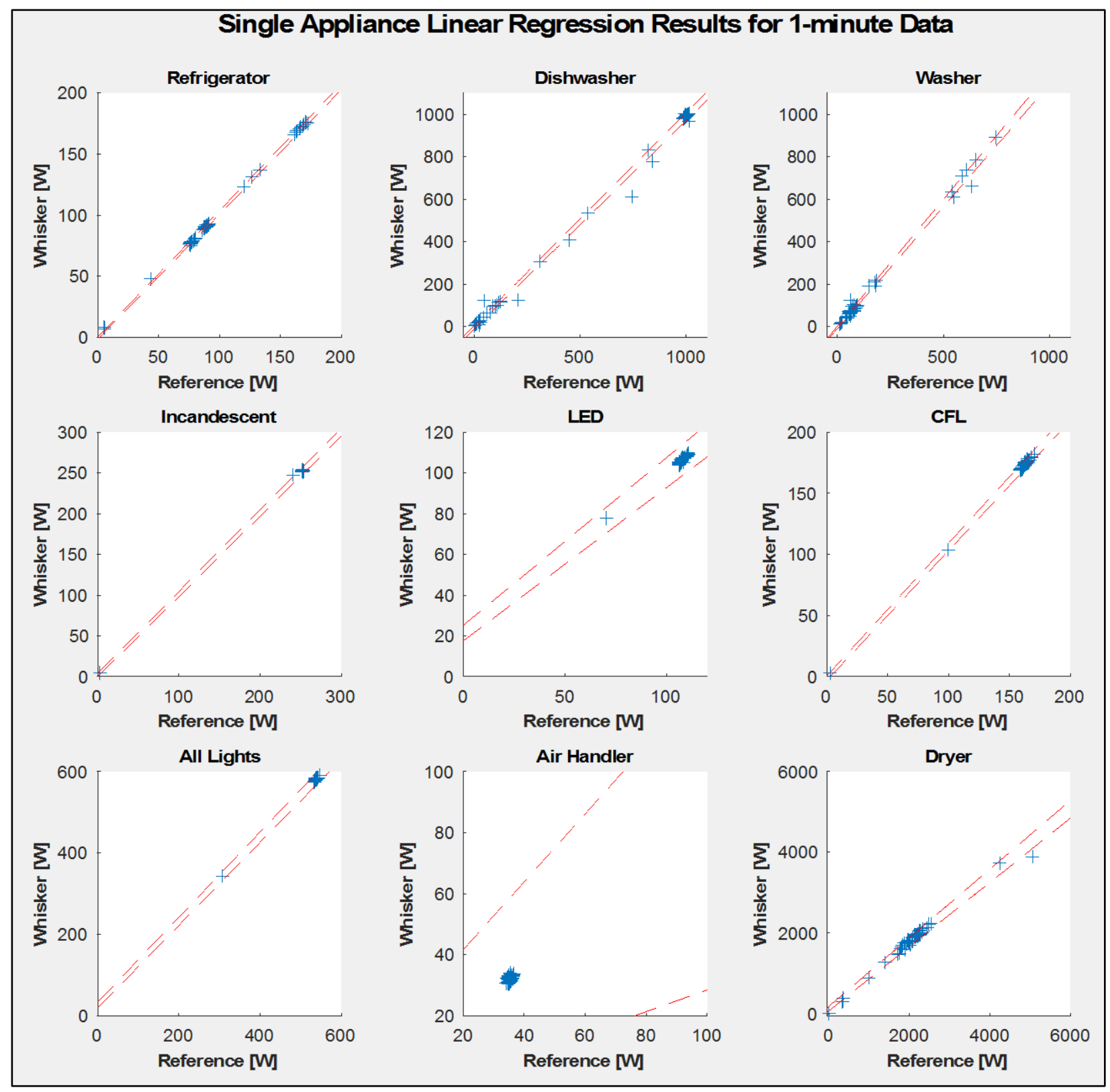

Figure 20. Linear regression $95 \%$ Cls shown for single appliance results using 1-minute interval data

These results indicate that the Whisker meters exhibit a reliably linear response with respect to the reference power measurements. Overall, the Whisker meters exhibited a typical relative accuracy (fractional scaling error) on the order of $\pm 10 \%$, which is consistent with the expected accuracy. The exact scaling error varied by appliance, with some appliances (or meters) showing significantly better than $\pm 10 \%$ accuracy and a few showing errors of up to $\pm 26 \%$. Offset errors were typically insignificant, with the exception of the dryer. Several of the appliances with larger estimated errors had operating characteristics that render their error estimates qualitatively less certain (discussed below). 
Because each Whisker meter was assigned to a single appliance/circuit breaker for the duration of the experiment, we are unable to quantitatively disaggregate the relative error inherent in each meter from any effects particular to the appliance each sensor was measuring. Nevertheless, the following qualitative observations apply:

- The 1-minute results from the air handler tests are so tightly clustered that the corresponding fractional scaling error (and therefore the 95\% CI bounds) are highly uncertain. This result should not be interpreted as a poor accuracy for this appliance but rather as a limitation of the analysis approach given the available data.

- As with the air handler, the different lighting loads remained nearly constant during their trials, which made it more difficult to determine the error metrics. For both the 10 -second and 1-minute interval data sets, the metrics are largely determined by one or two samples that represent load conditions during the transition between different lighting types. Qualitatively, the error metrics estimated for lighting should be considered somewhat less certain as a result.

- The dryer was the largest appliance load, and therefore the estimated offset error was also large relative to the other appliances. However, the offset error for the dryer remained small relative to the magnitude of the load, as can be seen in Figure 19 and Figure 20.

- Both the washer and dryer exhibited rapidly changing load power, often cycling multiple times within a minute. Even after the time series alignment procedure, these rapid changes contributed significant scatter to the 10 -second interval data. The rapid fluctuations may also have contributed to the relative fractional scaling errors estimated for these two appliances.

\subsubsection{Interference Analysis (Multiple-Appliance Trials)}

The single-appliance trials established accuracies for most Whisker meters on the order of $\pm 10 \%$, which was consistent with expectations, though a few meters experienced errors up to $\pm 26 \%$. The multiple-appliance trials were designed to investigate cross-circuit interference. This interference is best characterized by an interference rejection ratio, defined as the ratio of the actual power on a nearby interfering circuit to the observed interference on the measured circuit. The primary objective was to validate the 10:1 interference rejection ratio specified for the second generation of Whisker meters.

Figure 6 illustrates the effects of cross-circuit interference. The top plot in Figure 6 shows the results for the refrigerator from its single-appliance trial, which exhibited excellent agreement between the Whisker meters and reference power meters. The lower plot shows the same refrigerator measurements but with the lights and dishwasher also running. The power draw from the lights creates a constant negative offset on the refrigerator Whisker measurement, which can be seen early in the trial where the dark blue line of the Whisker meter is below the red reference line. When the dishwasher turns on, the Whisker meter is subjected to a large positive offset and begins reading a value significantly higher than the reference meter. Although this is an extreme example of interference because the refrigerator is a relatively small load and the dishwasher is a significantly larger load, it illustrates how interference from nearby circuits can impact measurements on another circuit. The step changes in the Whisker refrigerator measurements when the dishwasher cycles show that the interference rejection ratio for the dishwasher circuit is 
approximately 5:1, while the initial few minutes of data show that the interference rejection ratio for the lights circuit is closer to $12: 1$.

Visual inspection of step changes can provide an approximate measure of interference rejection ratio, but a more comprehensive evaluation requires a numerical model. The analysis presented here assumes that the observed interference on any Whisker-measured circuit is linearly proportional to the power on the interfering circuits. When complete reference data are available, as in the laboratory trials, equation (1) can be extended to include the effects of interference under this hypothesis:

$$
P_{W}=(1+s) P_{R}+b+\sum_{i} k_{i} P_{\text {Intf }, i}
$$

where $P_{\text {Intf }, i}$ represents the power of nearby interfering circuit $i$ and the interference coefficient, $k_{i}$, represents the inverse of the interference rejection ratio for that circuit. For instance, interference coefficient $k=0.1$ indicates an interference rejection ratio of 10:1. (For brevity, the CI terms in equation (2) are not shown.) Equation (2) includes the values for $s$ and $b$ from the single appliance trials and was used to fit linear regression models for the multiple-appliance trials 12-27. For each appliance, the results yielded estimates for the interference rejection ratios (the $k_{i}$ values) with respect to other appliances on nearby circuits.

\subsubsection{Model Quality}

To test the assumption that equation (2) is a valid representation of the behavior of the Whisker meters, the team examined the ability of the fitted models to predict the residual errors in the measured Whisker meter readings (after accounting for the offset and scaling errors estimated from the single-appliance trials) using the reference power measurements:

$$
\text { Residual Error }=P_{W}-\left((1+s) P_{R}+b\right) \approx \sum_{i} k_{i} P_{\text {Intf }, i}
$$

In most cases, the linear interference model of equation (3) explained most of the residual error. This result supports the hypothesis that cross-circuit interference is a linear function of the power consumption of the interfering circuits.

Figure 21 shows a set of parity plots for the estimated interference (from equation (3)) versus the measured residual errors in Whisker meter readings for the six appliances using data collected during trials 12-27. (Because the air handler and condenser were always run together in trials 12-27, we treat them as a single appliance for this analysis.) The ideal response characteristic is that the estimated interference is equal to the measured error, indicated by the dashed red line in the figure. The degree of tightness of the scatter in the samples around the one-to-one line indicates how well the interference model explains the residual variance in the Whisker meter readings.

- For the refrigerator, lights, and air handler + condenser, the interference model explains nearly all the residual variance. 
- For the washer and dishwasher, the interference model explains much of the variance (most data points are clustered along the one-to-one line), but there are also other sources of error that produce significant outliers (some outlier data points found in vertical pattern off the one-to-one line).

- For the dryer, the poorness of the fit indicates that interference is not the dominant source of residual error (most data points are found in vertical pattern off of the one-to-one line). As discussed in Section 0, the dryer experienced many rapid fluctuations in load power that were likely a significant source of measurement error, overshadowing cross-circuit interference as the dominant source of error. 


\section{Measured Residual Error vs. Modeled Interference for 10-second Data}
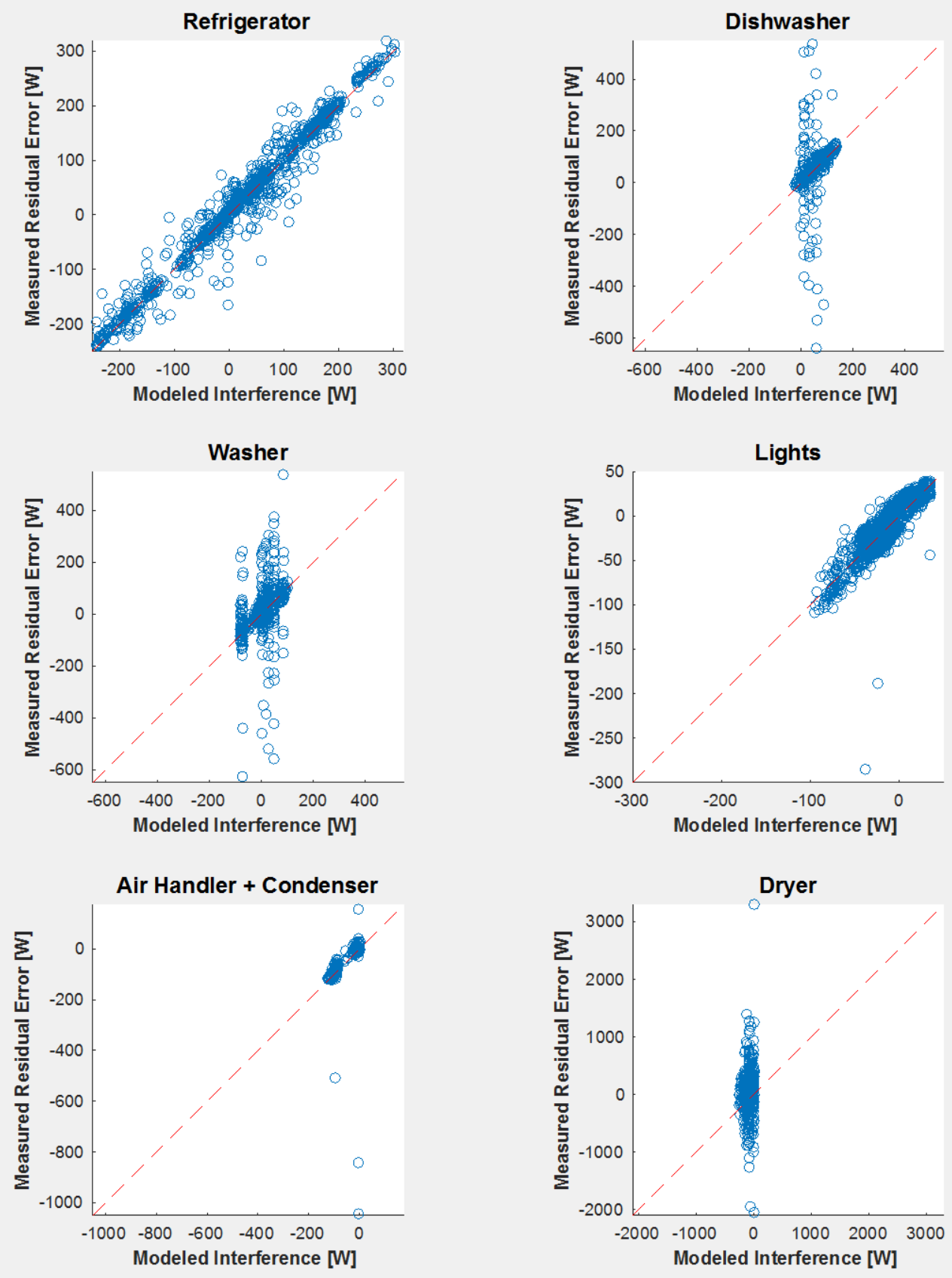

Figure 21. Residual error in Whisker meter readings vs. modeled interference for six appliances using a linear interference model

\subsubsection{Observed Interference}

Figure 22 presents the absolute value of the interference coefficients $k$ for each appliance circuit with respect to the other appliance circuits estimated from the model given in equation (3). The interference rejection ratio is the inverse of the absolute value of the interference coefficient shown in the figure: 


$$
\text { Interference Rejection Ratio }=\frac{1}{|k|}
$$

(The figure presents interference coefficients rather than interference rejection ratios because the latter become very large when interference is small and therefore presents scaling difficulties when plotted.) In the figure, the red horizontal line at $|k|=0.1$ represents a 10:1 interference rejection ratio. The error bars indicate the $95 \% \mathrm{CI}$ range for each estimated interference coefficient.

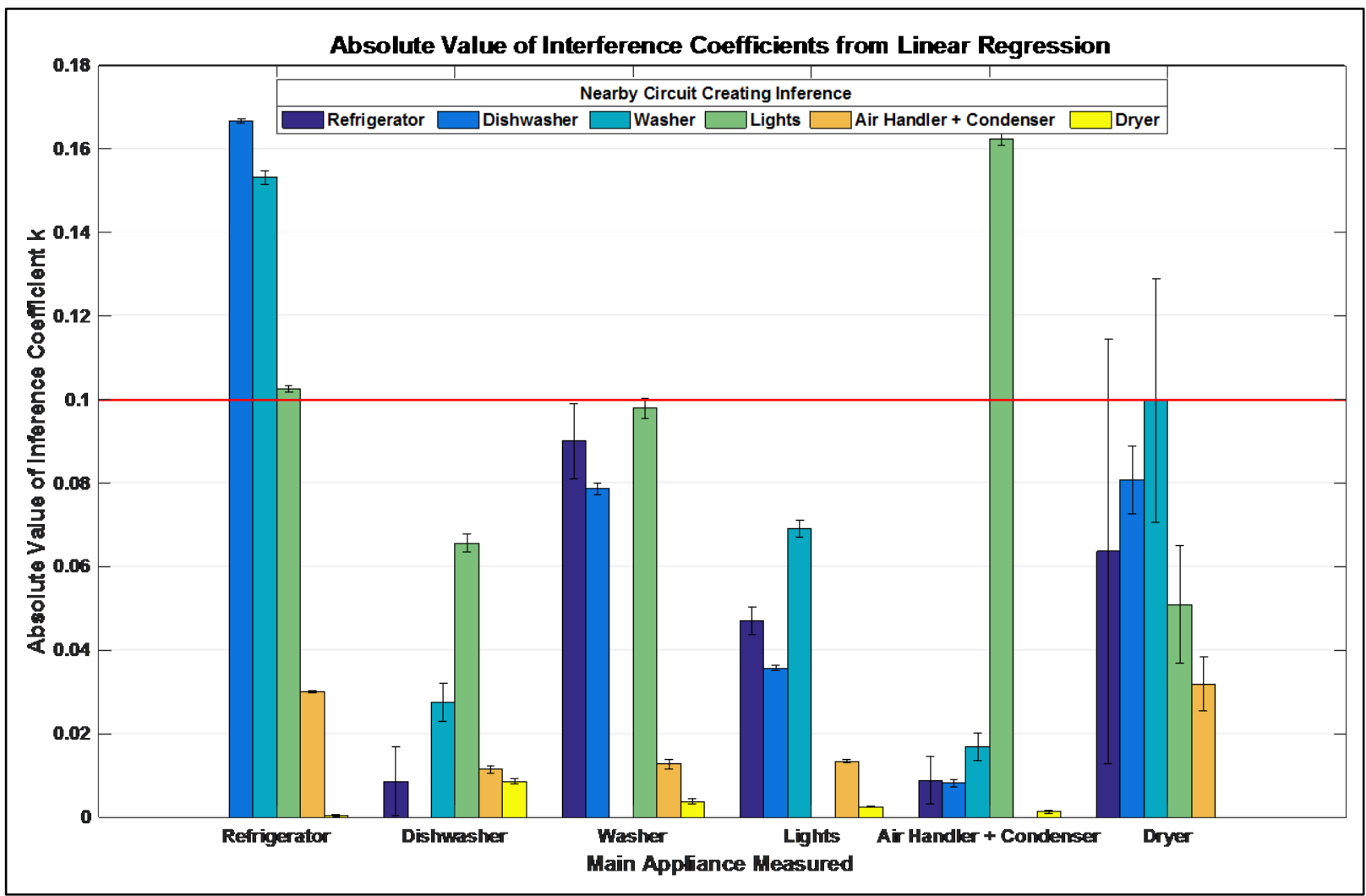

Figure 22. Estimated absolute value of interference coefficients (inverse of interference rejection ratio) for each appliance: smaller is better

Similarly, Table 4 presents the estimated interference coefficients for each appliance as well as the coefficient of determination, or $R^{2}$ value, of the interference model for each appliance. Given the consistently high $R^{2}$ values for most appliances, the team has confidence that the calculated linear interference coefficients correctly capture the nature of cross-channel interference experienced by the Whisker meters, though there are other sources of error that we have not captured with this technique. Because interference was not the dominant source of residual error for the dryer, the $R^{2}$ value was poor and the interference coefficients (and corresponding interference rejection ratios) were highly uncertain. Table 5 presents the corresponding interference rejection ratios. The larger interference ratios indicate smaller levels of interference experienced by the measured circuit. Cases that exceeded the 10:1 threshold are indicated with bold text. 
Table 4. Estimated Interference Coefficients

\begin{tabular}{|l|c|c|c|c|c|c|}
\hline \multirow{2}{*}{$\begin{array}{c}\text { Appliance creating } \\
\text { interference }\end{array}$} & Refrigerator & Dishwasher & Washer & Lights & $\begin{array}{c}\text { Air Handler } \\
+ \\
\text { Condenser }\end{array}$ & Dryer \\
\cline { 2 - 7 } & - & -0.00857 & 0.0901 & -0.0471 & -0.00882 & 0.0637 \\
\hline Refrigerator & 0.167 & - & -0.0786 & 0.0357 & -0.00815 & -0.0808 \\
\hline Dishwasher & 0.153 & -0.0275 & - & -0.0691 & -0.0169 & -0.0997 \\
\hline Washer & -0.102 & 0.0656 & 0.0979 & - & -0.162 & -0.0509 \\
\hline Lights & 0.0300 & 0.0114 & 0.0128 & -0.0134 & - & -0.0319 \\
\hline $\begin{array}{l}\text { Air Handler + } \\
\text { Condenser }\end{array}$ & -0.000448 & -0.00857 & 0.00379 & -0.00253 & 0.00132 & - \\
\hline Dryer & 0.992 & 0.545 & 0.717 & 0.787 & 0.837 & 0.0816 \\
\hline$R^{2}$ Goodness of Fit & & & & & & \\
\hline
\end{tabular}

Table 5. Estimated Interference Rejection Ratios

\begin{tabular}{|l|c|c|c|c|c|c|}
\hline \multirow{2}{*}{$\begin{array}{c}\text { Appliance creating } \\
\text { interference }\end{array}$} & Refrigerator & Dishwasher & Washer & Lights & $\begin{array}{c}\text { Air Handler } \\
+ \\
\text { Condenser }\end{array}$ & Dryer \\
\cline { 2 - 7 } & - & 117 & 11.1 & 21.2 & 113 & 15.7 \\
\hline Refrigerator & 6.00 & - & 12.7 & 28.0 & 123 & 12.4 \\
\hline Dishwasher & 6.53 & 36.3 & - & 14.5 & 59.0 & 10.0 \\
\hline Washer & 9.76 & 15.2 & 10.2 & - & 6.16 & 19.6 \\
\hline Lights & 33.3 & $\mathbf{8 7 . 5}$ & 78.2 & 74.5 & - & 31.3 \\
\hline $\begin{array}{l}\text { Air Handler + } \\
\text { Condenser }\end{array}$ & $\mathbf{2 . 2 3 \times 1 0 ^ { 3 }}$ & $\mathbf{1 1 7}$ & 264 & 396 & $\mathbf{7 5 5}$ & - \\
\hline Dryer & & & & & & \\
\hline
\end{tabular}

An interference coefficient of 0.1 corresponds to an interference rejection ratio of 10:1, which is the Whisker Labs' specification for the second-generation meters. Overall, the estimated interference rejection ratios meet the minimum goal of 10:1 and in many cases, the estimated multiple-appliance interference rejection ratios exceeded this 10:1 threshold. A few did not; the lowest observed interference rejection ratios were approximately $6: 1$. Interference rejection ratios were typically better for circuits that were located physically farther from the measured circuit, while adjacent circuits produced the largest interference.

\subsection{Discussion}

The laboratory tests generally supported the stated performance specifications for the secondgeneration Whisker meters for typical single-circuit accuracy of $\pm 10 \%$ (though only a narrow majority met this condition) and a typical cross-circuit interference rejection ratio of 10:1 or better. Although the Whisker meters are not as accurate as conventional power meters, they are easier and less expensive to deploy. Section 0 below discusses a number of analytics applications that benefit from high-resolution circuit-level power data but do not necessarily require high measurement accuracy in those data. The Whisker meters are well-suited for such applications. 


\section{Field Demonstration}

Following the successful laboratory demonstration, NREL recommended that Wells Fargo perform a field demonstration of the Whisker Labs technology. The purpose of the field demonstration was threefold:

1. Provide Whisker Labs with further experience planning for and applying its technology in a real operational scenario, which may lead to improvements in its technology's application and value proposition.

2. Evaluate the performance of and provide data for the improvement of the Whisker meters in their first deployment on a three-phase power system.

3. Expose the Wells Fargo Corporate Properties Group (CPG) to an emerging energyefficiency and demand management technology that was demonstrated as feasible in a laboratory setting.

The specific objectives of the demonstration as determined collectively by NREL, Whisker Labs, and Wells Fargo CPG were to:

1. Compare Whisker Labs equipment ease of installation and installation cost to conventional measurement and verification $(\mathrm{M} \& \mathrm{~V})$ equipment.

2. Evaluate the Whisker Labs meters power measurement accuracy in the field using conventional power measurement equipment as a reference.

3. Explore use cases for the Whisker meters given the results of the previous two tasks.

This section describes the $\mathrm{M} \& \mathrm{~V}$ methodology, evaluation of the installation process, and accuracy assessment, while Section 0 will describe the use cases for the technology.

Planning for the field demonstration started in early 2016. Representatives from Wells Fargo, CBRE (Wells Fargo's facility management provider in Colorado), NREL, and Whisker Labs visited potential demonstration sites on April 13, 2016, to collect information about the building load types and electrical distribution system and evaluate suitability with respect to a set of demonstration site criteria (Table 6). Collectively, the team selected the Havana Gardens bank branch in Aurora, Colorado, due to its Leadership in Energy and Environmental Design (LEED)level performance goals and potential for further energy-efficiency improvements related to automated building system control, in addition to meeting the criteria given in Table 6 . 
Table 6. Site Selection Criteria Checklist

\begin{tabular}{|c|c|c|c|}
\hline Priority & $\begin{array}{l}\text { NREL and Whisker } \\
\text { Labs Site Criteria }\end{array}$ & Notes & Havana Gardens \\
\hline Required & $15 \mathrm{~A}$ to $125 \mathrm{~A}$ breaker size & - & Yes \\
\hline Required & $\begin{array}{l}\text { Specific models of } \\
\text { breakers for which } \\
\text { Whisker meters are pre- } \\
\text { calibrated }\end{array}$ & - & Yes \\
\hline Required & $\begin{array}{l}\text { Internet connection to the } \\
\text { Whisker Labs hub }\end{array}$ & $\begin{array}{l}\text { Assume isolated cellular } \\
\text { modem network to be } \\
\text { created }\end{array}$ & Yes \\
\hline Highly desirable & $\begin{array}{l}\text { Panels with similar load } \\
\text { types such as a lighting } \\
\text { panel (demonstrate best } \\
\text { case) }\end{array}$ & $\begin{array}{l}\text { Panels with load diversity } \\
\text { as next preference } \\
\text { (evaluate stretch } \\
\text { application) }\end{array}$ & $\begin{array}{l}\text { Panels have load } \\
\text { diversity; not ideal for } \\
\text { product demonstration } \\
\text { but enables evaluation of } \\
\text { various use cases }\end{array}$ \\
\hline Highly desirable & $\begin{array}{l}\text { Local to NREL (Greater } \\
\text { Denver Area) }\end{array}$ & - & Yes \\
\hline If possible & $\begin{array}{l}\text { Single-phase } 120 / 240 \mathrm{~V} \\
\text { (demonstrate best case) }\end{array}$ & $\begin{array}{l}\text { Three-phase } 120 / 208 \mathrm{~V} \\
\text { next preference (evaluate } \\
\text { stretch application) }\end{array}$ & $\begin{array}{l}\text { Three-phase; not ideal } \\
\text { for product } \\
\text { demonstration but no } \\
\text { single-phase facilities } \\
\text { available }\end{array}$ \\
\hline
\end{tabular}

The site installation occurred on the evening of June 22, 2016, and was followed by a two-week commissioning period. Data collection, analysis, and feedback took place during an eight-month period between July 2016 and February 2017. The Whisker Labs and M\&V equipment were decommissioned and removed on February 21, 2017.

\subsection{Methodology}

\subsubsection{Equipment Overview}

The Havana Gardens site electrical distribution consisted of a single panel (L1) in three sections (L1-1, L1-2, and L1-3) located within the electrical room (Figure 23) and fed from a single main disconnect on the exterior of the facility. NREL recommended use of panel L1-3 for the demonstration. This panel serves a variety of loads, including rooftop units (RTUs) that provide building HVAC, interior lighting, electric water heating, plug loads, and the PV system on the roof. 


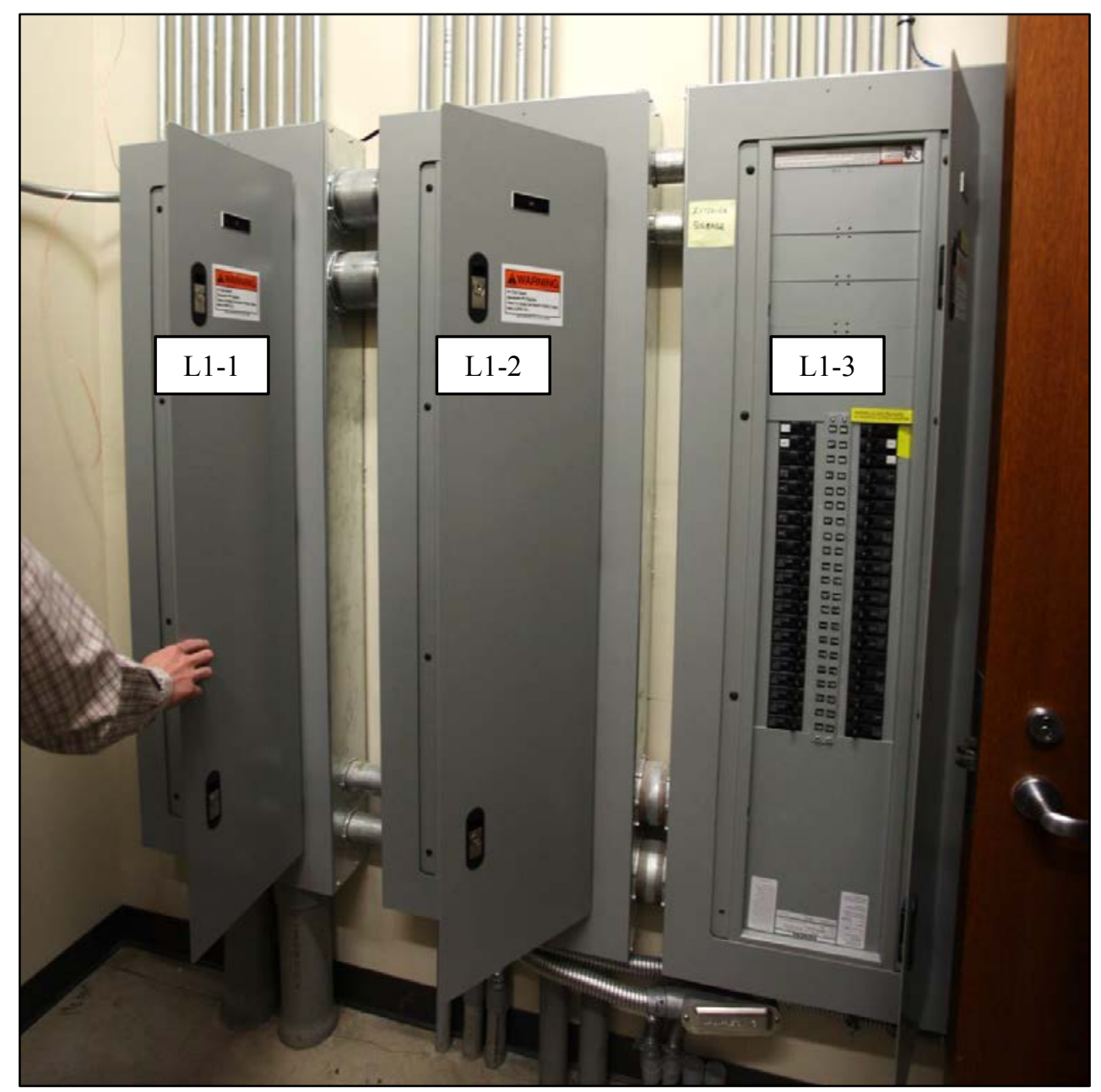

Figure 23. Location of Panel L1-3 within the site electrical room at Havana Gardens

Figure 24 shows the metering equipment used for the demonstration. Two types of meters were included in the metering plan (described later in this section):

1. Whisker Labs equipment: Whisker Labs provided 34 Whisker meters and four Whisker hubs for the demonstration. Each hub can accommodate up to 10 meters.

2. $\quad M \& V$ equipment: Instrumentation for $M \& V$ consisted of three power meters (Continental Controls WattNode Modbus model WNC-3Y-208-MB) and associated CTs (Continental Controls ACT-0750-XXX) connected to a data logger (Campbell Scientific model CR6). The M\&V equipment monitored three three-phase circuits (nine individual circuits). 


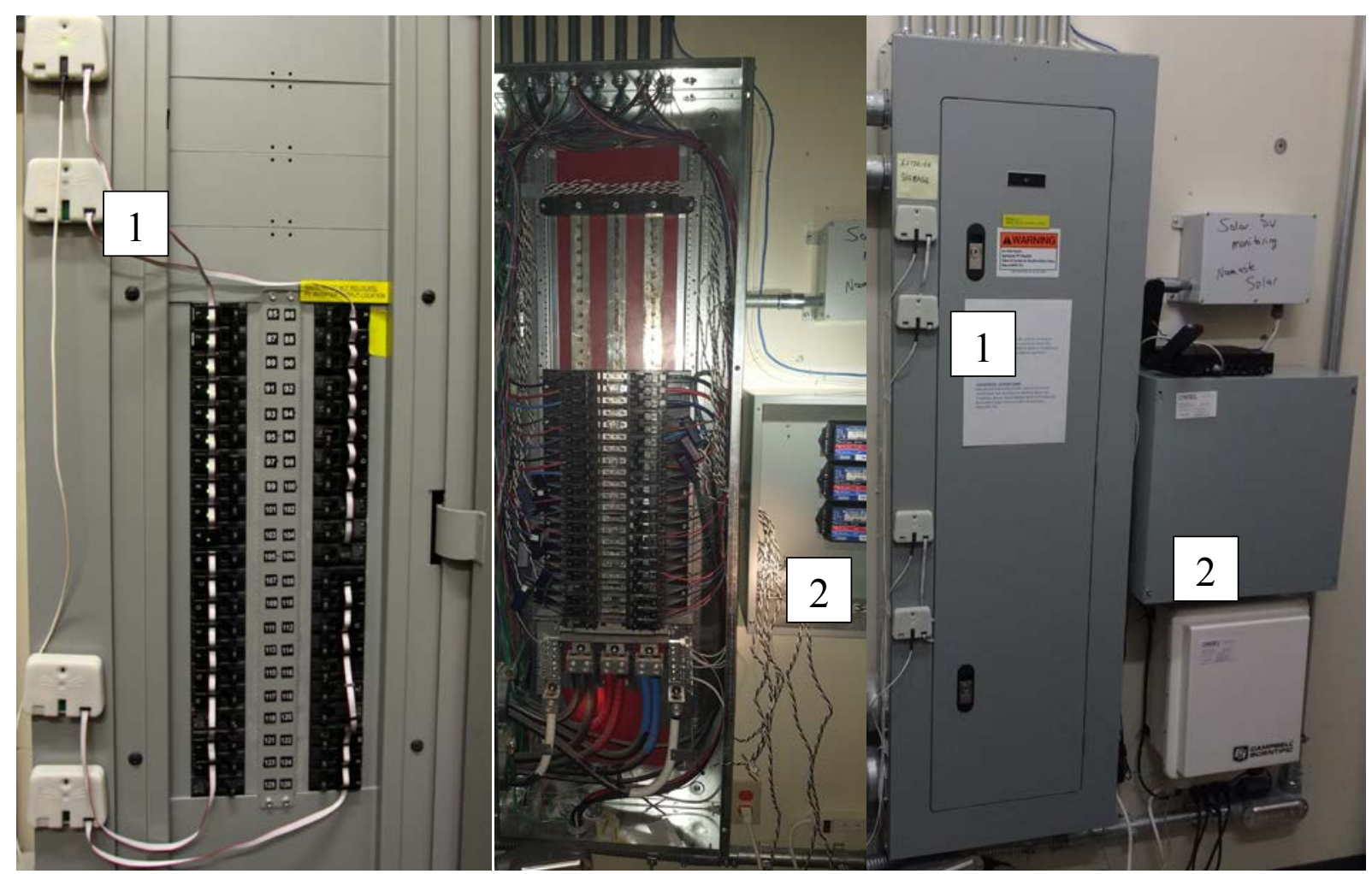

Figure 24. Havana Gardens metering equipment: (1) Whisker and (2) M\&V meters

The team deployed a local Wi-Fi network with Internet connectivity via a cellular modem (Cradlepoint model COR IBR600LPE-VZ) (Figure 25). For security reasons, the M\&V network was completely isolated from the existing building network. The cellular communication link provided remote access for retrieval of both Whisker Labs and M\&V data. 


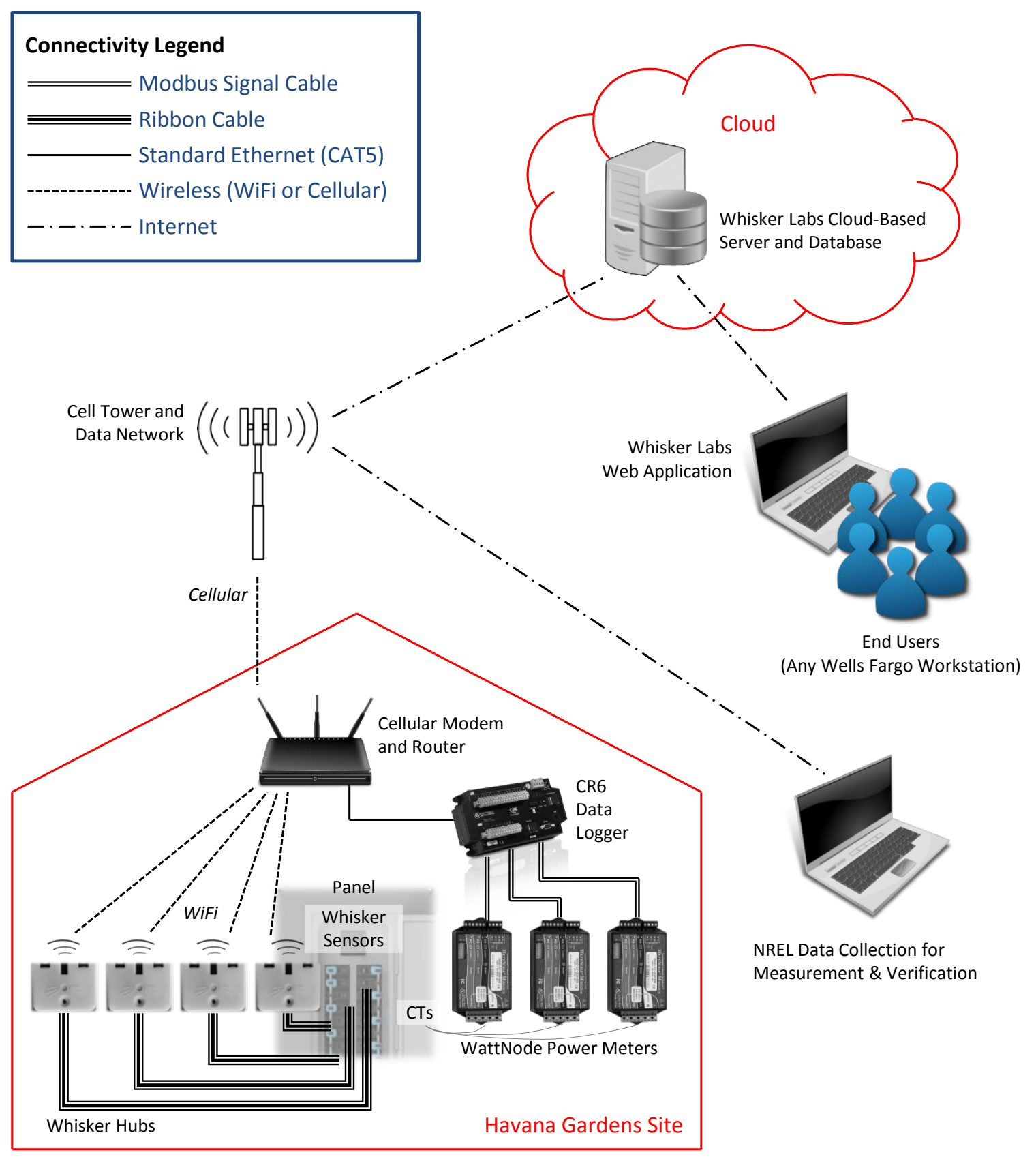

Figure 25. Network diagram for meter installation at the Havana Gardens site

\subsubsection{Installation}

The first objective of the field demonstration was to compare the ease of Whisker Labs equipment installation and installation cost to the conventional power measurement equipment selected for $\mathrm{M} \& \mathrm{~V}$. Therefore, the team monitored and documented the level of effort and cost of installation for both types of equipment.

The installation began with CBRE technicians installing the Whisker meters and hubs per instructions provided by Whisker Labs. As previously described, Whisker meters install with adhesive to the front of the circuit breakers; no access within the electrical panel was required for 
the installation. Therefore, no site electrical shutdown was required for this portion of the installation.

After the Whisker meters were installed, an electrician installed the $\mathrm{M} \& \mathrm{~V}$ equipment (CTs, WattNode power meters, and CR6 data logger) per instructions provided by NREL. The M\&V equipment installation required access to the interior of panel L1-3 for the CTs, a voltage tap, supplemental enclosures, and conduit. This portion of the installation process required a site electrical shutdown.

NREL documented the labor hours, approximate labor cost, and equipment cost for each installation segment. Additionally, surveys were given to the technicians and electricians to gauge their perception of the ease of installation of each submetering system.

As a final step in the demonstration setup, Whisker Labs and NREL installed and tested the cellular Wi-Fi communication network. The costs associated with network setup were not documented because the communication architecture and requirements do not differ between Whisker and conventional power measurement equipment. In addition, communications architecture is often unique to a particular site and may vary based on information technology policies, access to existing network infrastructure, and security considerations.

\subsubsection{Metering Plan}

The Whisker meters were installed on a subset of the 42 circuits in panel L1-3. Figure 26 shows the circuit monitoring plan; monitored circuits included lighting, HVAC, plug loads, and PV generation. The circuits not monitored included those providing power to control systems and small lighting loads since they were determined to have little opportunity for energy efficiency and offered no unique value to an accuracy assessment compared to other circuits on the panel.

A subset of the circuits monitored by Whisker meters were also independently metered with conventional $\mathrm{M} \& \mathrm{~V}$ equipment. The purpose of the $\mathrm{M} \& \mathrm{~V}$ equipment was to assess accuracy of the Whisker meters. Therefore, the $\mathrm{M} \& \mathrm{~V}$ meters were deployed to sample unique load attributes including load type (lighting, HVAC, and miscellaneous electric loads [MELs]), circuit phases, and capacity. In Figure 26, the columns labeled "WattNode" indicate the M\&V meters. 


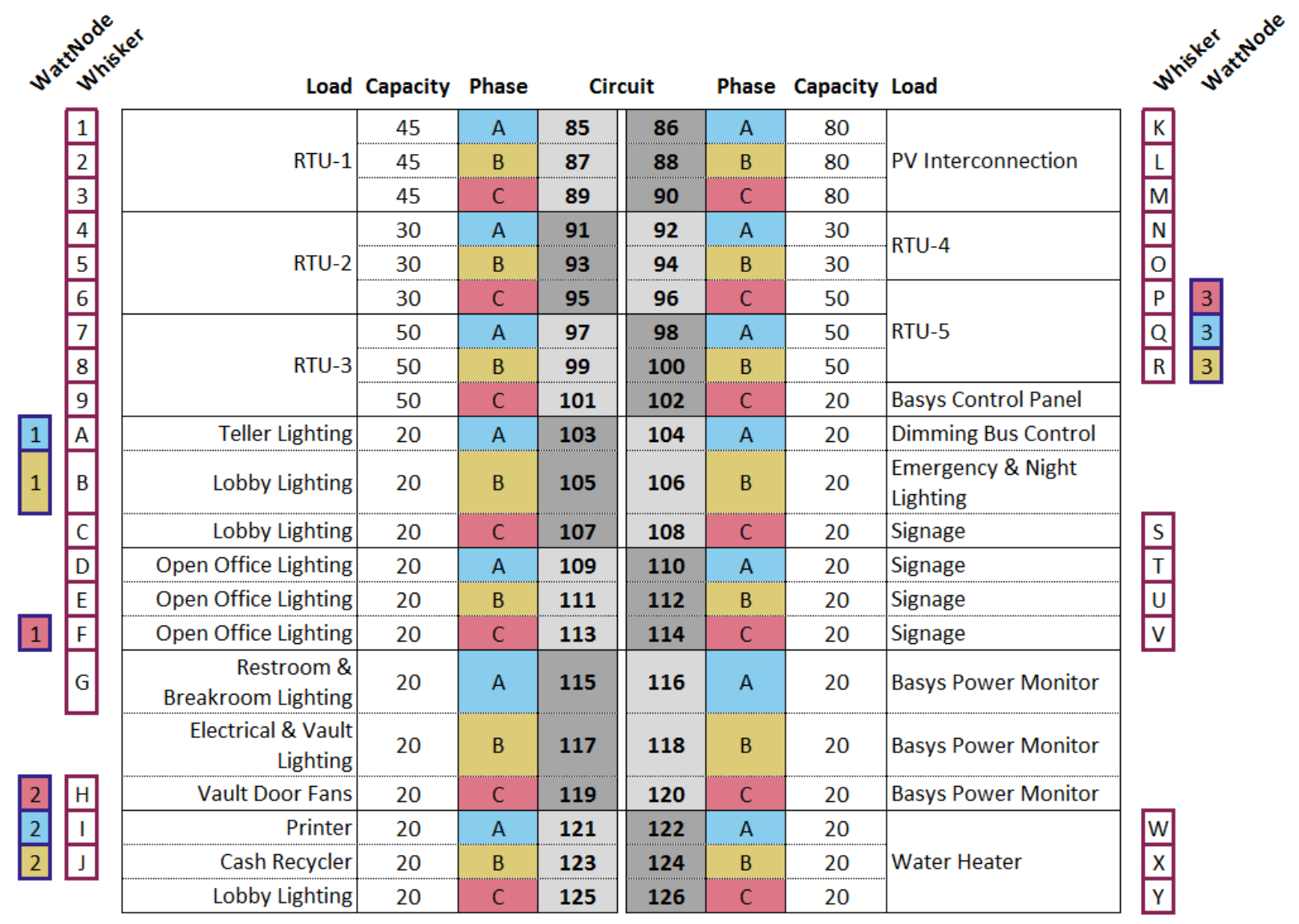

Figure 26. L1-3 Panel schedule and metering plan for the Havana Gardens site

\subsubsection{Data Collection and Analysis}

The data collected from the Whisker and M\&V meters were used to assess the Whisker power measurement accuracy and to identify energy and cost savings opportunities at the Havana Gardens site. To streamline the aggregation and alignment of data for both purposes, the team used the SkySpark analytics platform developed by SkyFoundry Inc. SkySpark is an analytics and rule-based fault detection platform for commercial buildings. Because SkySpark offers a wide variety of data intake options, including customized data intake over the Internet for third party applications (such as the Whisker API), the team selected SkySpark for time series data collection, aggregation, storage, and visualization. The team then exported time-aligned data from SkySpark for additional accuracy analysis in MATLAB.

The team also used SkySpark as part of the case study to determine how the Whisker power measurements may be leveraged within a state-of-the-art rule-based fault detection and diagnostic (FDD) system. The energy and cost savings opportunity assessment was performed directly within SkySpark. Visual inspection of the data using the SkySpark web graphical user interface (GUI) was a primary means of assessing opportunity for cost savings during the course of the demonstration. In addition, the team developed example rules to demonstrate the ability of SkySpark and similar analytics tools to use Whisker Labs data to detect lighting system faults (flagging instances where light power was outside of a predetermined expected range) and 
triggering alerts or notifications ("sparks" in SkySpark terminology) when system performance was not as expected.

\subsection{Results}

\subsubsection{Installation Process}

The installation of both the Whisker and $M \& V$ equipment was successful. A comparison of the two segments of the installation can be seen in Figure 27. The CBRE technicians were able to install the Whisker meters on the outside of the breaker using the Whisker Labs-provided stencil that determined optimal placement. Following a site electrical shutdown, the electrician and NREL support staff installed the CTs, voltage tap, cabling, and M\&V metering hardware.
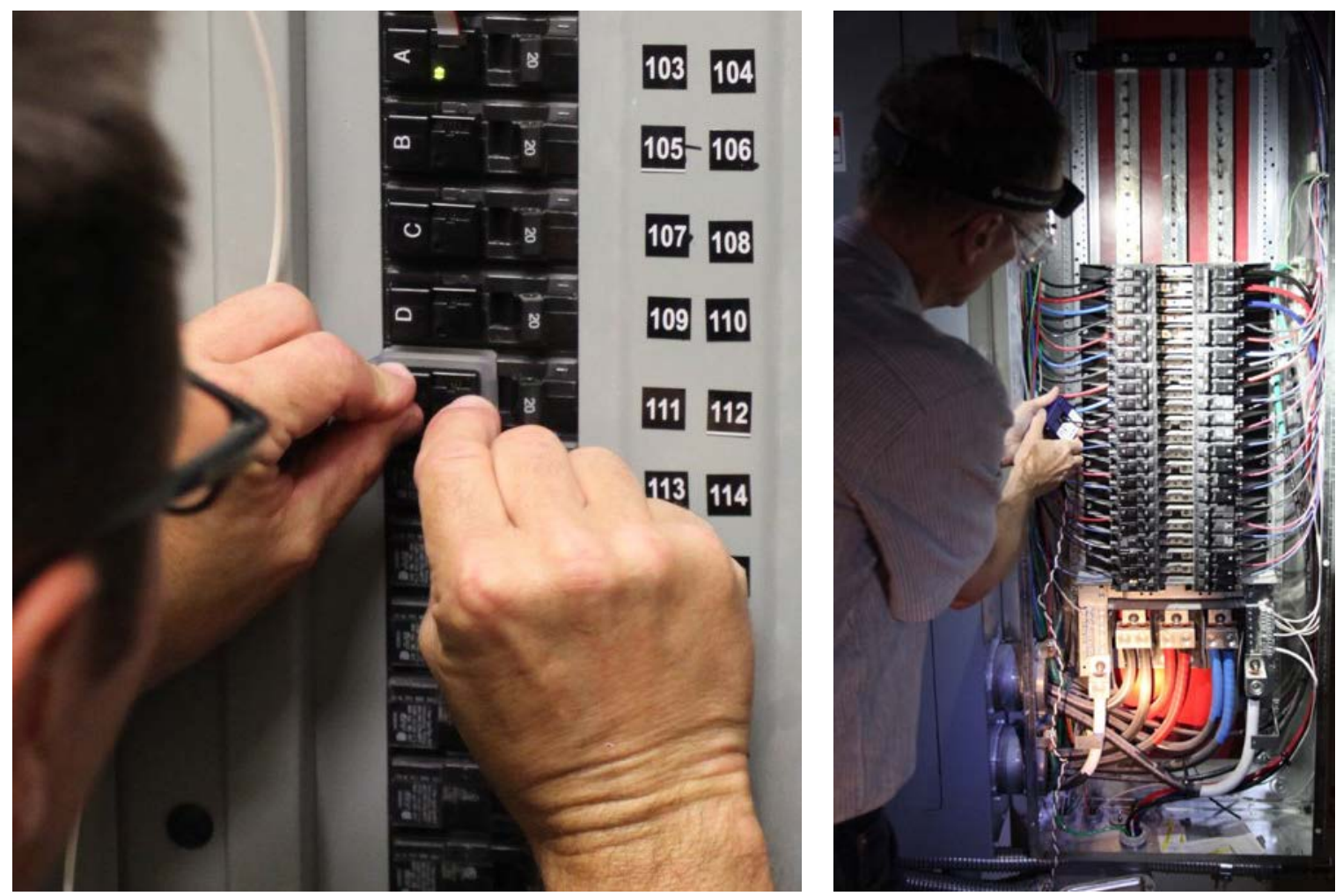

Figure 27. Wells Fargo/CBRE technician installing a Whisker meter (left) and NREL technical support staff installing a CT (right)

The installation of the Whisker meters was quick and straightforward. The NREL team received only positive comments in-person and from the surveys provided to installation participants. The two installing technicians noted in survey responses that the Whisker meters were easier to install compared to other metering technologies and that the instructions were clear and intuitive. One technician wrote "Having the ability to leave lighting on and no major tools needed made this a very easy installation."

The electrician feedback regarding the ease of the CT installation was also positive, noting that the installation "went smooth" but also noting that "the next one would be even easier." Impact to the site (use of ATM and presence of custodial staff) delayed the start of the electrical shutdown and some electrician time was required to adjust the NREL metering plan once the actual wiring architecture and space availability could be seen. While some of these items can be 
planned for to reduce the time required for conventional $\mathrm{M} \& \mathrm{~V}$ equipment, it is impossible to completely eliminate unknowns at new sites. (For instance, the team encountered similar hurdles during M\&V equipment decommissioning and removal.)

Table 7 provides a comparison of the installation costs for the two technologies. Assuming a hardware cost of $\$ 100$ per metered circuit, the total Whisker Labs installation cost was onefourth of the installation cost of the conventional $\mathrm{M} \& \mathrm{~V}$ equipment.

Table 7. Whisker and M\&V Equipment Installation Cost Comparison

\begin{tabular}{|l|c|c|}
\hline & $\begin{array}{c}\text { Whisker Labs } \\
\text { (meters, } \\
\text { hubs) }\end{array}$ & $\begin{array}{c}\text { Conventional M\&V } \\
\text { (CTs, meters, } \\
\text { logger) }\end{array}$ \\
\hline Equipment cost & $\$ 900^{1}$ & $\$ 3,394$ \\
\hline Labor-hours for installation & 0.75 hours & 3.5 hours \\
\hline Labor cost for installation & $\$ 100 /$ hour & $\$ 150 /$ hour \\
\hline Total cost of installation & $\$ 975$ & $\$ 3,920$ \\
\hline
\end{tabular}

${ }^{1}$ Assuming \$100/meter point based on Whisker Labs stated rolled-up cost of meters and hubs; normalized for nine points for comparison to the $\mathrm{M} \& \mathrm{~V}$ meter count (installation time remains conservative for all 34 meters).

The Wells/CBRE technicians offered suggestions for minor improvements to the Whisker meter installation process. One example written in a survey response was that "Pull tabs would be nice on the meters." This comment was in reference to the ability to easily remove and reposition the meters on misapplication. This happened for one meter during the 34-meter installation.

\subsubsection{Accuracy Assessment}

The Havana Gardens field test was the first installation of the Whisker Labs technology on a three-phase power system. In addition to further validating the accuracy and interference results observed in the laboratory, the demonstration provided Whisker Labs with data it can leverage to improve its technology for future use with three-phase power systems.

The team performed an accuracy analysis similar to the laboratory assessment using field data from Havana Gardens obtained during the month of September 2016. Per Figure 26, the team gathered reference power measurements for the cash register and printer circuits, one each of the lobby, teller, and office lighting circuits, one rooftop unit (RTU), and the vault door fans. However, the reference measurement for the vault door fans remained $0 \mathrm{~W}$ for the duration of the test.

Unlike the laboratory experiments, the team had no control over when each load was turned on or off during the field test; consequently, all of the collected data are analogous to the multipleappliance trials from the laboratory test that include interference. In addition, not all circuits were monitored by the $\mathrm{M} \& \mathrm{~V}$ equipment so it is impossible to completely characterize all sources of interference. In a commercial building environment, there are nearly always some appliances running. These were known limitations of the $\mathrm{M} \& \mathrm{~V}$ design, but it was impractical to install M\&V meters for all 42 circuits in the electrical panel. The team determined that the best approach was a real-world accuracy assessment in the presence of naturally occurring interference from nearby circuits. 
One additional challenge, encountered later during the analysis of the datasets, was that the reference measurements made by the Continental Control Systems' WattNodes were limited by a resolution limitation inherent in the fact that WattNodes measure accumulated energy. The power is calculated every 5 seconds by taking the difference in the energy register between the last scan and the current scan. The energy register has a default resolution of $0.0001 \mathrm{kWh}$, and for 10 -second interval data the corresponding power resolution is $36 \mathrm{~W}^{2}$ While the resolution for energy measurements using WattNodes is quite good, differentiating with respect to time degrades the power resolution for short time periods.

Figure 28, Figure 29, and Figure 30 are parity plots for each of the 6 datasets that had non-zero reference power. ${ }^{3}$ The three figures represent the same loads over the same period of time, but with data sampling intervals of 10 seconds (native resolution), 1 minute, and 15 minutes, respectively. The 1-minute and 15-minute data were obtained by averaging the 10 -second data. In each plot the blue "+" marks indicate power measurements for periods that the title load was on. The results of the linear regression are tabulated in Table 8 and Table 9. Averaging over longer time intervals has a more noticeable impact on the absolute offset (or intercept) than the fractional scaling error (or slope), which does not change appreciably.

Besides naturally occurring sensor noise, the scatter in the parity plots is attributable to two main sources:

1. Misaligned transitions due to clock drift: both the Whisker and reference measurements sampled 10 second average power, aligned to internal clocks synchronized from the Internet. ${ }^{4}$ However, internal clock drift can cause the 10 second averaging windows to diverge over time. During large, rapid transitions in power level, misaligned windows produce large differences in sampled power for a single sample (for example, see the RTU plot).

2. Interference from adjacent circuits: as in the laboratory tests, adjacent loads induce electromagnetic interference that affects the reading of each Whisker meter.

Error from misaligned transitions is not an error inherent to the Whisker Labs technology, but rather an artifact of clock synchronization. This error largely disappears when the data are averaged over long periods of time, as illustrated by the 1-minute and 15-minute plots. In a practical application, it is unlikely that precise clock synchronization with external data would be a critical requirement.

Scatter from interference also disappears with time averaging. However, if the underlying interference effects are not randomly distributed around zero, then they can still cause persistent bias errors in the time-averaged measurements even if the scatter has disappeared.

\footnotetext{
${ }^{2}$ In further investigation following the data collection period, the team determined that register resolution could be improved to include 7 significant digits instead of 4 , which would yield a $0.036 \mathrm{~W}$ resolution. Future tests will use this alternative configuration.

${ }^{3}$ The RTU measurement is the summation of three individual Whisker meters - one for each phase.

${ }^{4}$ In the laboratory tests, it was possible to align the reference data within 1 second of the Whisker data, but in the field test, alignment was to the nearest 10 seconds because neither system was sampled at a rate greater than once every 10 seconds.
} 


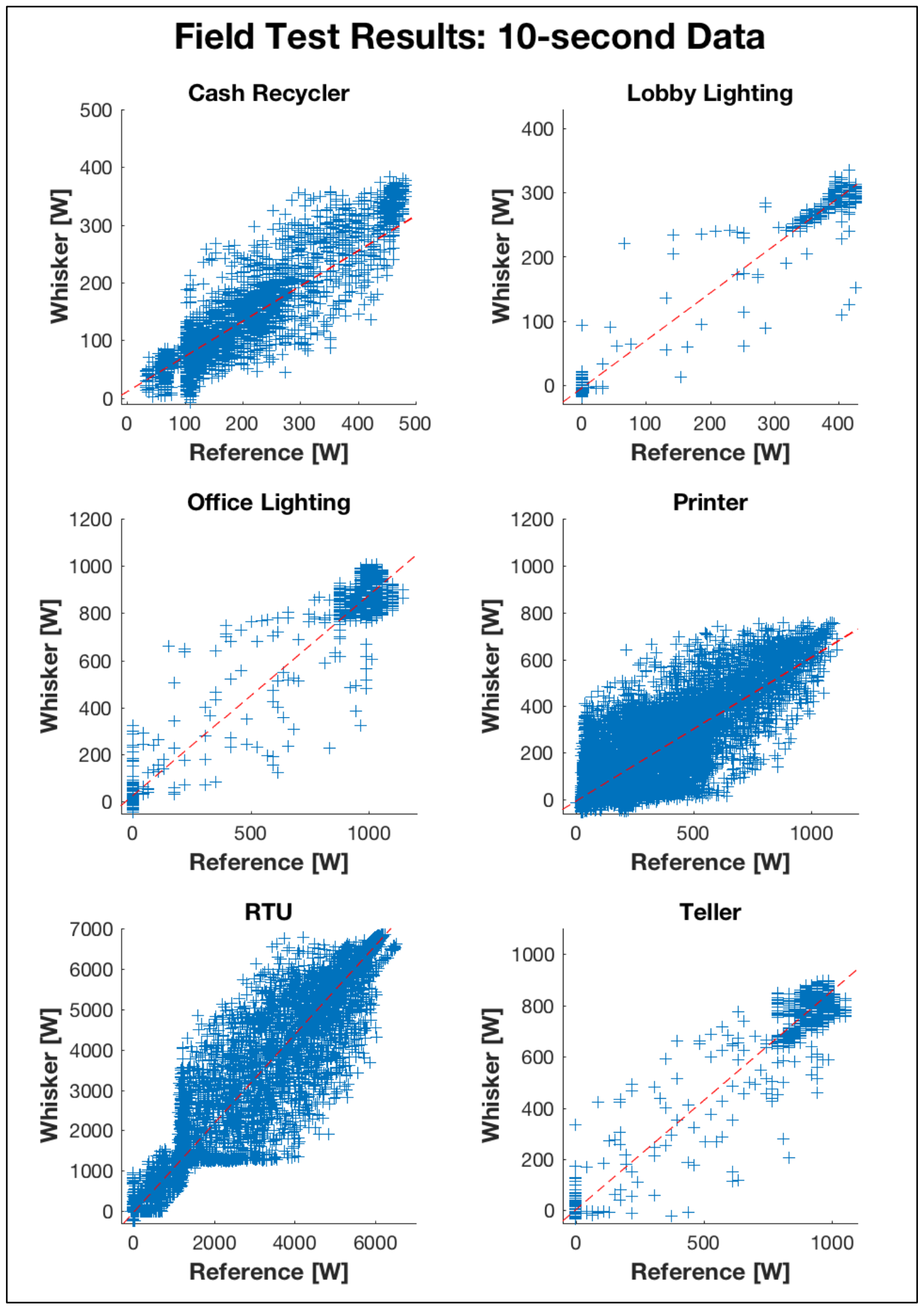

Figure 28. 10-second field test data. Observed scatter is largely an artifact of clock misalignment. 


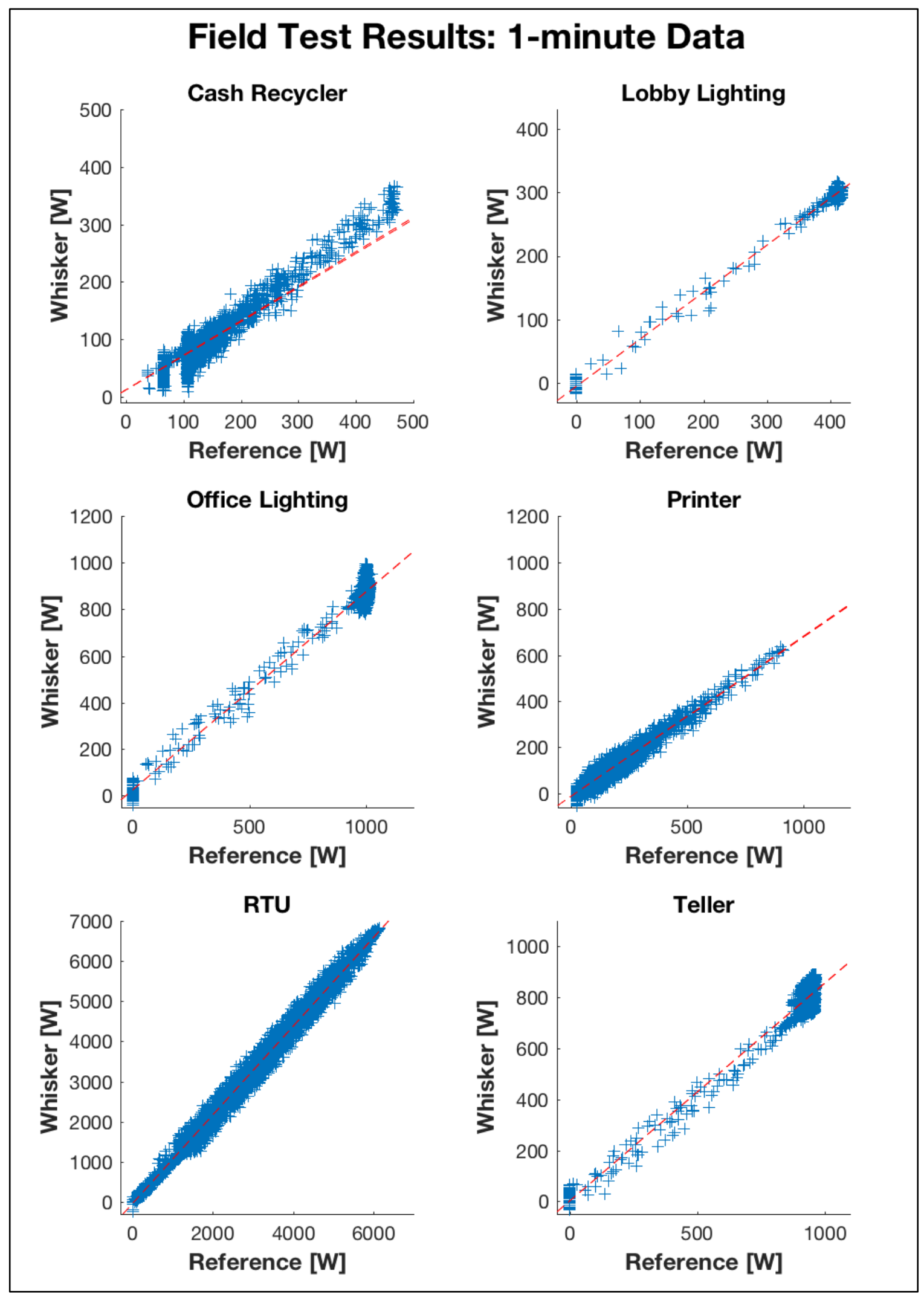

Figure 29. 1-minute field test data 


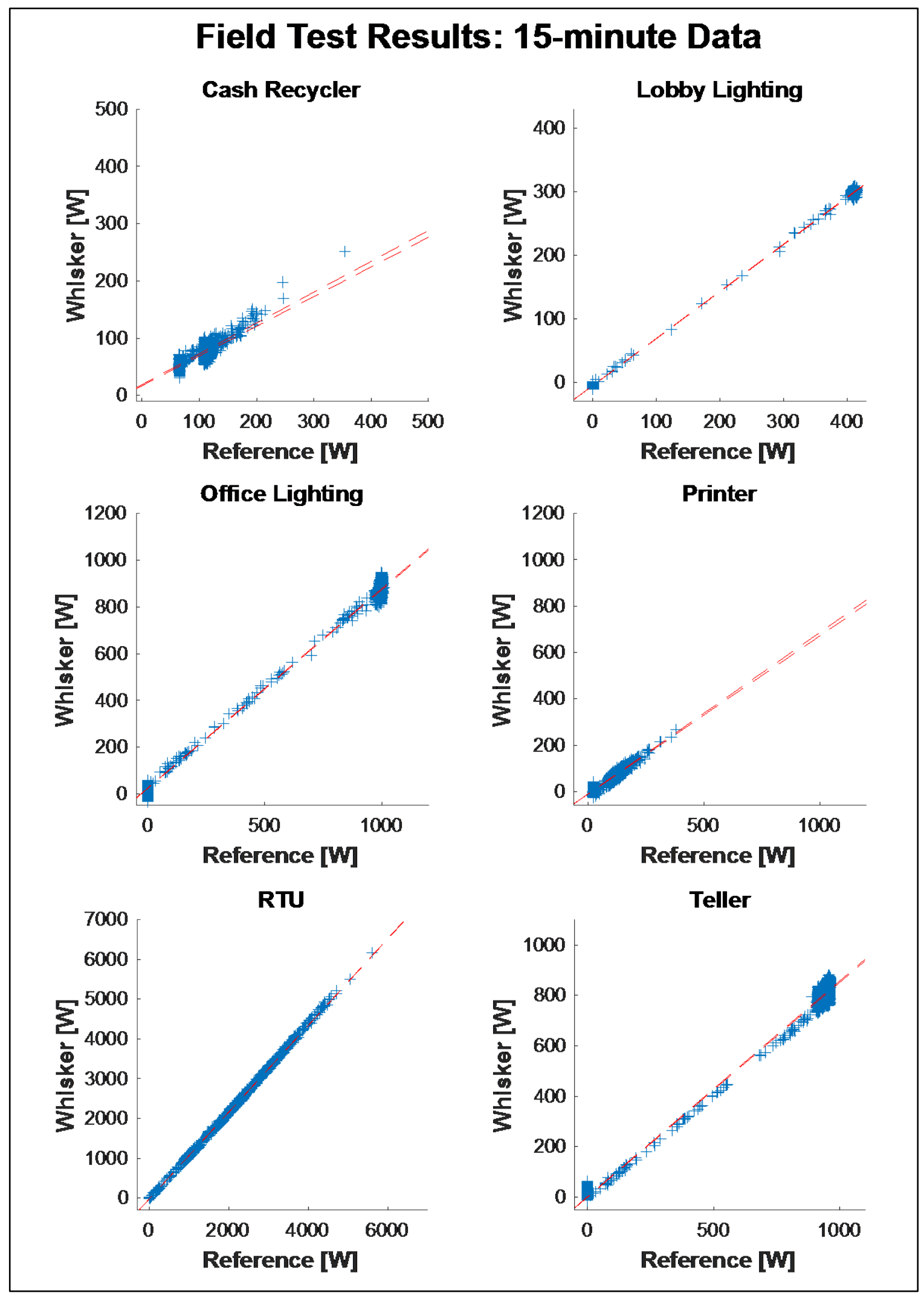

Figure 30.15-minute field test data 
As in the laboratory results, interference (or misalignment errors) may dominate to the point that it is difficult to estimate the error of any single measurement, but the overall effect of interference for a particular circuit is to some degree predictable, such that averaging over multiple samples will provide consistent results. In addition, if similar tests are repeated, we expect similar results for the overall offset and scaling error for each circuit.

The results show significant scaling errors but insignificant bias errors, with qualitatively larger scaling errors for the smaller loads. The observed scaling errors may be a result of interference, deployment in a three-phase power system (instead of single-phase), or both. Errors due to the latter are likely to improve in future generations of Whisker Labs' technology designed specifically for three-phase power systems. Despite the scaling errors, the Whisker meters correctly captured the short-term fluctuations and general trends for all monitored loads, which is sufficient for a variety of analytics applications.

Table 8. Field Test Results: Absolute Offset Summary

\begin{tabular}{|c|c|c|c|c|c|c|}
\hline \multirow[t]{2}{*}{ Appliance } & \multicolumn{3}{|c|}{$\begin{array}{c}\text { Absolute Offset } \\
{\left[\begin{array}{c}\text { W] } \\
\text { b }\end{array}\right.}\end{array}$} & \multicolumn{3}{|c|}{$\begin{array}{c}\text { Absolute Offset } \\
\text { 95\% CI Margin of Error } \\
{[\mathrm{W}]} \\
\sigma_{\mathrm{b} 95}\end{array}$} \\
\hline & $10 \mathrm{sec}$ & $1 \mathrm{~min}$ & $15 \mathrm{~min}$ & $10 \mathrm{sec}$ & $1 \mathrm{~min}$ & $15 \mathrm{~min}$ \\
\hline Cash Recycler & 11.0 & 12.1 & 18.0 & 0.123 & 0.281 & 0.904 \\
\hline $\begin{array}{l}\text { Lobby } \\
\text { Lighting }\end{array}$ & -5.09 & -5.15 & -5.15 & 0.044 & 0.0771 & 0.215 \\
\hline Office Lighting & 25.1 & 24.8 & 24.7 & 0.141 & 0.298 & 1.00 \\
\hline Printer & -6.08 & -11.1 & -11.2 & 0.170 & 0.168 & 0.582 \\
\hline RTU & -39.4 & -40.9 & -29.6 & 0.601 & 0.735 & 1.36 \\
\hline Teller & 1.51 & 1.29 & 1.04 & 0.138 & 0.312 & 1.15 \\
\hline
\end{tabular}

Table 9. Field Test Results: Fractional Scaling Error Summary

\begin{tabular}{|c|c|c|c|c|c|c|}
\hline \multirow[t]{2}{*}{ Appliance } & \multicolumn{3}{|c|}{$\begin{array}{l}\text { Fractional } \\
\text { Scaling Error } \\
\mathbf{s}\end{array}$} & \multicolumn{3}{|c|}{$\begin{array}{l}\text { Fractional Scaling Error } \\
95 \% \mathrm{CI} \text { Margin of Error } \\
\sigma_{\mathrm{m} 95}\end{array}$} \\
\hline & $10 \mathrm{sec}$ & $1 \min$ & $15 \min$ & $10 \mathrm{sec}$ & $1 \mathrm{~min}$ & $15 \mathrm{~min}$ \\
\hline Cash Recycler & -0.390 & -0.403 & -0.471 & 0.00131 & 0.00304 & 0.00995 \\
\hline $\begin{array}{l}\text { Lobby } \\
\text { Lighting }\end{array}$ & -0.260 & -0.259 & -0.259 & 0.000170 & 0.000301 & 0.000843 \\
\hline Office Lighting & -0.150 & -0.149 & -0.149 & 0.000212 & 0.000451 & 0.00152 \\
\hline Printer & -0.387 & -0.311 & -0.310 & 0.00138 & 0.00175 & 0.00680 \\
\hline RTU & 0.102 & 0.103 & 0.092 & 0.000315 & 0.000394 & 0.000877 \\
\hline Teller & -0.147 & -0.146 & -0.146 & 0.000219 & 0.000498 & 0.00184 \\
\hline
\end{tabular}

\subsubsection{Interference Corrections}

The Whisker meters are susceptible to cross-circuit interference from adjacent breakers and in the field demonstration, the maximum observed interference on adjacent circuits was approximately $10 \%$ of the power measured on the interfering circuit, and in many cases significantly lower. In other words, the interference rejection of the Whisker meters was at least 10:1 and up to 100:1, as illustrated in Figure 31. 


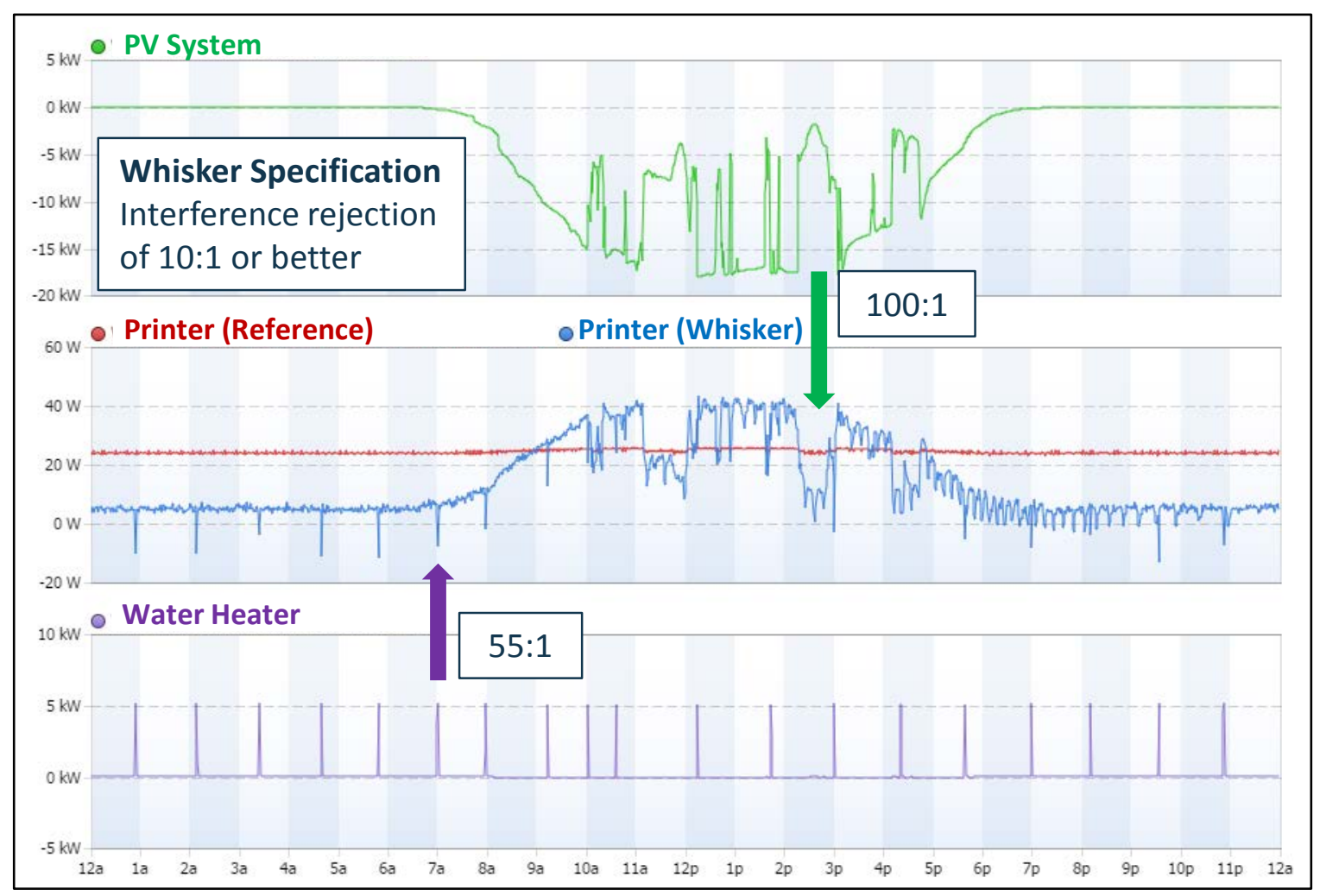

Figure 31. Observed cross-circuit interference rejection in Whisker Labs field demonstration

Despite strong interference rejection, cross-circuit interference can still present accuracy challenges when there are large differences in power magnitude between the measured circuit and the interfering circuit. This is the case in Figure 31, where the $20 \mathrm{~W}$ printer power measurement is affected by the $20 \mathrm{~kW}$ PV system. Even with a 100:1 interference rejection ratio, the interference signal from the PV system remains larger than the actual power consumed by the printer. Fortunately, post-processing techniques that incorporate data from multiple meters can enhance the interference rejection already achieved by the individual Whisker meters. Such techniques can improve the usability of the Whisker meter data when adjacent circuits have large differences in power magnitude.

The NREL team developed and tested one such post-processing interference correction technique using the Havana Gardens field data. The proposed technique requires only Whisker meter data. Under the assumption that cross-circuit interference is linear and neglecting meter bias, it is possible to represent the vector of observed Whisker measurements (known) as a linear function of the true power measurements (unknown) using a linear system of equations:

$$
w=M \cdot p
$$

where $w$ is the vector of reported Whisker measurements, $p$ is the vector of true circuit power measurements, and $M$ is a transformation matrix that captures both scaling coefficients and crosscircuit interference coefficients. (In this particular analysis, offset errors are neglected.) Expanding equation (4), we obtain: 


$$
\left(\begin{array}{c}
w_{1} \\
w_{2} \\
\vdots \\
w_{n}
\end{array}\right)=\left(\begin{array}{cccc}
M_{11} & M_{12} & \cdots & M_{1 n} \\
M_{21} & M_{22} & \cdots & M_{2 n} \\
\vdots & \vdots & \ddots & \vdots \\
M_{n 1} & M_{n 2} & \cdots & M_{n n}
\end{array}\right)\left(\begin{array}{c}
p_{1} \\
p_{2} \\
\vdots \\
p_{n}
\end{array}\right)
$$

Diagonal elements $M_{11}$ to $M_{n n}$ represent the scaling coefficient for each primary Whisker meter measurement and should be approximately 1.0. The off-diagonal elements of $M$ represent crosscircuit interference and will be much smaller (with a maximum of approximately 0.1 ). ${ }^{5}$ If the elements of $M$ are known or can be estimated, it is possible to determine the true power measurements by solving system of equations (4):

$$
p=M^{-1} \cdot w
$$

If reference data were available (that is, independent power measurements to establish ground truth), it would be straightforward to fit the $M$ matrix using linear least squares. However, for practical meter deployments, reference data will not be available and it is possible to estimate the elements of $M$ using only the Whisker meter data. Diagonal elements are assumed equal to 1.0 (no scaling error). The off-diagonal elements are unknown, but their general order of magnitude is known to be between -0.1 and 0.1 . Using the Whisker meter data, the off-diagonal elements can be estimated from observed step changes in the loads:

1. For all Whisker channels $w$, take the derivative. (This removes steady-state measurement interference.)

2. To screen out random noise, filter for samples containing large step changes (samples where the derivative is large).

3. For each identified sample, determine index $i$ of the measurement with the largest magnitude step change $\Delta w_{i}$. This identifies which circuit experienced the true step change in power level $\left(\Delta w_{i} \approx \Delta p_{i}\right)$.

4. For each sample, estimate the off-diagonal coefficients for all meters $j \neq i$ according to:

$$
M_{j i} \approx \frac{\Delta w_{j}}{\Delta w_{i}}
$$

5. When multiple off-diagonal coefficients are available from (7), combine by averaging or using a least-square fit to the linear system: $M_{j i} \cdot \Delta w_{i} \approx \Delta w_{j}$.

This process is illustrated in Figure 32. As estimates for the off-diagonal coefficients are generated over time, the estimate of the entire matrix can be refined and linear system (6) solved to improve estimates of $p$.

\footnotetext{
${ }^{5}$ Because the off-diagonal elements of $M$ are much smaller in magnitude than the diagonal elements, $M$ closely resembles the identity matrix. Therefore, the rows of $M$ are highly likely to be linearly independent, from which it follows that $M$ is highly likely to be nonsingular and hence invertible.
} 


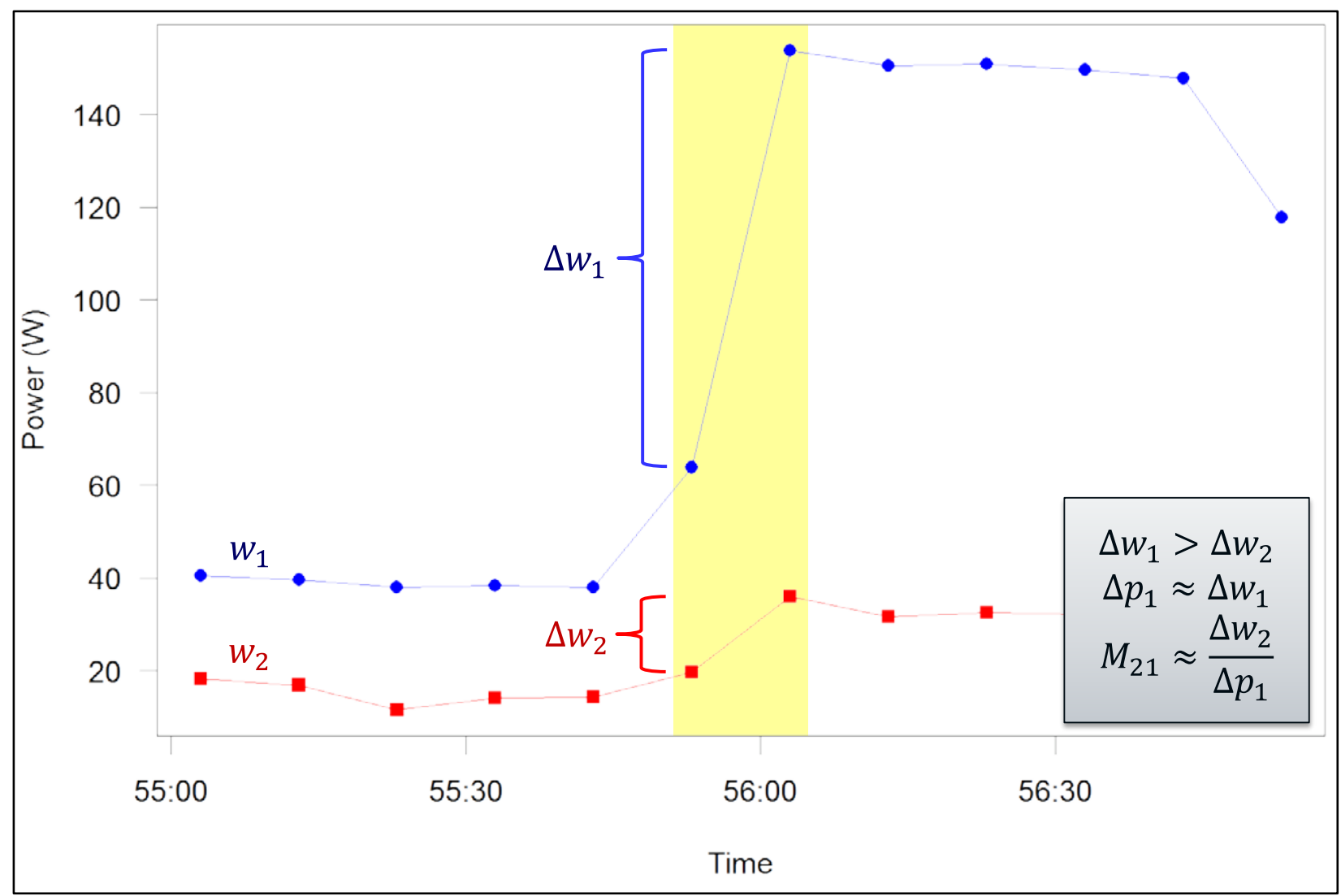

Figure 32. Estimation of cross-circuit interference coefficients from observed step changes

The team applied this interference correction to the Havana Gardens 10-second interval data, aggregated the results for the 1-minute and 15-minute intervals, and repeated the regression analysis. The team used data from August 2016 to estimate the interference correction coefficients and subsequently applied the corrections to the September 2016 data set. Because the 1-minute sample interval smoothed out much of the scatter in the data observed at the 10second interval, the analysis here uses the 1-minute results to illustrate the effect of the correction. 


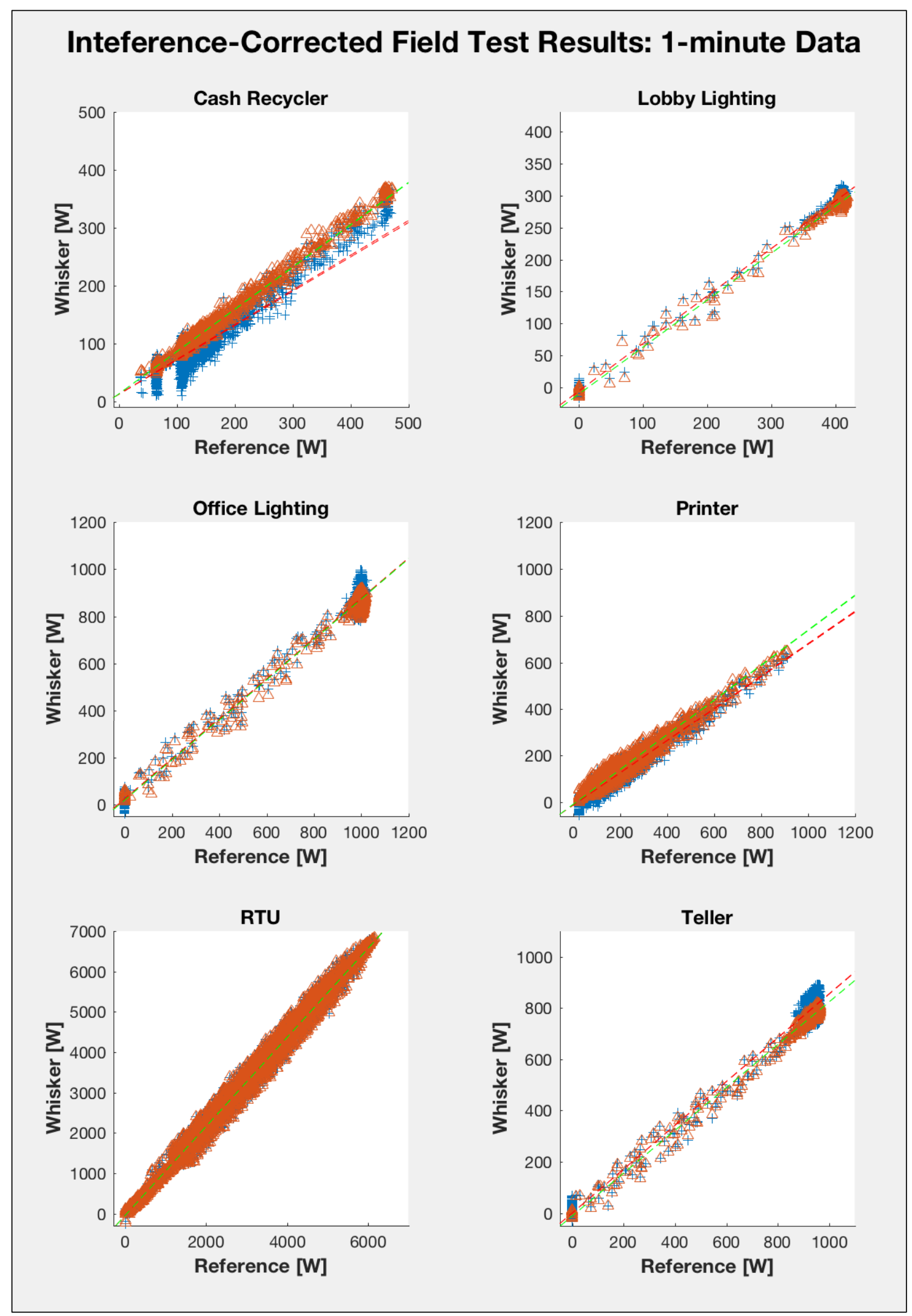

Figure 33. Interference-corrected 1-minute data 
Figure 33 shows the corrected data overlaid on the original parity plot for the 1-minute dataset. The blue "+" marks are the original data and the orange " $\Delta$ " marks are the corresponding interference-corrected dataset. The red and green dashed lines indicate the $95 \%$ CI margin for the original and corrected case, respectively. The individual data points are hard to see because of the overlay, but the general trend is that the correction tightens up the scatter in the data. Moreover, the correction in fractional scaling error (slope) is more significant than the correction in absolute offset (intercept). The results are tabulated in Table 10.

Noting that the purpose of the interference correction is a formulation to correct the data to improve agreement with the reference measurements, the right-most column indicates whether the fit parameters move toward or away from perfect agreement. If the data match the reference measurements perfectly then $\mathrm{b}=0, \sigma_{\mathrm{b} 95}=0, \mathrm{~m}=1$, and $\sigma_{\mathrm{m} 95}=0$. In most cases the interference correction improves agreement with the reference data.

Table 10. Results of Interference Correction

\begin{tabular}{|c|c|c|c|c|}
\hline Appliance & $\begin{array}{l}\text { Linear Fit } \\
\text { Coefficient } \\
\text { and Errors }\end{array}$ & Original Data & $\begin{array}{l}\text { Interference- } \\
\text { Corrected Data }\end{array}$ & $\begin{array}{c}\text { Toward (+) or } \\
\text { Away From (-) } \\
\text { Perfect Agreement }\end{array}$ \\
\hline \multirow{4}{*}{ Cash Recycler } & b & 12.110 & 12.848 & - \\
\hline & $\sigma_{\mathrm{b} 95}$ & 0.281 & 0.086 & + \\
\hline & $\mathbf{m}$ & 0.597 & 0.730 & + \\
\hline & $\sigma_{m 95}$ & 0.003 & 0.001 & + \\
\hline \multirow{4}{*}{$\begin{array}{l}\text { Lobby } \\
\text { Lighting }\end{array}$} & b & -5.150 & -10.013 & - \\
\hline & $\sigma_{\mathrm{b} 95}$ & 0.077 & 0.058 & + \\
\hline & $\mathbf{m}$ & 0.741 & 0.733 & - \\
\hline & $\sigma_{m 95}$ & 0.000 & 0.000 & same \\
\hline \multirow{4}{*}{ Office Lighting } & b & 24.770 & 19.339 & + \\
\hline & $\sigma_{\text {b95 }}$ & 0.298 & 0.152 & + \\
\hline & $\mathbf{m}$ & 0.851 & 0.854 & + \\
\hline & $\sigma_{m 95}$ & 0.000 & 0.000 & same \\
\hline \multirow{4}{*}{ Printer } & b & -11.099 & -7.444 & + \\
\hline & $\sigma_{\mathrm{b} 95}$ & 0.168 & 0.109 & + \\
\hline & $\mathbf{m}$ & 0.689 & 0.744 & + \\
\hline & $\sigma_{m 95}$ & 0.002 & 0.001 & + \\
\hline \multirow{4}{*}{ RTU } & b & -40.859 & -45.870 & - \\
\hline & $\sigma_{\mathrm{b} 95}$ & 0.735 & 0.733 & + \\
\hline & $\mathbf{m}$ & 1.103 & 1.102 & + \\
\hline & $\sigma_{m 95}$ & 0.000 & 0.000 & same \\
\hline \multirow{4}{*}{ Teller } & b & 1.290 & -10.439 & - \\
\hline & $\sigma_{\mathrm{b} 95}$ & 0.312 & 0.094 & + \\
\hline & $\mathbf{m}$ & 0.854 & 0.834 & - \\
\hline & $\sigma_{m 95}$ & 0.000 & 0.000 & same \\
\hline
\end{tabular}




\section{Practical Applications}

Conventional power meters provide high-accuracy measurements, but their installation is typically labor-intensive, disruptive, and expensive. In contrast, the Whisker Labs power meters offer moderate accuracy at low cost coupled with convenient, touch-safe installation.

The Whisker meters are well-suited for a variety of applications that require high-resolution power data but only moderate accuracy. These include commissioning activities (such as control and schedule verification), retro-commissioning, energy audits, FDD, and optimization of building controls. More broadly, the Whisker meters are a good fit for any non-intrusive or temporary power monitoring activity where the cost and inconvenience of conventional power meters cannot be justified.

\subsection{Havana Gardens Case Study}

As a case study, the team used the Whisker meter data to evaluate the performance of the Havana Gardens site and explore energy savings opportunities. The evaluation was not comprehensive; rather, it consisted of manual, periodic reviews of the Whisker data to check for obvious energy savings opportunities or other operational issues. This process provided the team with insight into the practical applications of Whisker meter data.

The site performed well based on the team's review, as expected for a recently constructed, LEED-certified building. However, the team identified three categories of opportunities based on observations of the data: control of MELs for portfolio-level energy cost savings, HVAC sequence of operations tuning for site-specific energy cost savings, and automated monitoring of signage for maintenance. Each is described below in terms of the specific findings at the Havana Gardens site as well as how the source Whisker meter data might be used for further analysis or application to other buildings. These opportunities are presented primarily to illustrate the benefits of submetered electricity data in general and of the Whisker Labs technology specifically; detailed potential energy and cost savings estimates are not provided.

\subsubsection{MELs Control}

The trend analysis presented in Figure 34 shows that the "cash recycler" load has a relatively high standby power and is not switched off during holidays, although it is turned off on weekends. At $50 \mathrm{~W}$, this equipment is a small load at a single site but may represent a much larger energy savings opportunity if present at a large number of bank branches within a portfolio. Similar opportunities may also exist for other, larger plug loads at the Havana Gardens site that were not part of the case study. This preliminary analysis indicates that advanced power strips or occupant behavior approaches could be used to consistently turn off unused equipment at night and on holidays. 


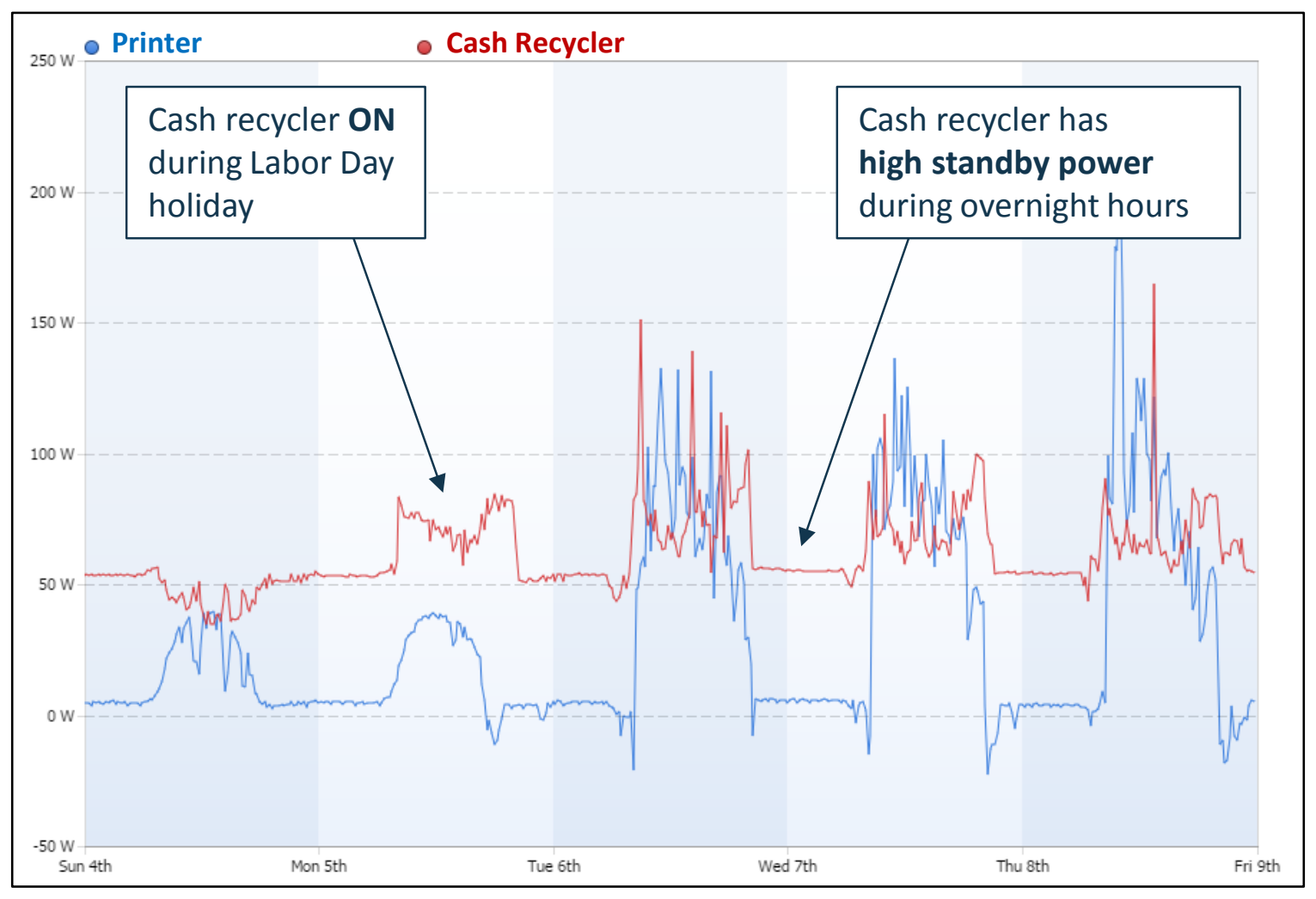

Figure 34. Havana Gardens site MELs control opportunity

\subsubsection{HVAC Sequence of Operations Tuning}

The trend analysis presented in Figure 35 shows a more nuanced issue that is likely unique in implementation for each bank branch site. In the current HVAC sequence of operations, RTU-3 provides ventilation, but not cooling, during unoccupied hours, while RTU-4 and RTU-5 are usually off during unoccupied hours but turn on periodically over the weekend to provide cooling. A potential improvement to the sequence of operations is that RTU-3 could provide cooling instead of using RTU-4 and RTU-5, possibly through setpoint adjustment to avoid excess fan energy and potential over-ventilation associated with running the other RTUs. 


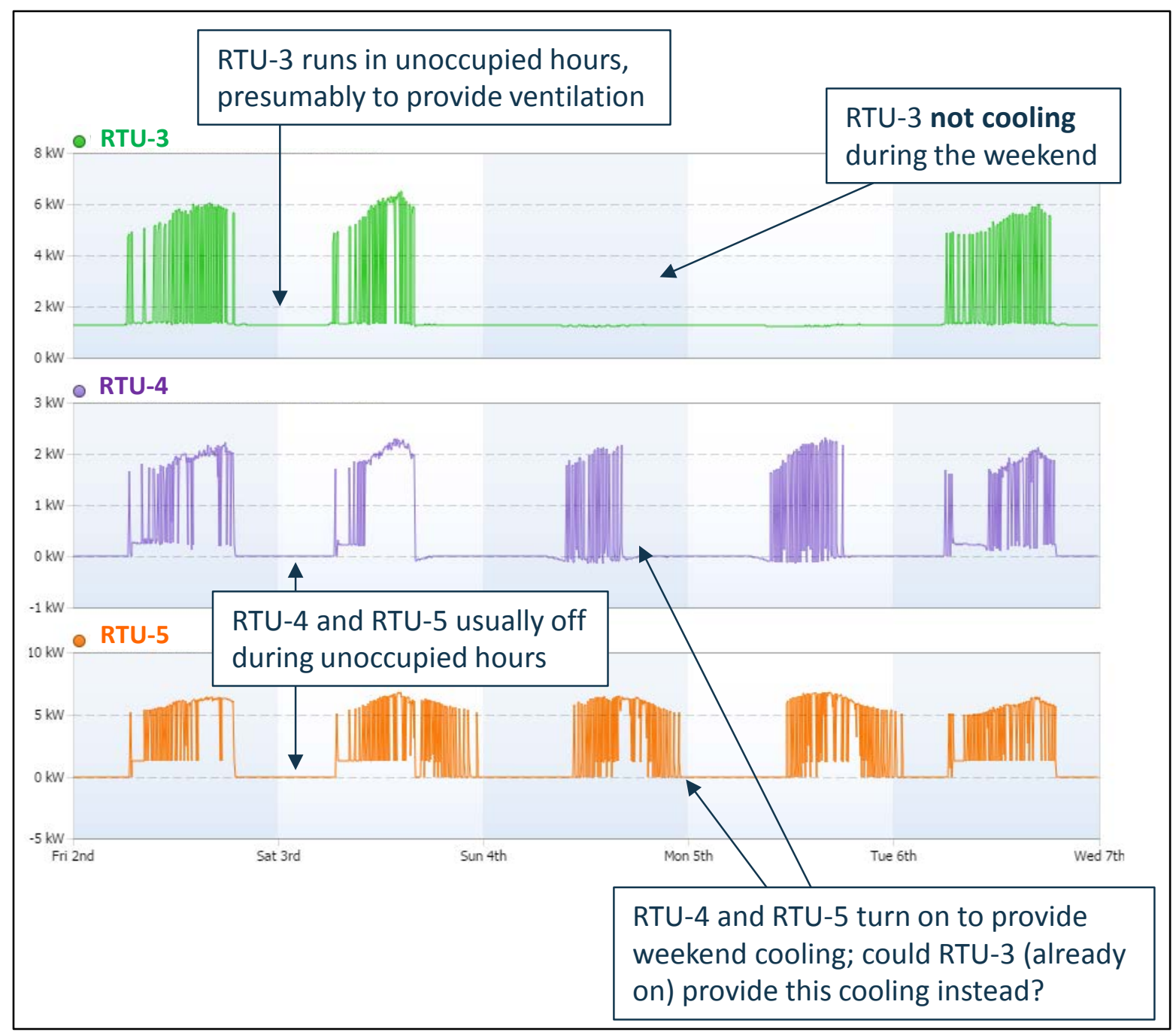

Figure 35. Havana Gardens site, HVAC sequence of operations potential improvement

\subsubsection{Signage Maintenance Notification}

Unlike the energy-efficiency opportunities identified in the previous examples, Figure 36 shows a maintenance cost savings opportunity. The Whisker meters were able to identify a drop in signage power from one night to the next that persisted for the remainder of the demonstration. The team verified that the drop was related to a lamp failure in the Havana Gardens exterior signage.

At present, the typical practice for identifying sign outages is to rely on periodic nightly rounds by maintenance staff to inspect signage. These inspections typically only occur quarterly due to the time and expense required. Rather than relying on manual inspection, maintenance staff could instead use Whisker meters to monitor signage remotely. Alternatively, software algorithms might leverage the Whisker meter data to automatically notify maintenance staff when a sign lamp outage has occurred. Such a system would significantly reduce both inspection costs and response time. 


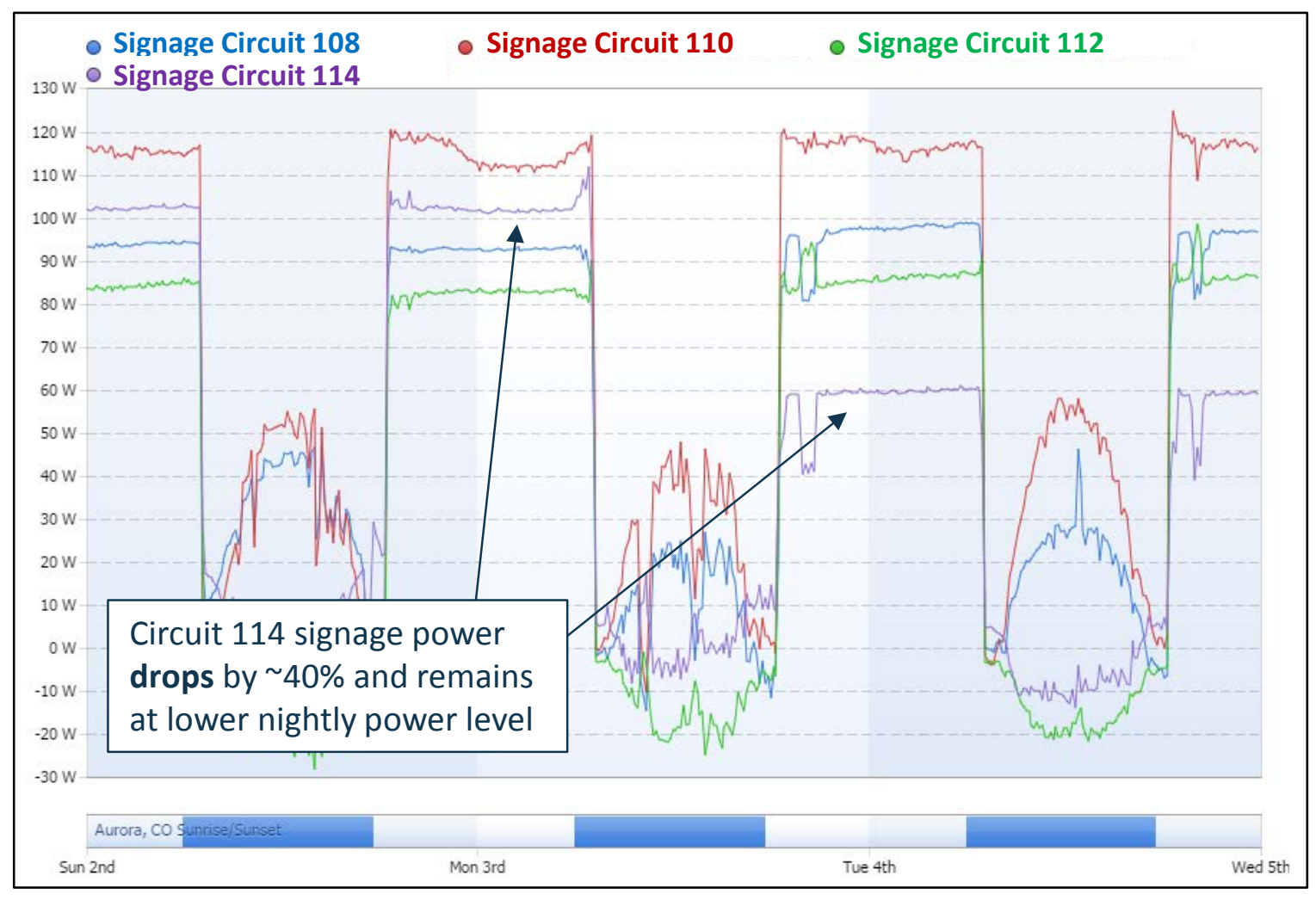

Figure 36. Havana Gardens site, signage maintenance notification

This signage maintenance notification use case represents the easiest actionable outcome of the Havana Gardens demonstration to implement in short term. A possible path to implementation is to use SkySpark or similar rule-based FDD software to set up a rule to detect a drop in signage power for each site and then send notification to maintenance staff when an event occurs. An example annual cost savings of the process change is described below.

- Common assumptions

- Assume $\$ 100 /$ hour in maintenance technician labor and transportation costs

- Baseline sign outage maintenance case (spot check and subsequent re-lamping)

- Assume 4 hours per month (2 hours per round, 2 rounds within each region) in maintenance technician night rounds to check signage

- Assume 4 hours per month ( 2 hours per fix, 2 sites, 1 time per month) in maintenance technician time for subsequent site visits to repair outages

- Estimated maintenance technician costs: $\$ 800 /$ month

- Alternative sign outage maintenance case (spot check and group re-lamping) 
- Assume 0 hours per month in maintenance technician night rounds to check signage; notifications provided by Whisker and SkySpark detection system (cost of setting up system not accounted for in this example)

- Assume 4 hours per month ( 2 hours per fix, 2 sites, 1 time per month) in maintenance technician time for subsequent site visits to repair outages

- Estimated maintenance technician costs: $\$ 400 /$ month

- Annual maintenance cost savings per region: $\$ 4,800 /$ year

- Freed up maintenance technician staff costs/time and costs to perform tasks such as preventative maintenance reviews of equipment that can be strategically replaced for greater energy savings.

\subsection{Recommended Applications}

The client for this technology may vary by application. For example, utilities may purchase and install a Whisker Labs system in customer buildings as part of demand response program to ensure that they get the feedback they need. On the other hand, a small commercial building owner may be looking for ways to reduce their energy costs and may purchase a system on their own. Other potential clients include energy service companies, insurance companies, FDD tool developers, or controls integrators. In most cases, it will be hard to make the case to purchase and install this technology based on potential energy savings alone, even though this system is much cheaper than the conventional alternatives. The applications highlighted here provide additional benefit to the building owner, but most will require sophisticated software applications to be built on top of the underlying Whisker Labs technology. Whisker Labs has developed an API that can be used by third parties to pull in energy data for use with different analytics engines and service applications. Additionally, Whisker Labs may begin developing its own applications to be used with its hardware. It is critical that Whisker Labs either develops its own application tools or works with third parties in the near future to ensure that consumers receive relevant, actionable information, rather than just providing time-series circuit-level power data.

Single-circuit accuracy and cross-circuit interference must be considered together when evaluating the Whisker meters for a particular application. In the presence of interference from nearby circuits, the accuracy of the Whisker meters is influenced by the relative ratios of the measured load to the surrounding loads. If the measured load is small and the surrounding loads are large, the interference is more likely to be significant even with a large interference rejection ratio. Conversely, if the measured load is large and the surrounding loads are small, the interference may be insignificant even if the interference rejection ratio is small.

Given a desired signal-to-noise ratio (SNR), a known interference rejection ratio, and the approximate power level $P_{W}$ of the measured circuit, it is possible to compute the largest acceptable power $P_{\text {Intf }}$ that may be present on an interfering circuit using:

$$
P_{\text {Intf }} \leq P_{W} \cdot \frac{\text { Interference Rejection Ratio }}{\text { SNR }}
$$


Generally speaking, an SNR of at least 10 is desirable for most analytics applications. Because the specified interference rejection ratio of the second-generation Whisker meters is also 10:1, this implies that the interfering loads should be no larger than the measured load. Therefore, the Whisker meters are best suited to panels where all the loads are approximately the same order of magnitude (such as lighting panels) or else to measuring only the largest loads on panels with diverse circuits.

\subsubsection{Schedule Verification}

If building owners have set schedules for equipment, circuit-level monitoring can be used to verify that schedules are working. This is especially useful for actions set to take place at night or on weekends when people are not present. We evaluated the equipment schedules as part of the Havana Gardens demonstration and found that the cash recycler was turned off on weekends, but not holidays. Schedule verification is likely most applicable for small commercial buildings that have significant unoccupied periods, but could also be applied to residential buildings where no one is home during the day. Circuit-level measurements may also help inform when a schedule should be employed. By evaluating the energy use during unoccupied periods, homeowners or building operators may identify equipment that can be turned off without any performance or comfort impacts. Based on lessons learned from the laboratory testing, it may not be possible to track schedules for smaller loads, but verifying the schedule of larger loads can be accomplished with the Whisker meters. Managing larger loads is also more valuable from an energy-savings perspective.

\subsubsection{Fault Detection and Diagnosis}

FDD generally refers to the process of tracking equipment energy usage over time to detect when the patterns deviate from normal. Ideally, meters should be installed when the building is newly being commissioned to capture the equipment usage profiles at the beginning of their life, but the Whisker Labs meters could easily be installed later and begin tracking equipment profiles. This application is best suited to the larger loads in a building, both from an accuracy and value standpoint. A few examples of the types of problems that FDD could help identify:

- Detect anomalies that increase energy consumption and can be corrected. For example, a clogged dryer vent could be identified by an increase in the per-cycle energy use of a dryer if standard load size and dryer settings are used. Detecting a problem does not always lead to an obvious solution though, so a savvy building operator may still be needed.

- Detect when equipment has failed without the need for regular maintenance trips. This application was verified in the Havana Gardens demonstration with an exterior sign outage. This is likely not an energy saving measure but can save time and money to identify outages and may be part of a branding plan to initiate quicker replacement of out-of-service equipment.

- FDD may also be able to identify when equipment is soon to fail. Degraded performance (higher energy use, longer run times, etc.) may be an indication that a piece of equipment is reaching the end of its useful life. Early detection benefits the building owner in several ways. It may be possible to avoid downtime that would come with a sudden failure. It also may enable the building owner to find the best replacement, rather than getting a 
replacement that is in stock, potentially resulting in the installation of more energyefficient equipment.

- Buildings with common space types such as apartment buildings (and possibly bank branches in the same climate) may be a good fit for an FDD application since there may be lots of duplicate equipment that could be metered. You may not have the system in place since commissioning, but if everyone's dryer is the same and one unit is using twice the energy, there is likely a problem.

\subsubsection{Demand Response Verification}

It can be challenging for utilities to verify the impact of demand response events in residential and small commercial buildings. A demand response event should reduce the overall load on the grid, but people are given the option to opt out of events. There will also be times when the appliance to be turned off during the event was not on. This type of technology could be deployed as part of the demand response program to monitor the specific end loads participating in demand response programs, such as water heaters or air conditioners, and the feedback would help the utility better understand the impact of their program. If the program is not having the desired impact, the data collected may also help program managers design a more effective demand response program.

\subsubsection{Energy Consumption/Generation Tracking in Subpanels}

The energy usage of electric vehicle chargers or generation from solar panels may be of interest to utilities and are often connected to residences with a subpanel. Subpanels that may only contain two breakers are ideal for the Whisker Labs meters since there are no other breakers to introduce interference. The Whisker Labs data should not be used for billing purposes but may be helpful for verifying EV charging times or monitoring the distributed generation sources in a utility's jurisdiction.

\subsubsection{Energy Auditing and Retro-commissioning}

Circuit-level monitoring, along with software tailored to the specific application (residential buildings, bank branches, convenience stores, etc.), could provide energy-efficiency recommendations. This may be particularly useful in residential buildings since it is less likely that the homeowners are paying close attention to their energy bills or have an understanding of what "normal" energy consumption should be for specific appliances. This application could include recommendations for equipment replacement, including an estimate of annual energy savings, or recommendations related to the operation of equipment, including recommendations related to when the appliances are operated or how a schedule may lead to cost savings.

Small commercial buildings may have staff that know the building and equipment well but may not be able to afford the cost of conventional submetering systems. The low cost and ease of installation of the Whisker Labs system would provide useful information and efficiency recommendations on a budget. 


\section{Conclusions}

Whisker Labs' main value propositions are that its solution is significantly cheaper and easier to install than its competition. In terms of ease of installation and use, the company has accomplished its development goal. For both the laboratory testing and field demonstration, the installation process was short and simple, especially in comparison to the installation of conventional meter systems. The laboratory testing established that the performance of the second-generation prototype Whisker meters was generally consistent with the specified accuracy of $\pm 10 \%$, with some meters reporting errors much lower than $\pm 10 \%$ and others with errors up to $\pm 26 \%$. The multi-appliance testing verified that typical interference rejection ratios of 10:1 or better were seen for the majority of cases. The field demonstration, which represented the first deployment of the Whisker meters in a three-phase power system, verified that the meters can provide value to analytics applications in commercial buildings. The Whisker meters are well-suited for analytics applications that require high-resolution data but only moderate accuracy. Examples of such applications include schedule verification, fault detection and diagnostics, energy auditing, commissioning and retro-commissioning, and verification of demand response. For these applications, the Whisker Labs technology represents a significant advance in the state of the art and provides clear advantages in cost and convenience compared to conventional metering technologies. 


\section{References}

Building Technologies Office. Wireless Metering Challenge. PNNL-SA-126137, Richland, WA: Department of Energy, May 2017.

ENERGY STAR. Sub-Metering Energy Use in Colleges and Universities: Incentives and Challenges. Washington, D.C.: U.S. Environmental Protection Agency, 2002.

Federal Energy Management Program. Guidance for Electric Metering in Federal Buildings. DOE/EE-0312, Washington, D.C.: US Department of Energy, 2006.

Lorek, M., F. Chraim, K. Pister, and S. Lanzisera. "COTS-Based Stick-On Electricity Meters for Building Submetering." IEEE Sensors Journal 14, no. 10 (2014): 3482-3489.

Mayhorn, E.T., R.S. Butner, M.C. Baechler, G.P. Sullivan, and H. Hao. Characteristics and Performance of Existing Load Disaggregation Technologies. PNNL-24230, Richland, WA: Pacific Northwest National Laboratory, 2015.

National Science and Technology Council Committee on Technology: Subcommittee on Building Technology Research and Development. Submetering of Building Energy and Water Usage: Analysis and Recommendations. Washington, D.C.: Executive Office of the President, 2011.

Parker, S.A., et al. Metering Best Practices: A Guide to Achieving Utility Resource Efficiency, Release 3.0. PNNL-23892, Richland, WA: Pacific Northwest National Laboratory, 2015. 